
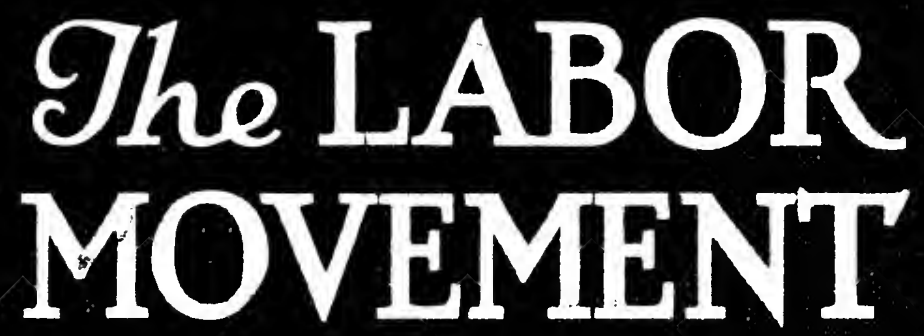

Frank Tannenbaum 
Enily<smiles>C1C2CC1C2</smiles> 
Digitized by the Internet Archive in 2007 with funding from Microsoft Corporation 




\section{The Labor Movement}

Its Conservative Functions and Social Consequences

\section{By \\ Frank Tannenbaum}

G. P. Putnam's Sons

New York and London Tbe Knickerbocker Dress 


\section{HD \\ 8072 \\ T2'}

Copyright, 192I

by

Frank Tannenbaum

Printed in the United States of America

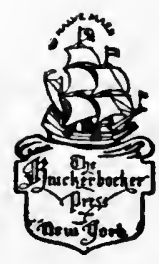


ThIs Book

Is Humbly Dedicated

TO

JOHN DEWEY 



\section{PUBLISHERS' NOTE}

$M^{R}$. TANNENBAUM has produced an account which is written with authoritative knowledge and which gives information of distinctive interest and value. His monograph is restricted to the presentation of the advantages secured by union organizations in the larger matters of the protection of the rights and the furthering of the welfare of the members. He points out also the value of the organization in developing among the unionized workers a social relation, and in so doing, in furthering their development and education.

The organization of the Labor Unions is, as is now generally admitted, desirable, not to say essential, for the purpose of protecting and furthering the rightful interest of the workers, or at least of that portion of the workers which is prepared to accept membership in the Union. It is further desirable as giving means by which agreements can be made and negotiations carried on between the employed and the employers.

Mr. Tannenbaum's study presents only the favorable aspects of the purposes and the results of the 
Unions of organized labor. The book, while suggestive and valuable, would, we believe, have been more complete if the author had seen his way to discuss the following matters which seem to many people outstanding characteristics of the labor movement as the public knows it.

1. Under the Constitution, all citizens have a guaranty of equality before the law, and it is the theory of the Constitution that no class or group of citizens shall be able to secure special privileges. One instance of such contention on their part is their refusal to accept incorporation. If, therefore, a Union commits a breach of law,- and there are too many instances of such breaches,-proceedings can be taken only against individual members.

A further evidence of the policy of the Unions of maintaining special privileges was their success in securing, in the act appropriating money for judiciary proceedings, a provision that no such money should be utilized for proceedings affecting the Unions.

2. The frequent failure of the Unions to give any cooperation to the authorities for the tracing of crime and for bringing penalties to bear upon criminals whose work has been done under the direction of organized labor, or for the purpose of forwarding some immediate aim of organized labor. There are innumerable instances of a policy of terrorism and of criminal action from the time of the blowing up of the Los Angeles Times to the present day, and we can find no instance on record of action on the part of the authorities of the Union to 
expel or even to reprimand a member for criminal activity.

3. The Constitution guarantees to every citizen equal protection under the law. The Union claims the right to prevent fellow citizens who prefer not to accept membership in the organization, from carrying on work, that is to say from getting a livelihood, and this claim has too often been maintained by force, by the breaking of heads or assaults of other kinds.

4. The community further criticizes the policy which has been increasingly manifested by the Unions for diminishing output. It is the insistence of the Unions that the standard of work shall be kept to that of the laziest, or most ineffective worker. They refuse to permit for the industrious or skilled worker the advantage of the additional product that he is able to complete. It is a well established fact that since the reduction of the hours of the working day, the output per hour has in many trades been materially lessened. This has been measured, for instance, specifically in such an industry as the laying of bricks.

It is to be hoped that in some future volume, a writer who has, as Mr. Tannenbaum has, first-hand knowledge of the methods of Union organizations, and is in substantial sympathy with the legitimate purposes of these organizations will be ready to put before the public a consideration of these issues between the Unions and the community.

G. H. P.

April 20, 1921. 

The Publishers' note and the book which follows represent differences of opinion, "G. H. P." and the author agreeing to disagree.

F. $T$. 



\section{FOREWORD}

THIS is neither a prophecy nor a religion. It is a 1 description. It is an analysis of the labor movement and an idea about its outcome. But ideas, "notions, theories, systems, no matter how elaborate and self-consistent they are must be regarded as hypotheses. They are to be accepted as basis of actions which test them, not as finalities. To perceive this fact is to abolish rigid dogmas from the world. It is to recognize that conceptions, theories. and systems of thought are always open to development through use. It is to enforce the lesson that we must be on the lookout quite as much for indications to alter them as for opportunities to assert them. They are tools. As in the case of all tools, their value resides not in themselves but in their capacity to work shown in the consequence of their use." 1

I quote this passage so that it will not be assumed that the kind of community suggested as the consequence of the growth of the labor movement

"John Dewey, "Reconstruction in Philosophy," Henry Holt \& Co., N. X., 1920, p. 145. 
is presented as an absolute and definitely predictable type. The labor movement is obviously on its way and this book attempts to indicate where it is seemingly going to come out. But the only thing I am committed to is the process and the reconstruction which it is imposing upon the world. I am not sworn to a particular outcome-simply because the facts and the forces are too numerous for anyone to describe in detail the particular form of social organization and insist upon that as a frozen, unchanging and immutable pattern. As a matter of faith I am willing to accept the world the labor movement is fashioning-because I have to accept it and because $I$ think it is going to be a better world than the one I know at present-even if it does not fit every detail of the picture drawn in this book.

It may be argued that I have seen only those things in the labor movement that I wanted to see. That would not be true. I am not unaware of the shortcomings of the labor movement. I know but too well its frequent narrow-mindness, its bickerings, its squabbles, its internal politics, its lack of social foresight, its jurisdictional disputes, and the tendencies that have made possible the New York City building scandals. I have described what seemed to me to be the significant and meaningful facts and forces in the labor movement. That does not mean that I am blind to opposing more destructive and less social elements than those which I have considered. Simply they do not seem to me as important or as deeply ingrained in the character of the labor movement. The process of social re- 
building which is going on carries with itself a certain amount of waste-and it is the waste which people are mostly conscious of when they think of the labor movement. It must be remembered that even in the construction of an ordinary building, the most skilled craftsmen litter the neighborhood with obstructions and with wasted materials. So with the labor movement-excepting that the craftsmen are learning their craft while building the structure, and that the materials are not only institutions which are being shed and rebuilt but human beings who are being molded in a crucible that is socializing the unsocial and creating the motives and ideals essential to a cooperative game where the substratum and material is competitive.

Amongst the criticisms of those who have read the manuscript are two which seem to me most significant. One is that it is an optimistic book, that I am very hopeful about human nature. I plead guilty to that charge. Having seen in considerable numbers those who are considered bad and unsocial by the community (I mean the men in prisons), and found them good, kindly and selfsacrificing when given the proper opportunity to be so, I must insist on the legitimacy of faith in those average and normal men and women who are the constant boast of the American community. The other criticism is that I have painted a static picture. That I show the labor movement achieving a certain social organization and do not suggest that it must of necessity move on because nothing stands still. The only answer I have is that what I 
have done is to attempt to describe a moving force re-creating our social organization and achieving a distinctly new pattern. I stop with the pattern that I can see, because I cannot see beyond it. That does not mean that there will be no beyond. It simply means that, so far as I can see at present, the future beyond the future has not revealed itself. The book is static in the sense that it describes a definite outcome-a photograph at the moment of arrival and nothing more. The reader is invited to disagree to his heart's content.

F. T. 


\section{ACKNOWLEDGMENTS}

WISH to express my thanks to many friends for 1 their kind help in the preparation of this volume. However, I am well aware that I can mention only a small number of those who have been of assistance, chiefly because one does not always know, or remember, the influences which have contributed most to the molding of one's thought. I must begin by acknowledging the great debt, both spiritual and intellectual, which I owe to the "Spittoon Philosopher" of the I. W. W., a remarkable group of keen men and women, mostly young, whom to know and love was a great privilege. Nowhere have I found more social-mindedness, more love of one's fellow men, more disinterested striving for making the world a better place to live in.

I wish to record my debt of gratitude to the many friends and teachers at Columbia University, whose interest, inspiration, and encouragement have proved a great joy. To a few of these who read the manuscript and by criticism and helpful suggestions have contributed to the making of this book, especial thanks are due: to Professor Carlton J. H. Hayes for numerous suggestions; to Professor B. B. Kendrick for suggesting the writing of the first chapter; 
to Professor Austin P. Evans for help with the English; to John Herman Randall for advising the division of the book into three parts; to Professor Henry R. Seager for criticism of the chapter on Labor Education; to Professor E. R. A. Seligman; and particularly to Mr. Mark Van Doren for revision of the English.

I am indebted to Dr. Paul Brissinden of the Department of Economics at New York University for suggesting a rearrangement of the material; to Dr. Woolman and Professor Kallen, both of the New School of Social Research, for valuable criticism of the discussion of incentive.

Thanks are here given to my friends and fellow workers, "Mother" Jane Roulstoun and Arturo Giovannittee for many happy disputatious hours we have spent over some of the problems of the book; to Mr. Frank Anderson of the Bureau of Industrial Research; and to Dr. Dorothea Scoville for reading the proof; to Miss Elma Bloch for helping put the material into shape; and finally to my wife, whose interest and assistance has been a constant spur to carry the work to completion.

I must add that I alone am to be held responsible for the shortcomings of opinion and the plan of the book. Its virtues are due to the assistance of many friends; its faults reflect a stubbornness that would not be shown the better way.

June, 1921.

$$
\text { F. T. }
$$




\section{CONTENTS}

PAGE

Publishers' Note • • • • . .

FOREWORD $\quad \cdot \quad \cdot \quad \cdot \quad \cdot \quad \cdot \quad \cdot \quad \cdot \quad x i$

PART I.

CAUSES

CHAPTER

I.-INSECURITY • • • • •

II.-The Center of Gravity . 23

III.-The Function of the Labor UNION . . . . . . 31

IV.-Labor Movement Psychology . 45

PART II

METHODS

V.-The Break of the Circle . . 69

VI.-ThE Method OF THE LABOR Movement . . . . . 81

VII.-Educational Function of the LABOr Movement • . . 91 VIII.-CoMradeship . . • . . 105

IX.-Conservative and Radical

LABOR • . . . . . 113

xvii 
xviii CONTENTS

CHAPTER

PAGE

X.--Industrial Government-

I.-The District Council • 126

XI.-Industrial Government-

II.-The IndUStrial UNioN • 135

XII.-Industrial Government-

III.-The National Unit . . 143

XIII.-Work ANd Wages . . . . 155

XIV.-The Conservative Function of THE LABor Movement • . 167

PART III

CONSEQUENCES

XV.-REMUNERATION • . . . . 179

XVI.-The Function of Industrial

Government . . • • 194

XVII.-Socialization . • • • 209

XVIII.-CoOperation AND Discipline • 218

XIX.-Producer and Consumer . $\quad 227$

XX.-Labor and Education . • • 238

XXI.-Educational Reorganization . 249 
The Labor Movement

PART I

Causes 



\section{CHAPTER I}

\section{INSECURITY}

UR age is dynamic. Social forces are in constant motion. Change, the upsetting of old ideas, struggles to formulate new ones, are the dominant features of our creative life. Never before was there so great a pressure against the established, or so great a craving for the new. This is true of all social phenomena. Nowhere, however, is it so characteristic as in industry. Change is the very life of industry today. New methods, new processes, new inventions, new markets, new fashions, new fads, new discoveries and organizations characterize the greater part of our industrial world. This constant change is reflected in our commercial market as well as in the expansion and contraction of our industrial activities. In contrasting this age with those which have preceded it we are impressed by their comparative quiescence. People lived in the same places, did the same kinds of work, used the same tools, wore similar styles of dress for generation after generation with but little change. Centuries of accumulated habit and custom were evident in the procedure of the community. 
Suddenly, as out of the night, a number of cumulative tendencies brought a change to this quiet, slowly moving, and fairly self-sufficient social organization. Society was torn from its roots and set adrift by the machine. Dynamic change replaced a comparatively static condition in the world through the unexpected growth of large factories, large cities, the building of railways, the tunneling of mountains, the spanning of rivers with mighty bridges, the breasting of the tide with coal and oilburning ships, the invention of telegraphy, telephones, air ships, and the automobile. But who can enumerate the ten thousand changes that have been wrought in the life of the community in the last hundred and fifty years? A miracle happened in the night and the world is dressed in different colors.

This sudden expansion of energy, this development and concentration of mechanical power, and this awakening of interest in experimental science stimulated a social metamorphosis.

Expansion is evidently a motive in all of our activities, and every individual, one might say, has been influenced by it. Ambition is the great virtue of the age, a virtue that will cover many vices. Our age forgives almost everything to the successful man. He need have little of morals and less of religion, just so long as he does something. What are you doing? What have you done? What are you planning? These are the great questions which everyone is asked, and they tell a tale characteristic of a world. This sudden loosening of human forces, 
entrancing, vivid, and wonderful as it is, has other consequences to which we are often blind. In exalting the achievements of the machine one must not forget the tale of suffering and hardship that has accompanied it. The changes so insistently characteristic of mechanical organization mean for the community an ever-increasing acquisition of new powers, new methods and new things; but for the great mass of individuals they have meant Insecurity.

Every change means a change for somebody, every new machine means that an old one has been displaced and that for an old craft, an old trade, an old business, an old habit, has been substituted something new. Insecurity is the dominant fact in the lives of every class in the community; no one escapes it. The rich and the poor, the professional and the artisan, the mechanic and the gambler, are all faced by the possibility of insecurity. Our whole industrial organization is dominated by the price market, and prices constantly change. Every time they go up or down there is a corresponding reaction in the mechanical organization that lies at the root of our industrial community. These changes carry with them contraction or expansion in industry, which in turn mean profit or loss, work or unemployment, contracts or lack of contracts, the power to meet bills, or the lack of that power. The fluctuating market, like a sea that never stands still, may well be represented as a shifting tide that works to undermine the ground on which the individual stands. Competition is only 
one evidence of this fact of insecurity. What does competition mean if not the effort to displace another man and his income? This continual insecurity has given our age peculiar characteristics, one of them being an excessive interest in money. The profit motive is the distinctive feature of a competitive age because profits, or money, imply security. Give a man that and you are giving him the basis of practically everything else. Land, houses, honors, pleasures, dignities and position are his if only he has money. This is reflected at every turn of our lives. How much are you making? What does the job pay? Did you have a good year? These questions have come to mean: Did you have a profitable year in terms of money?

The evidence of insecurity is beyond question. It is neither desirable nor possible in a book such as this to compile statistics on a large scale. Even in outline, however, enough can be quoted to show the evidence at hand and to carry the conviction that ours is an age of insecurity-individual, economic insecurity. This age has been described as one of skyscrapers, automobiles, newspapers, electricity, or as one of large-scale business, of trusts, while by those holding another point of view it has been called the age of political democracy and constitutional freedom. But none of these descriptions tells the tale from the point of view of the individual. For him this is the age of insecurity. If anyone undertakes to describe the last hundred years in terms of what it has meant to the individual man and woman he will have to tell a 
story of worry, doubt, hesitancy, sorrow and tribulation, centered around the fact of individual economic insecurity. That is the fact in the life of the individual. It is true of practically everyone, but it applies more generally and in its most trying form to the worker.

The fact that insecurity is characteristic of all parts of the community finds illustration in the failure of 1,307 banks in the United States during the period from 1900 to 1918 . In the year 1907 alone 132 banks were thus affected. What this means is that thousands of men and women all over the country who had striven to save something for old age, for sickness, for the education of their children, for the purpose of buying a home, suddenly found themselves insecure in the sense that there was very little indeed between themselves and actual want.

Between the years 1900 and 1918 there were 259,048 commercial failures in the United States! These figures, recorded by Dun, represent only the larger concerns that were known to have failed. ${ }^{1}$ What about those which were too small to get into Dun's? How many thousands or hundreds of thousands of small concerns such as soda-stands, grocery stores, bakeries, electrical supplies, and other innumerable varieties of business enterprises on a small scale go out of business every year and leave nothing but a heartache behind them-pain and heartache, but not a syllable in Dun's? What

${ }^{1}$ Figures readily accessible in "World" Almanac for 1920 , p. 499. 
about those who barely escaped failure? Dun's does not say anything about them. There is no record of the worry, of the sleepless nights, of the scramble for credit, of the borrowing amongst friends, of the selling of valuables, of the tears and the anguish which stood between the endangered business man and the record of a failure in Dun's.

The farmer, traditionally the basis of stability, the one element in the community whose independence has always been taken for granted, is also showing evidence of insecurity. The census of 1910 showed 37 per cent. of the farms were tenanted. ${ }^{1}$ A tenant farmer is an insecure person. He is not like the manorial serf or the ancient peasant or the present day owner who has something permanent. His security at best is contractual. Contracts, however, may prove impossible of fulfillment and the passing days bring the contract to an end and that means insecurity. The same census showed that 33.6 per cent. of the American farms were mortgaged. Now a mortgage may be a basis of credit for better operations, but it is also an evidence of insecurity, because mortgages may be foreclosed. This means that 70.6 per cent. of American farmers are not entirely secure, that they have to worry about moving off the land, or about keeping the mortgage paid. Sickness, bad crops, fire, any human misfortune would in this case imply the possibility that the ordinary misfortune could be made heavier by foreclosure for lack of payment. These figures do not include the mortgaged farms that are

${ }^{1}$ U. S. Census, 1910, vol. v, pp. 102 and 158. 
rented out, and there are bound to be a great many of these, nor do they include the farmer who operates on shares. There is, however, sufficient evidence of the fact that insecurity has invaded the last stronghold of social stability-the farming community.

What is true of the bank, the business man and the farmer is also true of the professional person. The professional has no security of tenure, with the possible exception of the teacher and civil service employee. Anyone who doubts that may convince himself by examining the advertisements in the want columns of the large newspapers. $\mathrm{He}$ will find engineers, chemists, managers, clerks and other professionals advertising for jobs, stating their qualifications and references and offering to serve for reasonable pay. The numerous agencies throughout the country concerned with placing professionals indicate the same fact. What is true of the professional is still more evident of the ordinary clerical help in an office. Stenographers, bookkeepers, file clerks, order clerks, bill clerks, time keepers and the rest of the office paraphernalia change very often indeed. I know a number of stenographers and typists and yet I know very few of these who have remained for more than two years in the same place. In one or two instances the changes have taken place about every three months. The fault may not be entirely with the office, but the fact of insecurity for the individual is there none the less.

However, it is when we come to the manual 
workers that this insecurity becomes manifest in its full significance. The worker's relation to his job is determined by forces which he does not control. It is the amount of profit his employment brings to the concern which determines whether he is going to have a job or not. The employer and still more the employee, are both tools of the market. This fact was strikingly brought out by the Federal Investigation of 1910 into the conditions of employment in the iron and steel industry. ${ }^{1}$ The policy as there stated is: "To operate at its fullest capacity during active demand, then, during a decline in the market to shut down completely and await an accumulation of orders or development of better prices." In practice this meant that only 9.8 per cent. of the workers were employed from forty-eight to fifty-two weeks, 25.4 per cent.-forty to forty-four weeks, 2.5 per cent.-twenty-eight to thirty-two weeks, 5.4 per cent.-twenty-eight weeks or less.

The census report' on unemployment showed that of $5,772,641$ male workers, ten years of age and above, engaged in manufacturing and mechanical pursuits, $1,631,057$ or 28.2 per cent. were unemployed at some time during the year 1910, and that of 1,312,668 females, ten years of age and above, in the same class of occupations, 294,346 , or 22.4 per cent. were out of work. Thus nearly two million workers, 27.2 per cent., over one fourth of

${ }^{1}$ Quoted by Lauck and Sydenstricker, "Conditions of Labor in American Industries," New York, 1917, p. 152.

"Ibid., p. 111. Summary of 1900 census. 
the total engaged in manufacturing in 1910 were thus affected.

In the coal mining industry during the year 1913 according to the United States Geological Survey, the workers in Colorado lost 117 days, in Illinois 116 , in Indiana 111 , in Iowa 109, in Missouri 119, in Ohio 100, in Oklahoma 109, out of a possible 306 working days during the year, owing to conditions in the industry. ${ }^{1}$ The evidence of insecurity may be substantiated in various ways. Here is a picture of the full working time lost in twenty-one industries according to a report of the United States Immigration Commission. ${ }^{2}$ In 19092 per cent. of the workers lost nine or more months' full working time, 9.5 per cent. lost six months or more, 18 per cent. lost five months, 20 per cent. lost four months, 32 per cent. lost three months, 56.7 per cent. lost two months. This is striking evidence when we remember that every day lost is a day without income for that particular individual, and also a day without income for his dependents.

Even among organized workers unemployment is a constant factor. The average in New York State for the following organized trades, as given by the unions, 1910 - 1914, shows that the building and stone-workers were idle 28.2 per cent. of the work-

${ }^{2}$ Ibid., p. 85, compiled from the U. S. Geological Survey in 1913, p. 751. "It should be remembered, however, that 1913 was a record year for anthracite workers and was exceeded by bituminous miners since 1890 in only three years -1898 , 1900 , and 1907."

'Ibid., p. 77. Compiled from reports of the U. S. Immigration Commission, vol. 20, page 453. 
ing days of the year. In transportation the percentage of idle days was 11.1 per cent., clothing and textiles 33.1 per cent., metal machinery 16.7 per cent., printing and binding 6.7 per cent., woodworking and furniture 20.3 per cent., food and liquor 10.8 per cent., tobacco 14.3 per cent., restaurant trade 7.1 per cent., public employment 1 per cent., stationary engineers 2 per cent. ${ }^{1}$

The causes of insecurity vary with time and with industrial conditions. The industrial organization never stands still. It expands or contracts, it develops new machinery and introduces new methods. All of these elements express themselves for the worker in one way-insecurity. To quote a famous passage from Beveridge:" "Changes in industrial structure are constantly recurring and constantly throwing men out of employment. The very life and growth of industry consists in the replacement of old machines by new, of established processes by better ones; of labor in one form and combination by labor in fresh forms, fresh combinations. The demand for labor is thus in a state of flux and reconstruction both as to quality and quantity. Men who for years have satisfied the demand in one form may find the form suddenly changed, their niche in industry broken up; their hard won skill superfluous in the new world, themselves also superfluous unless they will and can learn arts and find the way

${ }^{2}$ Ibid., p. 93. Compiled from Bulletin No. 69 of New York, Department of Labor.

'Beveridge, "Unemployment, A Problem of Industry," p. 111. 
into familiar occupations. They are displaced by economic forces entirely beyond their control and taking no account of personal merit."

These changes of form and place in industrial organizations are illustrated by the following statistics. ${ }^{1}$ Between the years of 1899 and 1909 the following changes in the working population took place in some American cities. Troy, New York, lost 12.7 per cent. of its working population; Pittsburgh, Pennsylvania (men only), 7.4 per cent., Homestead, Pennsylvania, 44.3 per cent., Pensacola, Florida, 20.3 per cent., Savannah, Georgia, 15.6 per cent., Hagerstown, Maryland, 22.3 per cent., Charleston, South Carolina, 16.7 per cent. In the four years from 1905 to 1909 Mobile, Alabama, lost 5 per cent., New London, Connecticut, 12.9 per cent., Lowell, Massachusetts (for women), 18.7 per cent. Every one of these figures implies shifting, going from one job and one place to another. They are indications of the search for security-and the evidence of its absence. These figures are but a few of the many available. They are chosen to illustrate the fact that lies at the root of the whole social problem-individual economic insecurity. If some cities have lost, others have gained, but individually the problem of loss or gain is more or less the same.

The influence of machinery is illustrated by the following from the New York State Commission on Employers' Liability and Unemployment. "In

"Lauck and Sydenstricker, "Conditions of Labor in American Industries," p. 124. 
the five years between the manufacturing censuses of 1900 and 1905 out of 61 leading industries in the State of New York nine suffered actual decrease of the number of their employees which might be traced to the introduction of machinery. The decrease in the number of wage earners is accompanied by an increase in the value of machinery, tools and equipment employed." 1 Here are some illustrative figures. Agricultural implements decreased in workers employed by by 8.5 per cent., and increased in horse power per wage earner 25 per cent. Iron and steel blast furnaces lost 2.1 per cent. of the workers and gained 41.5 per cent. in its horse power per worker. Smelting and refining of lead lost 10.8 per cent. of its employees and gained 52.7 per cent. in horse power per worker." This tendency is true of many other industries. Sufficient statistics have already been cited to show that in those particular organizations increase in machinery actually meant a displacement of the working force to a considerable degree, and the worker has of course no control over the inventive genius in any industrial community.

The character of the industry and the seasonal needs of particular work have a large influence upon insecurity. Such a relatively stable concern as a department store would seem to offer regularity of employment. And yet statistics for Boston department stores show that only a small portion of the force remained the entire year. Those who worked

${ }^{1}$ Ibid., p. 127-130, quoted from Third Report, 1911, p. 44.

'Ibid., p. 127. 
twelve months were represented by occupation as follows: Saleswomen 18 per cent., office employees 39.3 per cent., counter cashiers and examiners 15.3 per cent., messengers and bundlers 8.1 per cent., alteration workroom 5.9 per cent., millinery workroom 3.6 per cent., stock girls 14.5 per cent. ${ }^{1}$ In other industries where the seasonal factor predominates the situation is very much worse. Probably there is no more striking example of extremely seasonal industries than those to be found in California. While the average number of employees in canning was for instance in 1909, 7,757, the maximum was 160,667 in August and the minimum 2,781 in February. ${ }^{2}$

Recent studies in the labor turnover made for the United States Department of Labor show that an extremely heavy percentage of men and women do not remain in the same employment for any length of time. The proportion of those who work for a full year is in some cases so small as to be negligible. These studies have included such places as Chicago, St. Louis, Milwaukee, California and such varied industries as mining, meat packing. water transportation, brass foundries, and department stores. In spite of the wide variation in industries studied and the different parts of the country included the results are very much alike. On three passenger ships on the Great Lakes the crew

${ }^{1}$ Ibid., p. 99. "Compiled from Second Annual Report of Massachusetts Minimum Work Commission, p. 124. The statistics exclude all employed for less than a month during the year."

Ibid., p. 150. 
turnover was found to be such that 72.8 per cent. of working force worked about thirty days. The rate of turnover per 1,000 for coal passers was $1,787.5$; for assistant cooks 1,550 ; for pantrymen 1,250 and so on for many branches of the service. ${ }^{1}$ In eleven large and varied establishments in Chicago 16 per cent. of the working force worked less than one week; 12 per cent. worked from one to two weeks, 14 per cent. worked from two weeks to a month; 23 per cent. worked from one month to three months. That is, 44 per cent. of these workers worked less than one month; 67 per cent. worked less than three months. One of these, a car building concern, had a labor turnover of moulders of 363 per cent.; laborers 542 per cent., riveters 630 per cent. In a brass specialties concern 33 per cent. were displaced the first week, 57 per cent. the first month, 71 per cent. the first three months. To put these figures in a somewhat different form we have the fact that a concern with a working force of 14,320 hired 32,374 during the year. A concern with 8,730 hired 19,050 , one with a regular force of 5,219 hired 20,014 , one with 5,092 hired 12,792 , one with 7,287 had to hire 18,837 and one with 258 hired 2,105.' This fact in a similar form was found to be true of the two California oil refining concerns studied for their labor turnover. "Of the two refineries ' $\mathrm{B}$ ' hired 1,141 men to keep 420 positions filled. At refinery ' $A$ ' 3,067 men had

${ }^{1}$ Emil Frankel in the Monthly Labor Review of the U. S. Department of Labor for June 18, 1919.

'Ibid. 
to be hired to keep 965 jobs in the plant." "In refinery 'A' 222 out of 420 people who constituted the full working force left during their first week of employment, 172 during their second week, 181 during the first month; 206 during the first three months. Figures for these two refineries show that 93 per cent. of one and 87 per cent. of the other had quitted the service in less than one year." 1 These figures here quoted could be multiplied at length for many other industries which have been studied and where the conditions are practically the same. The fact that these figures represent fairly large industries does not materially alter the situation. Our manufacturing work is done in concerns that have shown a tendency to grow larger as the years pass. In smaller industries similar conditions seem to prevail. In the restaurant to which I am in the habit of going I have observed that there have been six new waiters in four months-and the place has only one waiter at a time. This is illustrative of many other occupations.

The existence of insecurity as a dominating fact in the life of the individual can hardly be disputed in the light of the evidence at hand. I will add just a few more facts regarding some of its manifestations. Having a home is a human tradition. Generation upon generation of security and stability of place have left a powerful memory of the home in the minds of our people. Our sweetest songs,

${ }^{1}$ P. F. Brissenden, "Labor Turnover in California Oil Refining." U. S. Dept. of Labor, Monthly Labor Review for April, 1919. 
our most idealistic literature, our best traditions are built about the home-the center of love, labor and cheer. And yet for many of our working people the home has disappeared. They have become strangers to the dearest and most cherished ideal of the ages. "Approximately three fourths of American-born wage earners live in rented houses. - . The most complete available data indicate that less than 15 per cent. of Greeks, Hebrews, Portuguese, Rumanians, Lithuanians, Russians, Servians, Syrians, South Italians and Magyar immigrants in industrial localities are owners of homes. . . . With very few exceptions as to race the great majority of workingmen's families are not owners of their own homes." 1

"In Paterson, New Jersey, one-fifth of the silk weavers' families own their own homes. . . . Practically all textile workers in Lawrence, Massachusetts, were found living in rented tenements according to the Federal Bureau of Labor report for 1912." Approximately 90 per cent. of the steel workers' families in the Birmingham, Alabama, district lived in rented houses according to the report of the Immigration Commission. Less than one half of one per cent. of workers own their own homes in the tenement district in New York City. Only 4.4 per cent. of the workers in Boston and 7.4 per cent. in Philadelphia are home owners. ${ }^{2}$

Not only do the workers not own their own

${ }^{2}$ Lauck and Sydenstricker, "Conditions of Labor in American Industry," pp. 303-304.

Ibid., pp. 304-305. 
homes but a great many of them do not even keep a family establishment. "That approximately a third of the workingmen's families in industrial localities and slightly less than that proportion of workingmen's families in larger population centers are unable to maintain a separate family existence appears to be a warrantable conclusion from a study of nearly 30,000 typical households. Among the families of native white Americans the proportion is about 10 to 12 per cent., while among newer immigrant families the proportion is very much higher." The percentage of women workers in factories and department stores who are "adrift" in some of the larger cities and do not live at home was found to be as follows: Boston 61.1 per cent., Chicago 36.7 per cent., Minneapolis and St. Paul 46.2 per cent., St. Louis 47.4 per cent. In Boston 56.6 per cent. of these women lived in boarding or lodging houses. ${ }^{1}$

The social consequences of insecurity is apalling. They cannot be stated in statistical form. The great sorrows, troubles and worries which occupy so large a place in the community because of the possibilities of economic insecurity are not to be described. They carry with them warped and narrowed souls whose greed and selfishness, whose fear for the morrow and whose love for gain have combined to make them unsocial. Men are often ready to undertake any occupation to stave off insecurity-or just to add to their financial gains because the habit of evaluating life in terms of money has become a

'Lauck and Sydenstricker, op. cit., p. 295. 
daily procedure. Crime, misery and sorrow are fed and maintained to a very large degree indeed by this constant pressure of insecurity. Its economic and physical consequences may be stated in some formbut never in full. "Poverty," by Hunter, is one way of stating it; "Darkest England," by Booth, is another. But fairly current examples of it are near at hand. In San Francisco one half of 7,000 applicants for jobs at the Cooperative Employment Bureau were incapacitated for work from lack of nourishment from disease and exposure. "In 19131914 San Francisco, Los Angeles and Sacramento each had thousands of these migratory workers, from ten to forty per cent. being destitute.... The same conditions were found to be true also of the Middle West and in the East, not simply because of seasonal industries but also amongst those most independent of season." 1

At the present writing the situation is fairly stable. Employment is general and economic conditions are, if not entirely satisfactory, at least not panicky. However, there are rumors in the air. Men are afraid of their jobs. Prices are falling and the market is not entirely satisfactory. It seems also that credits are being drawn in. It may be that a period of economic depression is at hand. The very possibility of it has already set innumerable people to worrying, to fearing, to hoarding. Insecurity is staring them in the face-and they tremble for their savings.

In 1914 the author had occasion to come into

'Lauck and Sydenstricker, op. cit., p. 173. 
close contact with the unemployed in New York City. He remembers seeing men pick bread out of garbage barrels and wash it under a street pump so that it might be fit to eat. Thousands of men slept in the parks, sitting closely huddled together with their collars drawn up, their hands in their pockets and heads tucked in to keep as warm as the conditions permitted. Men slept closely packed like herrings on the space in front of the Herald Square Building covering themselves with newspapers. In a certain church house which the author visited, they sat up all night, not being allowed to fall asleep. Insecurity is a basic fact in all of our economic organization. All elements in the community are subject to it. The banker, the business man, the small dealer, the professional, the skilled worker and the poor unskilled worker, all are subject to it, but the worker suffers most. This important characteristic of the age lies at the root of its greatest discords.

Before closing this chapter it may be worth while to contrast the life of to-day with that of the people before the Industrial Revolution. To take the poorest-the serf. He had neither great riches nor great prospect of becoming rich. He lacked the personal freedom upon which we place so much value, but he had stability and security. He had a little piece of land, a shack for a house, but he was secure in their possession because the landlord could not take them away. He had a few animals-poor, emaciated, and small, it is true, but still he owned them. His life, hard and comfortless as it may 
have been, did not carry with it the constant sense of insecurity. No boss could fire him, no one could dispossess him, and even the most exacting lord left him in unmolested possession of the little that he himself failed to take. At eighteen the boy could feel confident that at sixty, barring unusual accidents, he would retain his home, his land and his piece of bread. This fact of security was even more definite in the case of those above the peasant class.

The machine tore the worker from his moorings and set him adrift. The dynamic character of our civilization has invaded the peace of the whole community. Remarkable as the achievements of the last hundred and fifty years have been they cannot be told in full unless we include in the cost not only effort and material but also the lost security of the individual. The worker has become a nomad, in the sense that he has lost permanency of tenure. 


\section{CHAPTER II}

THE CENTER OF GRAVITY

$T^{\mathrm{HE}}$ machine has become the center of gravity 1 in the present-day industrial community. It is increasingly occupying the place once held by land and still claimed by commerce. Just as Feudalism was the expression of the dominance of land, and as capitalism was the expression of the growing inportance of commerce, so the labor movement is the direct and immediate consequence of the machine. It is its political and social outcome. Historically, a kind of feudalism in political organization always followed upon the growth of large land-holding, as the land-holding system resulted in the dominance of a few nobles and the subservience of a mass of inarticulate peasants. This system, in its final stages, was crowned by a strong and all-powerful central government such as was characteristic of France before the Revolution of 1789, and more recently of Russia, Germany and Hungary. The growth of commerce, the rise of a powerful commercial class, has everywhere expressed itself either in a complete destruction of the feudal organization, as represented by land holding, 
or in a distinct modification of it. England, the United States, and France furnish good examples of the almost complete dominance of the commercial class, because commerce was held to be and was the center of gravity, while Germany up to a recent date represented a modification of feudalism so as to give the commercial element its increasing share of control. The place once occupied by land or commerce is now being absorbed by the machine. The machine is the new center of gravity, and every addition to the mechanical character of our civilization increases the weight and controlling power of this new force.

The machine has a peculiar character. It is a grouping of mechanical forces which requires attendance on the part of human beings. It does not operate itself-it must be looked after, controlled, directed, its material must be fed to it and its finished produce taken away. That is, a machine is a mechanical beehive, and the human beings like bees buzz around it, each performing his allotted task. A machine, if it works at all, requires the assembling of human beings and compels their cooperation, even if only in a physical sense. Mechanical industrial organization is cumulative in character. It feeds upon other machines. Every industry calls into being other industries, differing in particular structure and function but not in essence. The printing industry requires large printing presses. These, in their turn, call for large foundry establishments. The printing industry also requires huge amounts of paper and to produce this 
there have been developed highly organized mechanical instruments for paper making. What is true of printing is true of every other industry.

It is important here to remember the fact that every factory is a grouping not only of machinery but also of human beings, and as the mechanical character of industry develops, as it becomes larger and more complicated, it draws about itself a greater and more numerous assemblage of men and women who spend their lives performing different functions demanded by the machine.

The cumulative grouping of human beings and the increasing complexity and interdependence of the machines about which they work is one of the characteristics of industrial civilization. This change towards the mechanical has, up to date, carried with it an increasing urbanization. The cities have grown at a steady pace, and one of the reasons for their growth is that mechanical organization has up to date centered in specific places. New York, Pittsburg, Chicago, represent a growing mechanical complexity as well as a growing cumulation of men and women who, even if they are employed in different industries, still operate primarily as attendants upon similar machines. Thus we have complexity of machinery, carrying with itself an increasing size of factory, and the herding together of thousands of men and women under a common roof in close physical contact. So comes the growing city, composed to a large extent of these same men and women working in different factories and of other men and women who attend to their phys- 
ical needs-the bakers, the butchers, clothing operators, who feed and clothe the mechanical worker. And they too are driven to spend their lives around the machine. Even the restaurant has been invaded by the machine-the Automat. The machine is thus the determinant of the activities, contacts, outlook, and method of life of the people who are grouped around it, and this influence is steadily growing in importance as new inventions eliminate older trades or create new ones.

The machine has additional consequences which are important in determining its influence. As it grows in complexity it becomes simpler in its demand upon the individual worker. The machine destroys skill. It takes a complicated process and breaks it up into its elementary parts. The concentrated technique of the shoemaker is subdivided into some thirty operations requiring thirty human beings, each doing one-thirtieth part of the work formerly done by a skilled man. One might say that, in so far as that particular task is concerned, the intelligence of each man has been reduced to a thirtieth of that of the skilled craftsman-at least the machine demands no more. Skill, however, represents many things other than form. It represents pride in work, interest and creative activity. The machine destroys these and enforces the simple repetitive act which is monotonous and dull. Thus we have, as a result of machine organization, cumulative groupings of men in close physical contact, carrying on a cooperative function and yet each one subjected to conditions monotonous, uninteresting 
and uncontrollable so far as the individual worker is concerned.

The fuller appreciation of the significance of the machine as the new center of gravity requires a little further description of the human bees who hum and buzz, work, sweat, growl and swear in our factories. The machine requires attendants. The attendants are human. The machine runs, at its very least, eight hours per day, and for eight hours men and women must keep pace with the black noisy giants around which they work. This means that their best time is taken by the machine. It means that most of the day, counting the coming and going, is occupied with the machine. The mechanical organization tends to be confined to larger cities so that the workers live in tenements, crowded for space, crowded for time, denuded of personal interests. Then, too, the overcrowding makes land dear so that the worker very seldom owns his own home. $\mathrm{He}$ is a tenant living at the mercy (often) of a strict and exacting landlord.

What is true of the landlord often becomes true of other relations which the worker has with the community. His purchases at the butcher's and the grocer's, his clothing, his amusements, are to be had only in terms of direct and immediate cash payment, at best a week's or two weeks' credit. His income, however, is determined by one sourcethe machine. He is completely dependent upon the opportunity to work about the machine, which he does not control. The situation for the individual worker, and in large cities the mass of the people 
are workers, is thus directly and immediately dependent upon his contact and approach to the machine.

In the factory where these men are in such close physical proximity the situation is even more tense. Here are some hundreds or thousands of men thrown together-their destinies bound by a machine. They work in the same shop, for the same employer, in the same industry, and they have a common contact. These men may be, and often are, drawn from all parts of the globe. They have, however, one thing in common. The machine reduces their interests to a common denominator. The machine develops new interests, new motives, new contracts, new problems, new connections, which for the workers as a group become the insistent and the basic things with which they have to deal. The machine is their common center of gravity. What land did for the noble in the days of feudalism and what the competitive market and free bank connections do for the merchant, the factory does for the worker. Wherever the machine invades the activities of the community it upsets older relations, destroys older interests and replaces them with their newer problem-the problem of the control and direction of the new force represented by mechanical industry. The machine, however, seems to know no limits. It is invading a constantly -increasing portion of the community's activities. It constantly compels new adjustments for more and more people. The control of the machine is the root problem of the labor movement. The labor 
movement is but the political expression of a new center of social gravity. Where men used to have land or commerce in common they now have the machine, and as the feudal organization represented the expression of the dominance of land, as capitalism represented and represents the dominance of commerce-so the labor movement is the blind and unplanned readjustment of men to a new economic center of gravity. This force is all powerful. It makes the labor movement. The labor movement is the result, and the machine is the major cause. The difference in the character of the machine goes far to account for the difference in the political manifestation of the workers, just as capitalism represented a difference from feudalism. This center of gravity, like all previous centers of gravity, is not only economic but also psychological and political in its consequence. It is, for the workers in the factory, the core of their contact with the world. It is their means of subsistence and their basis of life. The complexity of the machine, the noise, the dirt, the monotony, the consequent suppression of creative impulses and the opposition by the employers to collective adjustment on the part of the workers, explain the discontent, the bitterness and the insistence on greater control, as much as economic need itself. The fact that men in the factory are reduced to a group, and that control requires cooperation, explains the mass character of the labor movement. It is cooperative because production is cooperative, just as commerce is competitive. Commerce is interested in sales; commerce is subordinate 
to sales-industry to production. Sales are essentially competitive. Production is essentially cooperative. This largely explains the competitive character of capitalism and the cooperative character of the labor movement. Around this new center of gravity is grouped an increasing part of the community, and the adjustment to it is the meaning of the labor movement. But this adjustment, instead of taking place naturally and peacefully, is misunderstood and misrepresented because of the fact that the labor movement is compelled to carry on a battle for existence. Instead of being purely constructive, and creative, instead of facing the problem of technique and adjustment, of cooperation and control, it must carry on a struggle for the right to have any control at all. This, however, while an important element in the growth of the labor movement, and in the idealism which determines its warfare, is only incidental. The real essence of labor organization can become evident only after this new growth is expressed in a social realignment, and for the time being the best that can be looked for is a foreshadowing of the form and structure of the future as it shows itself in the present. 


\section{CHAPTER III}

THE FUNCTION OF THE LABOR UNION

THE labor union developed primarily as an in. 1 strument for self defence. It is an attempt to harness the machine around which the workers' destinies are spun, and along with that it is an effort to stem the tide of insecurity by which the individual worker's life is menaced. It is a reaching out for some hold that will be permanent, stable and secure in this shifting, changing world. The hope of greater security is the motive which drives the average worker into a labor organization. The labor union is the instrument of defence which the individual uses, an instrument built with effort and suffering to serve as a bulwark against a harsh, indifferent and changing world which gives no thought to the individual. Unless we see the labor movement as an irresistible coming together of men in terms of the tools and the industry which they use in common, for purposes of greater security by more effective control of them, we cannot and do not understand the labor movement at all.

Organized labor is an organic growth around the machine. It is a part of the machine. It can no 
more be separated from present-day industry than the machine can be separated from industrial civilization. It is the spiritual consequence of the physical cooperation which modern industry demands-and it is inevitable. The conscious motive of the average worker is greater security; but it is the commercial control of the machine which makes insecurity permanent in the life of the worker. Group control of a common center of gravityand with it the hope of more stability, more permanence, more security is the root of the labor movement. It is its object, its aim, and its method. The individual worker plans little more than greater bargaining power with his employer when he joins a labor union. His association with other men for control of the machine and the job which it provides has consequences which he does not plan, which he does not foresee. He must join a labor organization as a means of defence, and in the process of carrying out the implications of defence against the competitive character of the capitalist system he contributes to the rebuilding of presentday society-a contribution which represents a byproduct of the more immediate and conscious attempt to find security in an insecure world.

The fact that security is the prime motive in labor organization is made clear by some of the most characteristic rules and regulations of the various working class organizations. Workers organize in terms of their skill or in terms of their industry. They organize in terms of skill or industry because they feel that a united control of 
their labor power will give greater security and stability than individual competition will give. The initiation fee which has upon occasion been raised to prohibitive heights is simply an attempt to maintain such security and power for the particular group which has already been organized. The system of "Ca-canny," is an attempt to make a job -any single job-last as long as possible and thus maintain the security of income for the particular group in question. The opposition to machinery is but another illustration of the purpose of the labor movement-opposition to the machine because it forces union members out of employment. There is no opposition to the machine as such. There is only an opposition to the machine as it influences the security of the workers. Wherever possible, for instance, in the introduction of the printing machinery and at present of clothing machinery, the workers make every attempt to regulate its introduction so as to benefit and not to suffer from it. Thus in the clothing industry the labor union does not oppose the introduction of new machinery; it merely insists that workers displaced by the new machine be placed in another position by the firm which introduces it and benefits from it. ${ }^{1}$

These practices for establishing security and stability are only a few out of many which are . adopted for the same purpose. The opposition to overtime is not only an opposition to long hours that strain the strength and health of the workers,

${ }^{3}$ Statement in conversation by Mr. Schlosberg of the Amalgamated Clothing Workers. 
but also an opposition to overwork at one time and underwork at another time. It is an attempt to regulate income-the one means of security in a world where goods and services are rendered in terms of money. The demand for the eight and seven hour day is another illustration of this tendency. The eight hour day serves many purposes. But the one which is predominant in the minds of the workers is the belief that it will make more work and will make what work there is last longer. This is also true of the provisions made by many unions in their contracts for the regulation of the slack season. In some of the unions the workers are laid off in degree of seniority, in others the married men are laid off last, in others still the hours of labor are reduced with the oncoming slack season as to keep the workers on the job as long as possible, while in some unions the workers take turns at working a week each so as to maintain some semblance of economic security and stability.

To all of these regulations must be added the fact that many unions have unemployment provisions for their workers-sickness benefits, disability benefits, and in many cases death benefit provisions for families. All of these and others-such as the demand for government provision of unemployment insurance, sickness insurance and old age pensions -are evidence of the fact that the labor movement is primarily organized to make secure the lives of the workers and to protect them from evil consequences of the operation of our dynamic economic organization. 
The International Typographical Union, for instance, has a mortuary and old age benefit, a disability benefit, a union home, and a hospital for union members. That this is the function of the labor union wherever it is organized is illustrated by the fact that in Germany 58.2 per cent. of the union funds go for unemployment and sickness, invalidism and funeral benefits; in Great Britain 75.91 per cent. is used for the same purposes, while in Austria 36.72 per cent., in Sweden 17.86 per cent., in the Netherlands 25.2 per cent., in Denmark 62.39 per cent., in Switzerland 40.37 per cent., and in Norway 42.6 per cent. are similarly used. ${ }^{1}$ They serve the purpose of maintaining a stable working force, of maintaining a vestige of self-respect and feeling of security in a world that is constantly slipping from the form it had yesterday-and in the process displacing the hold of the worker upon his life and income. The labor union is thus the instrument, the means of holding on to a fleeing and changing world.

This function of organized labor is of very great significance. It not only characterizes the present labor movement but indicates its tendency. The labor movement serves as a means of stabilizing a dynamic world. To state it in other words, the labor movement serves to make possible the continuance of the dynamic character of our industrial organization within a social organization secure for

${ }^{1}$ Statistics of Trade Union Expenditures for 1912, published in U. S. Labor Dept. Monthly Labor Review for May 1916, p. 83. 
the individual. It tends in the direction of making possible the introduction of new machinery without throwing workers out of their jobs, of developing new methods without bringing suffering and need upon those whom it displaces. It is an attempt to balance human cooperation and deliberate adjustment against the forces of machinery and invention and against the interest of profit and business motive. It is here that the full significance of this phase of the labor movement makes itself evident.

The capitalistic system of production and distribution is the most unstable that the world has ever developed since man emerged from the barest savagery. Capitalist economic organization operates in terms of profit and through a market of great sensitiveness. Insecurity is true not only of the worker but of the business man, and there seems at present no immediate means of stabilizing the influences of the market and credit system upon business and commercial activity. These forces, coupled with the fact that there is keen competition among employers, tend to place labor organizations on a very precarious footing; they are in a sense allowed to exist upon sufferance. Their destruction may mean at any given time securing advantage over a competitor or saving oneself from bankruptcy. Motives of profit demand the greatest freedom from control in business organization. The signs of the market may and constantly do make demands for expansion or contraction of business activity, compel the shutting down of a factory, the elimination of certain types of goods produced, the 
development of new fashions and newer types or organization. Motives of profit also dictate the increase of the non-productive part of a business organization. They make for an increase in the advertising and selling agencies and tend to underestimate the productive side of the industrial organization. They make for insistence upon profit motives rather than upon those of service. The labor organization is a thing that stands in the way of freedom of manipulation for the manufacturer, and constitutes a hindrance to experimentation.

This difference of interest between the employer and the employee in terms of the fluctuating market makes the need for security an ever constant fact. What is of greatest importance is that security depends almost entirely upon organization and control by the workers. This fact alone, if there were no other contributing factors, would force the workers inevitably in the direction of greater organization, of more power and of greater control. Their very existence depends upon it. What follows is simple. The more complete the organization of the workers, the more power they have; the greater the number of rules and regulations they impose upon industry, the less freedom of response to the market-in terms of profit-is there left for the employer. The labor organization tends to restrict the freedom of competition, of change, of contraction and expansion in the present business organization.

One of the characteristic forms of control which the labor movement represents is the attempt to 
control hiring and firing. In Lynn, Massachusetts, for instance, the shoe industry is bound by contract to hire only through the labor union headquartersbut even firing is restricted and may be considered a grievance subject to arbitration. To quote the contract for the year ending September, 1920, section 8: "The discharge of any employee considered a grievance by joint council No. 1, shall be considered a difference within the meaning of this agreement and in case such employee is restored to his or her position, he or she shall be compensated for lost time because of such wrongful discharge in any amount to be fixed by the Board of Adjustment." 1 This same contract is characteristic in its restriction upon the changes in method and machinery which the labor movement develops in its attempt to secure the workers' income and tenure. Section six of this same contract reads as follows: "It is further agreed that if the employer decides to introduce new work or to change in any manner and form the process of manufacturing shoes from the manner and form in which the work is being done (at the time of the execution of this agreement) immediate notice shall be given to the proper agents of local unions affiliated with Joint Council No. 1, United Shoe Workers of America before any change takes place."

The attitude of the employers in whose industry

¿From copy of 1919 contract between Joint Council No. 1, United Shoe Workers of America and Lynn Mass., shoe manufacturers, supplied to author by one of the manufacturers. 
the labor unions have not as yet achieved sufficient organization to make such control an established fact, is interestingly illustrated by the following quotation taken from a newspaper account, headed "Call Lockout Blow at Reds," which concerns itself with a dispute between the Store Fixtures Manufacturers' Association and the workers. "The International Union," said Solon Jay Riesser, president of the manufacturers' organization, "is composed almost entirely of aliens who have become imbued with the Bolshevistic idea that they have a right to control the industry. The last demands as framed by this organization even took away the right of the employer to hire and to discharge the worker." " This fact of increasing control alone if carried to its full consequence would force almost a complete stiffening of the business organization. With the growth of this force there tends to develop a demand for greater control over the actual operation of the business group and for diverting its energies into channels of service rather than profit -a proposition not compatible with present business organization.

This division of interests-the need for security on the part of the worker and the need for freedom from restraint which security implies on the part of the employer - tends to make the struggle of the worker and employer an inevitable one until either the worker has been reduced to an impotent tool or the profit motive in industry has been displaced. There is thus no room, from present appearances,

${ }^{1}$ From the N. Y. Globe of May 11, 1920. 
for compromise between the worker and the business community. They operate in different directions. They require different types of organization. The labor movement, however, shows no signs of abatement. In fact it shows a distinct tendency towards rapid growth and absorption of other groups in the community. It tends to inclucle more and more the professional and the civil-service people of the community, each of whom is interested in stability and security, each of whom operates in terms of service rather than of profit. There is thus a growing combination of those elements in the community whose interests are other than those of profit. Between them and the group representing the profit motive there is obviously at present no sign of compromise.

Instability and opportunity for expansion and contraction, for cutting expenses and utilizing new methods to reduce the cost of production, are part and parcel of the business community. But all of these things simply add to the force of what has already been said-a continuation of the insecurity for the worker. The labor movement growing stronger and more insistent seems to make the obvious consequence of elimination of the business community an inevitable end of the present struggle.

One could of course argue that social legislation represents the same tendency. In fact the resistance to child labor legislation in the United States, the resistance to the welfare bills in the State of New York-a resistance which has lasted over some six years in spite of many attempts to overcome it- 
is proof of the insistence of the employing group upon freedom, upon non-interference in the way they run their own business. Legislation could, if carried to its logical conclusion, actually destroy the competitive character of the present commercial system and substitute State Socialism. However, the point argued in this chapter is that the labor movement tends to destroy the freedom of the employer as a necessary consequence of its growth, as a part of the development of the instruments and methods of achieving security for the individual. The labor union actually does what the legislation proposes to do-with the difference that it does not make for bureaucratic control of industry which is consequent upon legislative control. It is simpler and more direct, and responsibility is more democratically distributed. Control is also more constant, because it is in the hands of those who suffer from any let-down of the established rules. This is true unless one assumes that the labor movement may still be destroyed and the old insecurity of the worker's life made a part of the business process. This, however, seems at present to be little more than a wish of the business community, a wish which it has not the power, even if it had the will, to achieve. The other possible alternative is the assumption that the capitalist system can stabilize itself and stabilize the life of the workers and thus save itself from destruction. (This would assume that stability was the only drive behind the labor movement.) But such an achievement would require the elimination of individual 
competition and a kind of complete state capitalism -a possibility which seems beyond present conjecture.

There is apparently only one possible outcomeeither the workers will achieve complete security by eliminating the profit motive and the business community, or the business community will destroy the labor movement and get back for itself the absolute economic freedom which it enjoyed soon after the Industrial Revolution. To achieve this freedom for the business community seems at present a visionary and, as will be made clearer by some of the other chapters of the book, a hopeless dream. The labor movement which began as a defence against insecurity operates as a means of stabilizing a dynamic world without destroying its dynamic character and seems destined to achieve complete control of the industrial functions of the community by substituting service for profit in industrial enterprise-and with service introducing democracy into industry.

It might be argued that in describing the distinction between the employers' and workers' interests to be one between freedom for the employer and security for the worker, we are not stating the facts clearly. The employer, it may well be said, wants security and the worker wants freedom. But this statement leaves out the fact that the employer can have security under present conditions only if he has a competitive advantage over his fellow business men and that the maintenance of such an advantage generally implies the possibility of maintaining ab- 
solute freedom of control over his industrial operations. On the other hand, freedom for the worker is at present impossible without first achieving security of tenure. It is here that the real divergence lies between security of tenure through group control for the worker and freedom from outside interference for the employer.

The outcome we suggest as seemingly inevitable might also be disputed on the ground that there is a third way out. The state might assume the responsibility of security for the individual and leave the employer free to manipulate his industry as he sees fit. This is not practicable under present conditions. It would imply a degree of control over the individual worker's activities and operations by the state which can at present not be assumed as possible. The state that would undertake to maintain the income of the individual worker would also demand control over his activities. The right to determine place and function, hours and conditions of labor, would immediately follow upon the granting of a steady income to the individual, and the assumption of all this for the sake of maintaining freedom for the employer to carry on his competitive game cannot be entertained. It would mean the slavery of the worker to the state for the purpose of giving freedom to the employer to contract and expand, to make profits and undercut his fellow merchant and manufacturer. This is not to be had in a world such as ours-a world where individualism is so highly developed, where criticism is so constant, where the sense of personal equality is so 
strong, and where political democracy has become the basis for a movement toward industrial democracy, and where the labor movement has secured control over some of the more basic industries in the community.

There are apparently only two possible alternatives. Either the business community is going to destroy the labor movement or the labor movement will absorb the control and power now in the hands of the business community and by such absorption displace competition and substitute cooperation. This in fact seems to be the tendency of the labor movement. The analysis of the work and method of organized labor in the following chapters seems to predicate the displacement of the capitalist system by industrial democracy - an achievement which is implicit in the growth and development of the organized labor movement. 


\section{CHAPTER IV}

\section{LABOR MOVEMENT PSYCHOLOGY}

H who would know the labor movement, its H discontent and idealism, its hatred and love, its bitterness and enthusiasm, must strive to understand its psychology. Without such understanding it is not possible to appreciate the true character or real significance of its power over the lives of those who are part of it. The psychology of the labor movement, like that of any group, is complex and overlapping in motives, interests and ideals. In addition to the psychical factors characteristic of all group behaviour, such as imitation, emulation, the craving for conspicuousness, leadership and personal expression, organized labor exhibits a few very specific and peculiar features without which it would not be the vital force in the world that it is.

The modern wage worker is propertyless. $\mathrm{He}$ is a wanderer, a nomad. He has no hold upon the world except such hold as his job may implyand that is a very precarious and doubtful one. $\mathrm{He}$ belongs to no place in particular-except where he happens to be paying rent or board. He is not

${ }^{1}$ See the first chapter for some statistical facts. 
anchored. Has has no deep roots in the ground. He does not grow like a tree or fructify in a hundred ways like a farmer. He travels. $\mathrm{He}$ is a constant seeker after better things. He shifts from job to job, from factory to factory, from city to city, from state to state, and frequently, from country to country. No place holds him very long. $\mathrm{He}$ either loses his job or tires of it. It becomes monotonous, irksome, unbearable. Other horizons -horizons seen through a newspaper advertisement, a tale told and heard, or just a guess, a whim, a hope, an expectation-anything is sufficient reason for a man chasing his own soul to safety.

So he wanders. This is no exaggerated picture. Look at the statistics of the labor turnover, look up the number of migratory workers, the number of our hoboes, our unemployed, and you will agree. To wander is just the opposite in its implication to being rooted to a place, a home. Just as to the stabilized farmer all things have a sense of permanence, so for the worker all things are transitory. The wanderer's self is not involved. His personality is not concerned. All things he does are things of the moment. They involve nothing that is vital or basic. He is primarily shifting - shifting after better things, after the security of a home, after more congenial surroundings. He does not build. $\mathrm{He}$ cannot do so. In many cases he has lost the sense of homemaking. Where he still possesses the desire and the hope he dare not and cannot. He dare not because the shifting job may upset all his plans and make all his labors for naught-he can- 
not because he lacks the instruments, the time, the place and the means. The creative personal achievement is foreign to his experience. Neither the interest of work, the boastfulness in a job well done, the satisfaction of having carried a self-made plan into execution, nor the joy of success, neither play nor art, neither love nor pride, enter into his work. $\mathrm{He}$ is a cog, a tool, an instrument. He is not creative, conserving and careful. Such words mean nothing to him. The present is accidental, transitional-the future holds the positive. This place is but a station on the road toward a satisfactory" "berth." The required "berth," however, is always at least one station ahead-because every job is by and large monotonous, uninteresting, precarious and one of which he tires after a little while. The industrial revolution has torn the worker from his moorings and set his body adrift. But a drifting body tends to carry with it a restless mind. The search after a physical hold that will be permanent is made the harder by the growth of a mind that knows nothing of the conserving, constructive experience which is the heritage of people who own their own land. The picture of the farmer's life is just the opposite of this.

The basic difference between the present day worker and the peasant and serf of the past is the difference between stability and instability, between security and insecurity, between regularity and irregularity. The common round of tasks which filled the lives of the peasant from day to day and year to year has no existence for the mass of wage 
earners. Life for the wage earners is more hazardous, existence more precarious, their work and habits more unsettled, and change more constant. Unemployment, industrial irregularity, occupational accidents-all of these have their influence upon the mind of the worker. Even the steadiest temper, the most phlegmatic and least adventurous individual is always on the verge of being set adrift. Being set adrift tends to have the same general consequence temperamentally for most people-the gradual acquisition of the "casual labor" psychology. So many workers are drifting constantly, so many others have their regular habits and customary existence undermined by unemployment and lay-offs that even those who remain stationary are infected with the restlessness characteristic of the less stable.

Not all workers are actually drifting. Some few employees do remain in the same firm for a lifetime, but they are very few in comparison with those who do not live their lives in one single setting. Even those who prove themselves sufficiently well rooted to stay and fulfill their allotted calling in the same small round of daily coming and going-even those are never certain of the day when this security will terminate. If there were no other element of danger than the competitive and shifting market, the adventure of ordinary business is sufficient in itself to give the sense of insecurity - even if rather distant and vague to the most happily placed worker. This irregularity of employment means for the worker irregularity of income, and that has its influence upon health and nourishment, produces 
overcrowding and bad humor, and contributes to aggravate the disgust of the workers with the world as it affects their daily lives and well being.

A qualification similar to that concerning the insecurity of the worker applies to his non-possession of property. It is not true that all workers are absolutely propertyless. Some workers own their own homes, others have small accounts in the savings banks, and a few have stocks and bonds. It must, however, be remembered that the ownership of stocks and bonds, or having some money in the bank, does not provide the means of activity and joyful enterprise involved in the ownership of tangible property such as that experienced by the farmer. These newer and intangible possessions which the worker does upon occasion share do not provide the means for constant concern for his vital and personal experience. It does not make of itself for the development of stability, nor for keeping the worker anchored to a home, nor does it become the basis of a permanent mooring for the drifter. It does not, generally speaking, give him a material control over his destiny.

To be secure in the hereditary holding of a bit of land as was the peasant of two centuries ago or to own it as the farmer does to-day is to be bound up with something in a most significant way. It means that the peasant is rooted to his land. He belongs to it and it belongs to him in more than a legal sense. He grows with the growth of the trees and ages with the house that he helped build when a boy. A thousand memories, a thousand joys and 
little things done, stand guard at every turn and sanctify his existence. Not only pride in the past but hope for the future fills his daily existence with countless responsibilities. The house needs painting, and new stones whitewashed along the footpath would make the house prettier. This cow which he raised and of which he is so proud is soon to calve, and that is no mean responsibility. What is true of the house and cow and footpath is true of many other things on the farm. If it is not the house, then the barn may need thatching, the axe sharpening and the horse shoeing. If it is spring there is the prospect of the manifold responsibilities of the summer; if it is autumn there is the needed preparation for the winter, the storing up of wood, fodder, cider and fruits. In the winter the good farmer has numerous little jobs put away for just the few idle hours that can be spared between looking after the cattle, the horses, the pigs, the chickens, the cutting of the ice and the shoveling of a way to town through drifted and overblown roads and fences. This is no dry catalogue of mean and empty tasks. Each one of them involves the farmer's personality. Each one demands and at least now and then actually receives the interest, the love, the enthusiasm of the man who lives his life in his own little fenced-off world.

This is not meant to be an idealization of the farmer's life. One who has been brought up on a farm knows that it is not all honey and flowers, bluebirds and green grass. The life on a farm often involves tribulations, sorrows, disappointments. It 
involves things badly done and done out of season. It often means poverty, ignorance, loneliness, and narrowed and blighted lives. But all these things, good and bad, all the joy and sorrow, success and disappointment, are centered in the personality of the man. His work is part of his personal spiritual life; his family is a constant factor in his work. His wife and children participate in the toil and fun of the day. The man plays his own game. $\mathrm{He}$ makes the rules. $\mathrm{He}$, too, sees that they are executed or not-as the weather, the will, or the fancy determine. Variety, differentiation, interest, play, love for animals, pride in one's work in the light of neighborly opinion, boastfulness of one's achievements, exaggerated hopes of one's undertakings, cunning wisdom about one's own trade, all of these elements find their place and do their part in shaping the daily life of the farmer. These things carry with them a certain positiveness of character, a certain rounded self-assurance about one's own tasks, a certain pride in one's orbit of dominance and creation which the instrumentalized factory employee does not know. They carry a careful, conserving, constructive, building type of mind-a type that takes pleasure in spending the hour after the regular tasks and daily chores are done-the hours of twilight which may occasionally be free to a systematic farmer-in planting shrubs around the house or in adding a special variety of fruit to the orchard.

The worker, as has already been pointed out, lacks this experience, this attitude toward life. He 
is restless, dissatisfied, and in search of different and better things. This constant change is stimulated by the precariousness of the average worker's job. He not only leaves his job but he is often discharged or laid off. These all tend toward the same effect. The constant change of place tends to make the shifting process into a habit. A habitually shifting life carries little that is fruitful and satisfying, that appeases and completes it.

Instability for the individual means lack of regularity, and for society as a whole it means constant friction, constant change, constant upsetting of old standards and the increasing difficulty of creating new ones. The older agricultural economy which the industrial revolution upset was one that lent itself to the growth of custom, habit and tradition. Order, regularity, system, and repetition of the tasks of yesteryear were the prevailing forces in the world before the machine tore mankind from its traditional mode of life and labor. For thousands of years men lived lives defined by custom and made familiar by habit. The weight of centuries of traditional method was involved in each task done and in each plan made. A hundred centuries of routine dominated social organization. Men felt safe and comfortable in the knowledge and sureness of previous procedure. Men accepted the world they lived in with but little questioning. Doubtthe doubt of the wisdom and propriety of the manner in which things were done-was not so keen, so widespread and so distinct an aspect of the world in which men found themselves. Mental discomfort 
was at its minimum. This has all been changed. The premium instead of being on the traditional has been transferred to the novel. New things, new ways, new methods, new explanations, new procedure, are the demands and the expectations that fill our daily lives. Ours is above all a dynamic age-and it is dynamic not only in terms of new mechanical processes but in terms of new relationships, which these new processes enforce upon society. All of these forces compel a re-valuation of accepted values and contribute both to the agitation of the mind and to the discomfort of the body.

To this fact of change and irresponsibility there is to be added another important element in the worker's life-his keener, more vivid and more constant sense of insufficiency. This is very important, and to understand it we are to grasp fully the significance of a certain contradiction in our present world. The industrial revolution among its many other contributions to our working order has added a peculiar paradox, a paradox involving the approximate equalization of the imagination of men at the very time when inequality of possession was increased. Men are both more equal and more unequal than ever before in the history of the world. They are more equal as men and less equal as possessors of material wealth. The imagination, the background of basic information and the sense of values, of needs and of qualitative understanding, is more nearly on a level than ever before. At the same time, however, income, ownership, is less equally divided amongst men than ever before. 
Actually, men desire more because they know more, but they satisfy these desires less, comparatively, than when their needs were more limited.

The inequality of wealth is extraordinary. A single illustration will do. Nine-tenths of the wealth in Great Britain is possessed by less than one-tenth of the population. To place this graphically before the imagination, all one has to do is picture a division of one hundred dollars amongst ten men on this basis. One man would get ninety-one dollars and the other nine, one dollar each. This is not quite correct, as the actual division is even more extreme. Ninety dollars would go to less than one person if such a thing were possible. This is a striking fact, one that the annals of English history cannot duplicate. It is unique historically. What is true of England is true in a less degree of the United States.

Never in the world have the poverty and riches of the migratory worker on the one hand and the multi-millionaire on the other existed side by side. Poverty is relative. Absolute poverty is rare. A beggar is infinitely richer than he who owns nothing. The beggar generally possesses a torn suit of clothes and a leaky pair of shoes. That is not much, it is true, but it is something. He may be said to be on his way from absolute poverty to absolute riches. But he has a long way to travel. The peasant in the France of Louis XIV, the serf serving the estates of Henry VI of England, or the slave on our Southern plantations was richer relatively than is the modern migratory workerricher at least in the possession of security. I am 
speaking comparatively; unless the ability to read and to ride a box car is considered a kind of wealth, one might almost say that the wandering worker is actually poorer.

The full significance of this inequality comes from its opposite-the greater imaginative equality that has accompanied this cumulative differentiation in worldly goods. It is remarkable how much like each other men are to-day-remarkable when we think of the differences that separated them before. The millionaire and the beggar both read the New York Times. The beggar feels and is more like the millionaire than the serf ever was like his master. They see the same "movies," read the same magazines, are thrilled by the same daily occurrences, and show the same intelligence, on an average, in their judgment of world-important facts, and are often equally interested in them. There is no qualitative differentiation. The difference is one of gold, and that is not spiritual. It is a difference of degree and not of kind. The poor do not feel the awe or humility before the millionaire that used to be characteristic of the lower classes. They are conscious of their equality. It only makes the difference one that rankles because it is obvious, because it limits the powers of satisfying a stimulated imagination and the demands this imagination makes upon the world.

The peasant had little. He lived, however, on a plane, imaginatively, very much lower than his lord. He knew and saw little of the broader relations and implications of life. He did not share so fully the 
ripened thought and experience of his age as does the present day worker. He wanted less both comparatively and actually. To-day the worker wants actually more and secures comparatively less. $\mathrm{He}$ feels this greater difference the more keenly just because he is on a basis of greater spiritual equality with his richer and more fortunate employer. This makes dissatisfaction with the present greater and the hope for a fuller, richer and more satisfying life more acute, more insistent, and more pressing. It stimulates the wandering, searching, yearning aspect of the worker's existence. It is a constant stimulus to restlessness. It is an important contribution to the worker's discontent and an element that goes into the making of the worker's psychology.

The equality of which I am speaking is different from equality before the law, or from that implied in the equal rights to hold property, to travel, or even the equal right in the pursuit of happiness. It is a greater social and spiritual equality. It manifests itself in the similarity of clothing, dress, home and amusement, in education, reading matter, customs, political ties and social habits. It is an approximation of equality in all things except money-and it makes that one variant very conspicuous. The separation between man and man has become more objectionable just because it has been so simplified. It makes the worker's life obviously incomplete, his insufficiencies more conscious, and his blame more immediate. This has made the desire for an adjustment more vivid. I 
am not implying that the individual variation has been eliminated. If anything, that has probably been increased. The differences between the classes have been diminished in most respects excepting that of possession, and that rankles in the mind of the worker because it is the obvious limitation upon his further growth and development. It presses and gnaws against his greater demands for expansion, for actual equalization in terms of experience and satisfaction. It makes for discontent, for bitterness, and for the desire to change the world. The wandering temper and habit, the dynamic character of our civilization, and the greater imaginative equality determine the general background for the development of the peculiar manifestation of the worker's psychology.

The first of these peculiar elements is his aversion, his constant and almost irresponsible disgust for the mechanical, routine, oppressive and dehumanizing nature of the daily function. This fact cannot be overemphasized. No reiteration is too vehement to express the hopeless feeling of loathing for the machine and the monotony that it forces upon the workers - the constant drilling of unchanging motion, a never-ending repetition that destroys all interest and kills all creative effort. This feeling of hatred is doubly strong because it is constant and, for the worker, infinite and without escape. It is a hatred born of instinct and not of understanding or analysis. The analysis and understanding may come later and supply the drive for revolutionary temper and enthusiasm. But with the average 
worker-conservative and radical-it is an instinctive resistance against suppression of the freedom for play, for interest, for creativeness. For all men are in their own spontaneous way artists and creators, and the curse of the machine is that it standardizes thought and kills it, standardizes emotion and destroys it, standardizes the artistic sense and annihilates it.

One day while doing some organizing work along the waterfront I came across a typical labor group -a group of longshoremen carting heavy boxes on their little two-wheel hand carts. They were a typical labor group of America-typical because they were of all nations and of all races. In that small force of about fifty men there were Italians, Irishmen, Polacks, Jews, Russians and men of other nations. In their midst stood a foreman, a big, burly fellow. He stood there with his hands in his pockets, tall, blonde, with a heavy voice that was harsh and snappy, and all he did was to repeat without end one single phrase, "Hurry up, hurry up, hurry up," a phrase that fell with the regularity of a clock upon the ears of the working group and at the sound of which the men bent their heads a little lower and quickened their step as if stung by a whip. Every half minute or so he repeated the same command. It was never varied; it was never changed. The words were the same, the tone and inflection were the same. The men, like whipped dogs, only bent their heads a little lower at each command and made a quicker motion with their feet. Occasionally there was evident a gleam of 
hatred, of bitterness and of despair on the part of some of the men. But as a whole they submitted. They submitted because their submission was inevitable.

It was inevitable because the single worker is helpless; these men were not organized. One of the reasons why they were not organized was that this lashing had driven all ambition, all energy, all initiative out of them and made them helpless and fit only for despair and an early grave. The waterfront is characteristic of other labor centers, only that the machine is duller and its sound harsher than the human voice. I am not imputing personal bias to the foreman. He simply represents the process of reducing the worker's activity to mechanical standards.

What the mechanical work required by a modern industry is, and what its significance may be, is illustrated by numerous available descriptions, but we will content ourselves with only one. "An eyewitness at the Stock Yards describes a scene in one of the large packing houses. 'A month ago,' he says, 'we stood with a superintendent in a room of the canning department. Down both sides of a long table stood twenty immigrant women; most of them visibly middle-aged and mothers."

"Look at that Slovak woman," said the superintendent.

She stood bending slightly forward, her dull eyes straining down, her elbow jerking back and forth, her hands jumping in nervous haste to keep up with the gang. These hands made one simple precise 
motion each second, 3600 an hour, and all exactly the same.

"She is one of the best workers we have," the superintendent was saying. We moved closer and glanced at her face. Then we saw the strange contrast. The hands were swift, precise, intelligent. The face was stolid, vague, vacant. "It took a long time to pound the idea into her head," the superintendent continued, "but when this grade of woman once absorbs an idea she holds it. She is too stupid to vary. She seems to have no other thought to distract her. She is a sure machine. For much of our work this woman is the kind we want. Her mind is on the table." 2

One who knows anything about the European peasant woman cannot accept the placid description of the superintendent. A mother and a middleaged woman who had traveled across two continents and had the initiative to seek a new home is not the type whose mind is on the table. What share the working at this speed and monotony had in placing the mind on the table we will leave the reader to judge for himself. We do not insist that all foremen are such as we described or that all factory work is of exactly the kind done by this particular woman. But life for the workers is sufficiently strained in their working hours to have this general effect.

This drive, this impetus, this drilling helps to explain a great many things in the lives of the

' Posthumous article of Prof. Carlton Parker in the Atlantic Monthly for March 1920. 
workers. It suppresses personality. Personality, however, will not be suppressed without some rebellion. It helps to explain the hobo who will not submit, the derelict who cannot endure and breaks down, not having been created to pass through this crucible of speed, monotony and impersonal activity, like a $\operatorname{cog}$ that whirls without end and without understanding. It helps to explain the lower criminal classes, "the submerged tenth" that seeks a life of ease and parasitism rather than submit to being crushed and disfigured in soul and body by a meaningless machine. It helps, too, to explain the love, the passion, the bitterness and the idealism that is found in so large a measure in the labor movement. It helps to explain it because in the labor movement the worker finds relief from monotony, opportunity for expression, place for play and individuality. This service to the man who works in our modern industry is one of the great functions of the labor movement. I do not mean the conscious intellectual participation of the worker in the labor movement and in its ideals, but rather the fact that the labor movement saves the worker from intellectual and spiritual petrification, that it saves him from drying up spiritually, and that this unconscious function, this by-product of the normal activities of labor organization, explains a great deal of the passion, the love and the idealism that is connected with it.

The other element in the psychology of labor is born of conscious strife. The labor movement is still to a large extent a movement struggling for existence. As a consciously creative movement it 
is still in its early stages, its positive creative aspects being chiefly by-products. This conscious struggle against an organized and powerful opposition culminates in "class consciousness." I am not speaking here of the theory of the class struggle-I am speaking of the fact as the workers know it. Hundreds and thousands of workers are class-conscious without ever having heard of Marx and without coming in contact with the doctrine as such. They are class-conscious because their struggles for existence and their desire to escape from oppression and monotony, find constant opposition.

I know of men who would not be called I. W. W.'s, who talk with a hatred of the capitalists and the capitalist system much more emotional and bitter than that which any revolutionary worker conscious of the ideals of the labor movement indulges in. I know good patriotic workers who could not be called socialist by any stretch of the imagination -if socialism implies a conscious rejection of the present system and the acceptance of another where the wage system has no existence-who indulge in revolutionary talk and (unconsciously) in revolutionary activities. They hate the present world because they have so little share in its control and because they are outside the sphere that participates in the manipulation of the forces dominating their lives and activities. Men who have been on strike, who have been clubbed by the police, who have been driven by the militia and who have been persecuted, know something about the facts of the class struggle even if they know little about its theories. 
The element of importance that is subsidiary to the two just described-the instinctive opposition to the mechanical suppression that is characteristic of the machine and the feeling of class hatred-is the intellectual and critical nature of the labor movement. There is a general conviction among thoughtful workers that the present world works badly; that it is poorly organized; that unemployment, poverty, ignorance, social injustice, are things which intelligent control and ordinary good human intentions could prevent if only there were the will and the desire that they be prevented.

This conviction is strong, and the strength of the conviction is in proportion to the revolutionary idealism of the workers. This conviction leads to the conclusion that the present system is not only bad but is kept so by the perfidy and selfishness of the powers who are benefiting by the present system. It thus adds to the hatred and to the instinctive opposition against being reduced to mechanical instruments by the machine, the belief in the villainous character of the capitalists as a class, a conviction that adds contempt to hatred and leaves a constant bitterness that knows no end.

Opposition by the capitalists-an opposition that is based often upon ignorance and generally upon selfishness and class standards-makes for a constant aggravation of this bitterness. This opposition, where successful, has other consequences than that assumed by the employers. It prevents organization. But organization is education, is discipline, is group control, is sense of power and 
influence. Lack of organization is not lack of discontent or lack of hatred. It is lack of social cohesion, lack of group activity. It means that deliberation, planning and direction are eliminated. It means power-the power of the mob-without conscious coordination. The labor movement is opposed to the mob and mob activity and is supplanted by it only in despair. The labor movement desires change but it aims at a change that involves as little friction as possible, the amount of friction being always determined by the strength and bitterness of the opposition.

I cannot leave the general discussion of the psychology of the labor movement without describing the function of organized labor as it affects the centering of the worker's interests upon the problems concerning him most vitally. The psychological maladjustment of the worker makes him an easy prey to all kinds of emotional appeals. Uneducated as he often is, lacking both the time and the training required to make an analysis of the evils and the forces with which he is confronted, the worker is apt to accept any easy and ready rationalization of the world and its implications. This in particular if it provides an easy escape and emotional outlet from his pent-up and suppressed activity. The excitement and rationalization of a Billy Sunday meeting, a Holy-Roller exultant dissipation, leaves the worker both exhausted and momentarily relieved from the gnawing of the forces about him. In a minor degree this service is performed by dime novels, drink, baseball scores, 
moving pictures and political excitement. Any rationalization, any explanation, any drawing out of interest, of emotion, of the sense of play and creative activity mitigates the feeling of oppression produced upon the workers by their monotonous existence. Political movements achieve the same end. They serve chiefly in taking the worker's attention from his immediate problems and centering them either as a rationalization or as a means of emotional dissipation in things that are not of pertinence in his daily life.

The Socialist Party differs from other political organizations in that it concerns itself consciously about those things which seem to be most vital to the worker's life and labor. By its agitation it helps to crystallize discontent, gives it meaning and sets for it a definite goal. It must, however, be noted that the Socialist Party concerns itself about those problems rather than with them. It tends to postpone immediate activity by centering interest in things outside the sphere of daily contact and function in which the worker operates, and it thus in a measurable degree unconsciously participates in the work performed by all other agencies that go to distract the worker's attention from his immediate problems. It is here that the labor movement per se becomes most significant.

The labor movement provides an emotional outlet. It provides room for creative activity. It gives play to all of the instincts and passions that are characteristic of human nature. But it does all these things in terms of the values, functions and 
problems with which the worker is always called upon to deal. It keeps the worker's mind always centered upon the core of his difficulties. It prevents distraction, loss of emotion and energy. It makes significant to the worker the thing with which he deals as a member of the community and through which the worker acquires social significance-his work. It thus provides the means of escape from suppression and this emotional outlet becomes in itself contributory to the final solution of the problem which is the chief cause of the workers' evilsindustrial autocracy. 
PART II

Methods 



\section{CHAPTER V}

THE BREAK OF THE CIRCLE

PROFESSOR HOBSON, in his little volume on "Democracy after the War," has a remarkable chapter entitled "The Closed System." In this chapter he shows that the capitalistic world is a hydra-headed, multicellular and interlocked organization in which every feature is dependent upon and supported by every other. The imperialist, the protectionist, the militarist, the financier, the politician, are all interlocked. It is useless, as he points out, to attack any one of these separately in the hope of destroying it. If the evils of the world of capitalism are to be eliminated, every feature in it must be subjected to a simultaneous and united attack. He reads the reformer, the specialist, the man with a particular hobby, a lesson which ought to be convincing to the point of action and union among the various forces that would eliminate the evils resulting from the capitalist system.

The labor movement is generally conceded to be the most powerful single force in the struggle to break the vicious circle. It is most powerful for many reasons, one of the obvious reasons being that 
the struggle on the part of the labor movement is most persistent and most constant. Instead of being impelled, as are many reform and even revolutionary groups and individuals, by idealistic motives and theoretical considerations, the labor movement lives and works by the constant necessity of selfdefence which the present system imposes upon it. This is a much more forceful and pertinent factor in its activities than any idealistic, moral or political consideration. I do not want to be accused of undervaluing the moral, socially minded and ideal or revolutionary motivation which is the driving force behind a good many reform and revolutionary activities. All I insist upon is that they do not compare in persistency, stubbornness and drive with the force which the labor movement, no matter how conservative, carries with it.

The labor movement is the wall of protection which the individual worker has developed through group organization in the face of a merciless competitive system that reduces him to a bought "hand" to be discarded and thrown away when it has grown weak, profitless or old. Between absolute helplessness and despair on the part of the worker and such protection and defense as he has there is practically nothing except the strength of his organization. It is this fact that makes the labor movement the most constant force for social change in the community, for the present world is in a conspiracy, conscious or unconscious, against the gains and the achievements of the workers' organizations. This conspiracy is bound up with the competitive 
system and can apparently come to an end only with its destruction. This is one reason, and probably the most powerful single reason, why all labor must of necessity be revolutionary in fact through the elimination of competition which threatens its very existence every day of the week. It must be obvious that this is so under the present scheme of things. While competition lasts it may be, and in fact generally is, to the advantage of any given employer or on occasion to an individual worker to disregard, evade or deny the rules, regulations, conventions, and principles achieved and enforced by the organized labor movement. The competitive system gives advantage to him who can escape the rules that bind the group with which he is associated, and the labor movement is but an organization set around the enforcement of standards and rules which it asserts from time to time. It is this constant struggle of competition to undermine the control and power of the organized labor group which makes labor always on the aggressive, always on the lookout, always suspicious, always insistent upon more power. This is, of course, not the only motive, nor is greater power the only consequence, but it is very generally the most immediate one.

Just as the capitalist system is a circle of predatory interests closely knit together, so the labor movement tends to become a closely organized and united group of defensive and aggressive activities set within and against the capitalist system. It is not necessary to exhort the labor movement to unite against the capitalistic system. No moral appeal is 
needed except to hasten such unity, for the nature of its activities and the character of its struggles enforce unity at the point of defeat.

I am not oblivious to the shortcomings of the labor movement in point of organization. I know but too well its jealousies, its short-sightedness, and its bickerings over petty things. What is obvious, however, is that without planning it finds itself generally uniting and developing instruments for common action, not because it has in mind the destruction of capitalism but because a struggle with a competitive system compels it to parallel at all points the methods of defence which the capitalist system has developed.

The instruments which the labor movement is developing in its struggle against capitalism and with which it is paralleling the structure of capitalistic society may be divided into two kinds-the direct and the indirect. They may also be described as the instruments of aggression and defence. The capitalist system developed as a competitive system, and it insisted and still does insist upon competition among workers. The labor movement, however, has developed on a cooperative basis. It substitutes collective bargaining for individual bargaining. Competition is replaced by cooperation. This is the first striking parallelism in the growth and structure of labor organization. The basic principles of activity are directly opposite, at least in theory, and approximate each other in practice : collectivism for individualism, cooperation for competition.

The growth of capitalism into large trusts, into 
mighty national and organic groupings covering the raw materials and the manufactured product was paralleled by the growth of international unions, and now these unions are very rapidly developing into industrial unions. The Steel Trust is paralleled by the Amalgamated Steel Workers Union which covers the whole industry and all of its trades and combines them into one organization. The railways, growing into large national and international organizations more and more dominated and controlled by single financial groups, are paralleled by the growth of the four railway Brotherhoods and the Railway Department of the American Federation of Labor. As capitalism becomes more unified, labor immediately tends to follow the same lines of unity. The chamber of commerce is set off against the National Trade and Industrial organizations of a labor congress. When capitalism becomes international it is faced with an ever more powerful international labor organization. That capitalists have achieved greater cohesiveness, greater unity, both national and international, is to be explained by their very much greater mobility, education and foresight, and by their fewer numbers. Labor has the difficulties of language, ignorance, prejudice and provincialism to deal with. He would have to be a bold man indeed, however, who would deny that all of these handicaps are constantly losing their force and power and are constantly becoming less significant in the growth of the power of the labor movement.

The most striking evidence is the present phenom- 
enal spread of international solidarity on the part of labor. Not only are strikes often given international financial support, but there is constant evidence of definite economic cooperation. Labor is in many places convinced that the attack upon Russia is engineered by the same financial groups that are most antagonistic to them at home, and they have attempted to meet these powers through international strikes. The fact that these strikes have proved abortive simply goes to show that labor has not overcome all of its obstacles. It does not prove that the trend towards international working class solidarity is absent or that the consciousness of international solidarity is not developing. When American longshoremen refuse to load ships with ammunition because they believe that they will be used to fight Russian workers; when Italian sailors compel their captain to put into port with a ship carrying rifles meant for Siberia because of the same reason; when Scandinavian workers refuse to handle ammunition for Russia for the same reason, it seems evident that international capitalism is tending to be met on an international scale by an internationally conscious labor movement. The other element in the direct and aggressive method is the establishment of a labor press. The workers are convinced that the labor movement is not fairly represented by the press of the day and so is developing a press of its own. Every International Union generally carries a paper of its own,

${ }^{2}$ Witness the threat of a general strike in England if war were declared against Russia. 
and this paper becomes in practically every case an instrument of aggressive resistance against the capitalistic press and the capitalistic system. Just as the capitalist press defends the whole of capitalism, so the labor press tends to develop a united front against it and defend the cause of labor in its totality. This is true also of education, of the public platform, of the magazine, of pamphlet literature, and of the public forum. Every agency of the capitalistic system is tending to be paralleled and used for defense of the labor movement.

When viewed as a movement for the ultimate control of the destinies of labor on a democratic basis, the methods of the labor movement which are direct and unconscious are of equal and even greater importance than those which I have called direct and aggressive. Capitalism, with its large autocratic organization of industry, depends for its smooth workings and uninterrupted continuance upon a pliant, submissive and easily managed working force. One of the first consequences of the labor movement is to upset this basis of the capitalistic system. It develops critical, aggressive, evaluating, non-submissive and bold characters out of a very meek and submerged working force. It compels the raising of the question of a validity, propriety, honesty, and the proper ordering of the present scheme of things on the part of those who have never seriously questioned the present arrangement of the world. This is one of the first consequences of organization.

The labor movement and the workers in general, 
because of their experience with the character of the capitalist press, lose confidence in it and cease to believe it. This is a very striking fact in the current world. The capitalistic press has overdone its service to the present system and it has, to a much larger degree than is generally believed by people who are not acquainted with the working class movements, lost its hold upon the workers. It is common to describe the newspapers as the "reptile press," and to paraphrase titles-to speak for instance of "The New York Crimes" and the "Evening Tell A Lie." This simply means that these papers add bitterness and scorn to the workers' appraisal of the present system, a fact that does not contribute either to the service these papers, are performing for the present system or to the wisdom of their procedure. It is notorious that the workers have a tendency to disbelieve all things said against them or their class by the large capitalistowned papers. We have thus the defence, instinctive and unavoidable, against all the propaganda of the defenders of the present system.

It seems indeed remarkable that a class better equipped by education, by powers of advertising, of propaganda, of insinuation, than any other class in the history of the world should be losing all moral standing before so large and ever-growing a part of the working class community. The present system has at its disposal the newspapers, the magazines, the advertisers, the moving pictures, the public platforms, the public schools, the church and the forum, and yet it fails to convince the less educated 
and generally gullible part of the community, either of its good intentions or of its truth or the correctness of its facts. It cannot do so, because through experience the workers have found that all of these agencies are used on occasion with all resource and without restraint to defeat, discredit and ridicule those who represent and speak for them; and the more intelligent a worker the less credulous he is of the material, opinions and motives avowed and used by these agencies. This fact is so evident and well known that a speaker can always rouse enthusiasm and laughter by referring to the press of the country and its supposed honesty.

This feeling of distrust has gone to the extent of disbelieving the words of not only the press but of the politicians, the statesmen, the "public spirited citizens" and spokesmen for the status quo. To this must be added the use of the power of organized labor for purposes other than those for which it originally organized. The workers organized for the securing of better wages and greater security. They find themselves compelled, however, to use this power for other than what to the outsider appear purely personal gains. During the British railway strike the workers on the newspapers showed a spirit of extreme restlessness, in one case going to the extent of refusing to set up an editorial which was against the strikers. They felt themselves called upon to do so because of the conviction that the interests of the capitalist system were being defended with their cooperation in an issue which the workers insisted was purely a wage issue, but 
which the whole ruling group in the community apparently felt called upon to decry as an issue growing out of a movement against the government. This feeling of being participants in an unfair attack upon their class, the sense of being made the instruments of abuse, participants in the defeat of their class by a united capitalism explains this fact as well as others like it. The behavior of the Canadian newspaper workers on some of the Dominion papers is of the same category. This, too, explains the sympathetic strike. The workers feel instinctively that the capitalists are fighting a united battle and that they are called upon to refuse to be a party to the method of using all of the community's instruments to defeat any one section of workers. The labor movement thus parallels the closed capitalist system and tends to do so ever more consciously and on an ever larger scale.

The refusal of the British workers to load ammunition for the Polish-Russian War, the refusal of the Irish workers to carry ammunition for the British Government in Ireland, the decision of the International Trade Union Movement to boycott Hungary, are all illustrations of the growing solidarity of the working class movement on international lines. This international solidarity which is thus developing is but a closing of the links in the working class chain of power and control which, used with ever more effect against the power of the capitalist organization, tends to destroy the closed circle of the capitalist system.

This tendency is of great significance, when viewed 
in its totality. We see the growth of a paralleling method of control, of aggression, and of defense along every highway and byway. The ramifications of the labor movement are as wide as the world of capitalism and are tending to become equally significant and patent in the minds of the workers. Never before in the history of the world has an opposing system of ideals, of methods, of powers, of ends, tended to secure so powerful a strangle hold upon the social organization which it confronted and with which it battled. Every avenue of control is dominated, every power is duplicated with greater or less completeness, but always tending to be more complete, more positive, more secure. The world may be in a closed system of capitalist control generating power and influence for its own preservation, but within this system is developing another force of equal extension, only of greater numbers, of equal width, of greater depth.

The imperialism and militarism of capitalism is opposed by the pacifism and anti-militarism which is general among workers. The trust is met by the industrial union, the competitive by the cooperative principle, the propaganda of the class in power by the derision and refusal to believe on the part of those whom they would persuade, the internationalism of the capitalist system by the unity of the workers' movement, and the capitalist press by the workers' press, capitalist education by working class education.

The workers are building a net of powers, of control, of influence, of sympathies, of ideals, of 
methods, and of ends, which are incompatible and contrary to the present system. The closed circle is met by an ever-expanding working class circle set within it, extending from its organization in the shop, in the community, the industry, to the nation, and internationally to cover the growth of capitalism. This power constantly increases and expands and strains the powers and functions of the capitalist system.

Where this will end seems evident. It seems evident because it is probably inevitable that the growth of the labor movement is not compatible with the competitive and profit motive in industry. It seems destined to achieve security, and through security the freedom of self-determination in which are bound up all of the moral and ethical implications of the labor movement. 


\section{CHAPTER VI}

THE METHOD OF THE LABOR MOVEMENT

THE labor movement bridges the age-long gap 1 between the hand and the brain. This elimination of the division between the brain that conceives, that plans, that organizes, and the hand which executes, which puts into actual shape and concrete form, is the basic method of the labor movement. Labor throughout the ages has been considered menial. To be a hand-worker has generally meant that one belonged to a lower class. This implication was given philosophical expression and justification by the Greek definition of the slave. A slave was a man without a soul-and a slave amongst the Greeks was a worker. A free citizen generally did not work. ${ }^{1}$ Work was on the whole considered a disgrace, a proof of a man's lack, not only of social position and free citizenship, but of spiritual essence.

In spite of certain aspects of Christianity that general view has been carried up to date. There has persisted a suggestion of lowness, of servility, of lack of intelligence and character in the fact that

'Alfred Zimmern in his "Greek Commonwealth," p. 251, has developed a different picture and indicates that Aristotle's generalization was probably too hasty. 
one was a worker. To be low-born meant to be born in a class that worked for a living. This assumption, that in some way the commonness of labor makes the man common, has still a strong hold upon many of our good people who on proper occasion talk of the dignity of labor, a dignity which they themselves are, generally, in no evident hurry to share by becoming laborers.

Any fact of long standing, any institution of persistent continuity, any social phenomenon which lasts over a great length of time, no matter how incongruous it may seem at the beginning or how strange and out of place when it first appears on the horizon, will in time be rationalized, explained, and ultimately justified. This has happened with all important historical changes. It was true of Christianity, of Democracy, of universal military service and of such things as public school education.

In no case, however, is this tendency towards rationalization and justification of the persistent so well exhibited as in the case of servitude; of human slavery and subordination of the worker. The civilization of the Greeks rested upon slavery. It rested upon the deliberate and direct subjection of man to the service of man. The thinking Greek gave this fact the simple explanation that a slave was simply a living tool. He was a being lacking the force which would make him human-a soul. This explanation was not unknown to some of our Southern apologists in the days of slavery.

With the coming of Christianity, the break-down of the Roman Empire, the invasion of the Germanic 
tribes, slavery was very slowly transmuted into serfdom. The earlier explanation that a slave had no soul now became untenable. All Christians had souls to be either damned or saved. The very existence of the Christian Empire depended upon an inclusion of all men within the formula of a human being with a soul-a divine spark that gave the lowest some relation to the eternal. The subjection of a large part of the community to labor for the benefit of a small group of nobles, bishops and princes was however still the groundwork of social organization.

An explanation-a new one-of this fact was needed, one that would not deprive the lowly and the poor of their communion with the Divine. This was found in the doctrine that God had appointed all men to their particular station in life-a doctrine of social harmony. Like the notes on a piano, each occupying the place which best fits a harmonic scale, so each individual fitted properly into the scale of social organization then conceived. The worker and the idler, the peasant and the lord, the noble and the king, had all been given their work, their place and their reason for existence. Obedience to God involved the acceptance of this harmonic division between the function and income of the separate individuals, not only as a good but also as a merciful fact (a fact which no man could doubt without doubting the wisdom of the Lord and the justice of His mercy).

The rise of cities, the commercial revolution, the coming of the machine, gradually destroyed serf- 
dom, drove the worker from the land and forced him into overcrowded cities. The period which saw these economic and social changes also witnessed the gradual disappearance amongst many men of the belief in the perfect wisdom of the social and political arrangements of the Almighty. This change was characterized and stimulated by the Protestant Reformation, the rise of the Anabaptists, the growth of science and of the material philosophies and with them the development of the Deists and Skeptics. The old explanation was no explanation to those who rejected traditional Christianity, and their number was ever growing.

Servitude, however, remained a constant social phenomenon. The man who had been a slave, who had gradually become a serf, was now called a freeman, but his freedom was chiefly a freedom to go hungry if he had no work or was not willing to accept work under the conditions provided by an employer. Serfdom had been transmuted into what is called wage slavery, which is more unmerciful, when it is unmitigated by labor organizations, than any slavery hitherto known. This persistence of servitude had to be explained, especially since the age which saw these changes was reputed to be one of freedom and equality. A rationalization was soon found. I do not say it was manufactured. I say it was found. Poverty, inequality, disease, and drunkenness, crowded homes and overworked children had to be explained. Any fact that is persistently with us has to have an explanation even if it be false. It was found in a very simple state- 
ment of what seemed to be true. The poor were the weak. They were the unfit. They were the defeated in the struggle for existence. Life was a struggle for the survival of the fittest and they who did not survive as capitalists continued as workers, died as beggars, were jailed, transported or hanged as criminals. This was the explanation that made all things simple and all Christian consciences easy. The rationalized justifications which have hitherto been given are still in common use in one form or another to justify the present subordination of the workers. The conservative and reactionary philosophy is a mixture of all these attitudes expressed in different form and in different ways as the occasion may demand. But they are stated and used to justify the present state of things, and the present state of things is what has been described as industrial autocracy.

Before an attempt is made to discuss the method of the labor movement in actual operation it is necessary that it be clearly understood what the worker means by industrial autocracy. Industrial autocracy is not only ownership by a small part of the community of the resources and tools upon which the whole community lives and with which it works, but it is also management and control by the same small part or their immediate representatives without the cooperation of the rest of the community.

Under present economic conditions all production is very involved and depends upon the cooperation of many people. All economic activity is a function 
performed by a group, but it is not a conscious group function. Many people associate to make industry go, but their association is physical rather than spiritual. They are assembled together like bricks in a house, each depending upon the other, but having little conscious unity, or, better still, like horses in a team that work in unison without understanding the object or purpose of their activity. A worker is taken off the street and put on a job. $\mathrm{He}$ is told to do a certain piece of work. At the end of the week he is paid for having done it. His payment is generally the only force, the only interest, that keeps him at his task. There is, generally, no interest, no spiritual participation, no creative effort, no joy involved in it. The little that does come is that which results from any kind of physical activity and which dies off soon enough, as the monotony and repetition keep wearing on his nerves and his labor begins to tire his muscles. His imagination, his creative powers, are things for which he is not paid and which generally are not expected of him. He is left to enjoy such amusement and personal activity as his time, energy and means leave room for outside his work. The planning, the organizing, the giving of unity and coherence to the functions of all the workers, all these things are in the hands of the managing group. Between them and the workers there is no relation other than that between a driver and his team or that between a checker player and his checkers.

The player moves the checkers about and places them to the best advantage without consideration 
of what they are. He is playing the game and they are the tools, the instruments with which he plays, and between him and them there is no other relation. This is what is meant when labor is described as a commodity. To the managing group it is a thing to be moved and used and discarded when not wanted. This is what managers mean when they say that they will not stand interference in their own industry. It is their game and not the game of the workers, of the group upon which they depend. This is the character of modern industry and this is what the worker means by industrialautocracy.

The method of the labor movement is to make this process of industrial activity impossible. The method of the labor movement is to make the function of an industrial group a conscious group function. The problems of sanitation, of hiring and firing, of the hours of labor, of the speed with which the workers work, of apprenticeship, often of the machine used, become subjects of controversy, discussion, agitation and control. The workers thus develop interest in their function, ${ }^{1}$ in their industry. The physical cooperation is strengthened by a spiritual one, by a conscious interest in the same problem and a constant desire for the assertion of

${ }^{3}$ As an illustration it may be of interest to note some of the demands of the Teachers Union printed in the January, 1919, number of the "American Teacher."

2. Teachers members of all boards of education.

3. Council of teachers in each city or town.

4. Teachers council in each school.

5. Permanent tenure during efficiency. 
the group opinion. It is this fact that makes organized labor so powerfully creative and constructive in character.

Those who point to the strike, the boycott, sabotage, ca'-canny, as evidence of the destructive character of organized labor take the defensive and temporary aspects of the activity of labor, as its basic and fundamental traits. In its struggle for existence, for power, for control, the strike has been and still is of fundamental importance. It has creative influences upon the growth of character and initiative among the workers, but as a contribution to permanent social method the strike is of a temporary and secondary nature. The labor movement is using the strike to substitute group control for individual control. It is using the strike to destroy industrial autocracy. With the disappearance of industrial autocracy will probably come the elimination of the strike as a weapon. The strike is a method of war and has no value in peace. What the labor movement is doing is contributing to the function of the group in industry as a group and to an understanding of its basic unity and interdependence. An industrial union is the synthesis, the unity of the working force in an industry. The skilled and the unskilled, the trained and the untrained, are interdependent in fact and in thought. They cooperate in a common product. The stage hand, the musician, and the actor become necessary to each other. This is the vital contribution to industrial procedure which the labor movement is making. 
A theater that is established upon a cooperative basis is a good illustration of the method of the labor movement. In such a theater the function of the whole group, from the actor to the stage hand, the musician, the scene painter, the business agent, the electrician and the usher, is concerned with the production of a successful performance. The group meets for purposes of planning and discussing the part and contribution of all the participants in the common activity. They compromise and subordinate each his particular work to the common end. Each man becomes in that sense an artist. Each is spiritually concerned with the effect and outcome of their united efforts. The actor and the electrician become conscious of their common needs and their common dependence. This is the method of the labor movement. It makes mutual participation, mutual cooperation, mutual suggestion and criticism, mutual subordination to the purposes in hand, the method through which men work.

The labor movement has in part achieved this in its struggles. Wherever possible it has achieved it in work, and the whole problem of industrial democracy is bound up in it. It is not the strike or the boycott, not sabotage or ca'-canny which is the basic method of the labor movement; it is the spiritual and intellectual unity of purpose and function which is the vital contribution to human cooperation that is being forged by the labor movement. The labor movement, by making the hand and the brain not only interdependent but partici- 
pants in each other's efforts, unites them into one organic and inseparable whole.

Note-The growth of interest in the efficiency of the industry as a result of organization is illustrated by the recent charges of inefficiency which the railroad workers made against the railway managers. These charges included amongst them:

1. Bad methods in the purchase of coal, coal inspection, and poor methods of firing.

2. Poor shop equipment which made efficient labor difficult.

3. Poor methods and resulting wastes in water consumption.

4. Poor methods of service supply.

5. Poor methods of shop accounting.

6. Loss due to labor turnover which could be remedied by proper management.

7. Needless loss and damage.

8. Wastes due to remedial defects in car equipment.

9. Wastes due to defective power equipment.

10. Wastes due to inefficient handling of tractive power.

11. Wastes due to inadequate engine terminals.

12. Wastes due to advertising and propaganda.

13. Wastes due to too liberal dividends and consequent reduction of the reserve for renewal of equipment.

These charges issuing from an organized group of some two million workers represent what is meant by the tendency of organized labor to make a group function into a conscious, personal and meaningful participation in the problems of industry by the labor movement. This is the proper method of organized labor. It makes the function socially significant in a different sense than that implied in the mere fact that one works at something. It is an indication of the possibilities for efficiency and power which lie inherent in organization by the workers in industry. 


\section{- CHAPTER VII}

EDUCATIONAL FUNCTION OF THE LABOR MOVEMENT

I ABOR organizations serve other than material $\perp$ ends. The material aspects are more often emphasized because the worker in his constant struggle for physical security is chiefly conscious of them. The gains in money and better conditions, shop control and economic stability are the things that count in the immediate evaluation of the services performed by the labor movement. Not only the worker but the outsider-the onlooker, sympathetic or critical, favoring or disparaging the activities of organized labor-generally sees the struggle of the workers as primarily one for material goods and greater leisure.

Sympathetic observers regard the gains in leisure as a great achievement. This leisure becomes to them the ground upon which the worker can develop divers interests and relationships away from his work, interests that are social and educational, and activities which would help to give him the status of a man with varied contacts. In short, both the worker and the sympathetic outsider generally sum up the achievements of the labor movement in terms 
of more money and shorter hours, while the means by which these ends are gained-the strike, the passionate struggle for mastery, the suffering, and the pangs of bitterness which come with it-are disparaged even by the workers. If only the gains could be had without this suffering, how much better it would be! This disparagement of the struggles of the labor movement ranges from direct condemnation by the unsympathetic to acceptance as a necessary evil by its friends. It is the contention of this chapter that such an evaluation of the activities of the labor movement is not only incomplete but in a large measure erroneous. Important as are the gains in money and free time, they cannot be described as the only or even the most important contribution of the labor movement to the lives of the workers or to the morale of our time. The activities of the labor movement carry with them another set of values-values which are not easily determinable, which cannot be weighed and measured with specified instruments, and which yet constitute a most important consequence of organized labor.

The labor movement has a profound spiritual influence upon the workers who join its ranks. It has that influence, primarily, because it is a struggle that compels unity, solidarity, suffering, trust, and good fellowship. It forces the workers to achieve self-determination by acquiring a sense of group consciousness, self-reliance, and willingness to assert one's self in the interests of the group.

The labor movement, striving for better conditions of livelihood, develops character as a by- 
product, and fighting for union recognition contributes to the growth of personality. It aims at organizing for purposes of defense and becomes the means of an aggressive social mindedness. The workers join their unions to make a better bargain with their employers, and in the process of building, protecting, developing the organization, in the discussions, debates, deliberations and disputes, the raising of new problems and evaluation of different methods of procedure and conduct, they become conscious of other than purely personal problems and of other than selfish aims.

The worker's spiritual life tends to receive its synthesis in terms of his union activity and affiliation. To him the union grouping becomes a ready as well as the natural means for expressing and satisfying three characteristic values, the material, the social and the spiritual. The labor union embodies his material hold upon the world. It, too, generally includes his friends and associates in strife and play, and its activities provide the zest for a constant re-evaluation of his relation to the community.

The labor union is a democratic organization. It is usually composed of equals in wealth as well as in social standing. The workers are also more or less vividly conscious of common problems-problems presented by their particular shop, industry or trade. One of the first consequences of labor organization is to make the individual more conscious of his helplessness and of the insistent need for cooperative effort. It makes dependence upon the group, and 
harmony within it, the basis of operation. The equality of its members, as well as their individual helplessness, is more striking than that of the members of most any other democratic organization.

A labor union is thus a highly homogeneous group in the sense that its background of fact, power and goods is homogeneous. The longshoremen are by and large knit closely in more than a physical sense. They have a fairly common setting; their experiences, education, needs, problems and present desires approximate each other much more than they do in a political organization where the differences in wealth as well as social status may range from the highest to the lowest. This fact, combined with the individual helplessness, tends to give the members of the labor union a feeling of comradeship, of brotherly good will, of loyalty and trust, which is strikingly manifested in every labor effort.

The labor union is the instrument which determines one of the most important contacts of the worker with the world at large-his work. It is this which makes his helplessness as an individual so keen and his dependence upon his group so constant.

To the worker his work is all important. Without it existence would be difficult indeed. All that he has, his plans, his hopes, his ideals, his dreams, his ambitions, his family connections, his prospects of marriage or of educating his children, are centered in the fact that he is working and that the labor union is the instrument which gives all of 
these elements such apparent security as they seem to have. It determines the principles, the conditions, the setting, the remuneration, the hours, the control, which the individual worker has over his work. The organized worker has his material wellbeing set within the range of control and power of the union organization, and that fact tends to make the union's activities and methods of procedure of immediate concern to the individual. He stands to lose or to gain by every move of the organization. This gives the labor union a hold upon the thought, the interest and the attachment of the worker which has far-reaching spiritual connotations.

As a democratic organization the labor union operates like all democracy. It agrees by disagreeing. It works in terms of majority rule. Decisions are made, policies worked out, and courses of action adopted after discussion. A democratic organization, if it is to be vitally effective, must harmonize individual idiosyncrasies, and where the interests are so vital the individual opinion is likely to be strong as well as personal. Each one has a tendency to think his way the best, especially when so much is at stake. This helps to explain the extreme heat and stubbornness which characterizes so many of the discussions of labor organizations.

The point involved may seem trivial, but there is usually a long debate, often intensely personal. This situation may, and occasionally does, lead to irrational and useless disputes, to an aggravation of the spirit, to an over-evaluation of the importance of little differences-a state of affairs which often 
makes harmony difficult and operation unduly strained. This fact, however, has its influence upon the membership. It is one of the means of the development of individuality and personal opinion. It makes for the growth of responsibility. It stimulates thought, interest and self-consciousness. It makes the helpless and often hopeless worker feel a sense of importance, of having contributed to the discussion, of being someone who must be "reckoned with." The labor union gives him his dignity, his right to be considered in the group with which he is associated. To many of the workers who have had so little of play and competition of thought and opinion, of strife for leadership and self-assertion, this experience means a rejuvenating of self, an awakening and resetting of outlook as well as interests and motives. All of this tends to make the union to which the worker belongs the center of his emotional outlet as well as the center of his social connections. This process is in part a transmutation of the material into the spiritual.

It is in the labor union that the worker often finds his best friends and his bitterest enemies. His struggles for leadership, for emulation, for selfassertion, find their place and their outlet in the union meeting. If he is an aggressive type, personally ambitious, desirous for place, acknowledgment and honor, the labor union is a constant battleground for the attainment as well as expression of these ends and motives. If, on the other hand, he is more timid, a person who operates in terms of loyalty and personal friendship, he 
finds leaders to follow and friends to assist and work for.

The average local union is small. The contact amongst the members is constant and personal. The problems are so keen and the differences of opinion so numerous that the personality of the workers is stimulated into constantly greater self-assertion and importance. The worker finds himself in a socializing vortex from which he cannot escape. It makes a man out of him, one might say, almost in spite of himself. It is the basis of his most vital associations. Friendship, love and family are closely bound up with the activities of the union. The union has its balls, picnics, parties, benefits and funerals. Every little union has numerous committees-committees to visit sick members, to arrange entertainments, to look over the books, to confer with other organizations. A large portion of the membership finds opportunity for self-expression by being active on one of these.

The labor union is also the center of all kinds of discussion. The conditions of the trade, the nature of the organization, the problems of leadership, the politics, both of the union and of the community, creep into the debates. There are also the reports of the delegates to the convention, to the central labor union, bringing issues and problems before the workers which are pregnant with interest and valuable for the building of a greater socialized outlook. The appeal from locals in different parts of the country, the news of international labor conditions, all of these come before the local organiza- 
tion, are discussed and debated, voted upon and decided.

The individual worker who first joined a labor union for purposes of making a better bargain with his employer now finds himself drawn into a world of association and information, outlook and contact, of which he never dreamed. He finds that he belongs to a world of intimately connected and associated people of whom he is only one but one whose activities and operations are of immediate concern. The man grows with his responsibilities, with his knowledge and with his associations.

This social relation, this newer and wider contact, has very important consequences for the individual. It takes the isolated man of limited experience, of narrow views, of little power and well-nigh helpless subordination to a world outside and beyond his control, and gives him the means of escape. It provides him with struggles that test his fibre and stiffen his will. It takes him out of himself and makes vivid a world beyond the selfish "I" and makes personal interests that are remote and unmeaning to the detached individual. The intensity of the atmosphere during a strike, a strike conducted on a democratic basis, is a group war in which every one is both a soldier and a general. There are discussions and debates, disputes and differences of opinion during the struggle as well as after.

It is a spiritual experience that cannot be overvalued. It revivifies the life of the worker-a change that may be real in more than a figurative 
sense. It gives, or tends to give, the isolated individual a sense of group purpose and a social imagination, a glimpse of a bigger and more complicated as well as a more related world than his former experiences have provided. The labor union does all of these things by the very nature of its being a group organization concerned with a common and essential need for mastery and control over a strange and indifferent world, a world which to the individual worker is without mercy. The labor union thus serves the worker in a material and social as well as a spiritual sense. It builds character, initiative and dignity. It gives the worker a feeling of importance, a sense of power, a socialized imagination, and the training in cooperation upon which the very existence of his group depends.

This service to the individual and to the community which is contributed by the labor movement as a by-product of its normal activities is beyond measure one of its greatest contributions to the morale of our time. The importance of this contribution varies with the groups of workers that come under its influence, and the variation tends to be proportionate to the helplessness of the individuals of whom the group is originally formed. Labor organizations are from this point of view socially and spiritually significant in the extent to which they take in and organize the most helpless and unfortunate worker. The organization of the skilled, well-placed, and fairly independent worker, where he exists, is important, but it is in organizing the unskilled, the foreign, the migratory, the work- 
ers who drift and are always insecure, that the labor movement performs its most signal social function. This in a measure tends to give the I. W. W. an importance which is generally overlooked. It makes independent, self-reliant, thoughtful and sociallyminded men out of migratory, unskilled and isolated workers. I take the I. W. W. as an example because it has been most prominent as an exponent of the interests of the unskilled and unorganized.

Every union of workers, however, performs a similar service and the difference is one of degree and not of kind. It might also be remarked that this fact probably tends to explain the loyalty which the workers who have been organized by the I. W. $W$. have shown to the organization in the face of almost unbearable persecution. Their need for association is so intense, their individual helplessness is so great, that no amount of pressure, apparently, can break the love, the idealism and the loyalty which has grown up around this instrument of selfdefense and this means towards personal dignity.

Other groups that have a pertinent basis for association perform this work in a measure. Few, if any, however, ever achieved so deep an influence as has the labor movement. Organizations like the church and the school approach it, but in neither is there at present that particular setting which has given the labor union so important a hold on the spiritual growth of the individual, if by spiritual growth is meant the development of dignity, sense of importance, personality, initiative and power of cooperation. The labor union is a constant relation 
that centers about the most important thing the worker does-his work. It is generally responsive to the needs, the ideals and the interest of the group. And lastly, but most important of all, it is organized democratically where individual and deliberate cooperation are the basis of success and growth.

Another important distinction is that the other organized groups have aimed at the development of a particular type, an ideal individual, and the means have always been subordinated to the end. The means were in theory supposed to furnish guidance, but in practice they generally proved to be suppression. They aimed at perfection and achieved distortion. But to the labor movement the growth of the individual is not a conscious aim. It has not concerned itself with the development of perfection amongst its members. This being the case, the influence of the group and of its activities flow unhampered and without conscious control. It permits its members to become what the group struggles make of them. The activities of the labor movement, however, are social in character. They are fundamentally unselfish, always involving other than purely personal gains, always arousing the question of group interest and group responsibility, with the group ever growing larger and more representative of the community. This tends to result in a highly sensitive social consciousness amongst the individuals-a sensitiveness for social justice and decency that is hardly to be found in so deep a - character in any other part of the community. Another aspect of labor's activities in this con- 
nection is the fact that it deals with the one group which has always been neglected and generally considered negligible. It develops personality in the proverbial "beasts of burden" who were denied the possession of it. It is to those who were always looked upon as the "stupid masses," the "great unwashed," that the labor movement is giving the benefit of democratic organization and of group influence. Those who were supposed to have no soul are finding one in mutual service, struggle and cooperation. They to whom all right of expression was denied, who were neglected and abused and considered the dregs of society, the defeated in the struggle for existence, are through the influence of organization given all of the respect and power hitherto denied them.

The point, however, that I am trying to emphasize is that it is in the influence upon the individual members that the labor movement achieves these new values and achieves a moral right to them in just the degree in which the individual worker grows in character and responsibility. For the greatest thing in the world is, after all, human personality, human dignity, and the labor movement gives it to those who have for ages been the "hewers of wood and drawers of water."

In the light of the current discussions of industrial democracy, responsible cooperation, socialized and common human interests, this contribution to individuality becomes the very basis of our future growth. In a community where leadership, initiative, cooperation and social interest are limited to 
a few, there can be no hope of true industrial democracy or spiritual community. These values can, however, only be had through a gradual acquisition. They are acquired on the basis of experience, of contact, of struggle, of cooperation stretching over many years. The union is laying the personal and the spiritual background for social democracy. It is doing all of this because it is an organization which is not only large but democratic and vital to those who are members of it. An army is organized activity on a large scale, but it is the very antithesis of labor association. It is the democratic character of the organization, it is the fact that men meet there as economic equals and strive for a greater degree of unity on a voluntary basis, that gives the labor movement its spiritual significance.

The organized labor movement is thus the people's university. More than our colleges and academies, more than our churches and public schools, does the labor movement tend to contribute to the growth of interest and social-mindedness as well as responsibility.

The university and the college reach comparatively few people and only for a short period of time. The church has its hold on many workers, but this hold lacks the vitality of the labor movement. The labor movement touches the worker's everyday interests and influences his daily existence more directly and more immediately than the church. The public school is important. Here. however, the influence is exerted over a narrow spar 
of the worker's life and is often incomplete, as a large portion of workers go to work before they finish their elementary schooling. The labor union is constant and lifelong. The man's work is his hold upon life, and his labor union gives that work such permanence, interest and sense of personal responsibility as it has achieved.

In the schools men learn to know. In the union organization men acquire the technique of living for each other and with each other. It is here that men grow out of themselves and assume social responsibility. It is here that the workers learn to adjust their daily lives to the principle "that an injury to one is an injury to all," and it is upon this highly social basis that the future must be built and is being built by the labor movement.

This reconstructing of the world goes on daily in terms of actual adjustment, of practical problems and pressing needs. This is not a theoretical harmonizing of the worldly differences of men but a practical, constant and every-day settlement. This adjustment is in terms of the personal cooperation of the men and women in the labor movement, and the labor movement gives them what is best in personality-dignity, self-reliance, courage and social interest. 


\section{CHAPTER VIII}

\section{COMRADESHIP}

THE labor movement is building a new world. $I$ It is creating in its own stumbling way a new set of values, a different type of control from that with which we are acquainted, and is defining anew the problem of human responsibility and restating in factual application a new basis of human cooperation.

This new set of formulæ, of conditions, of ideals and valuations which the labor movement is creating may, in a general way, be summed up in the word "comradeship." Here the word "comrade" has the meaning of associate in labor, in common human effort. It carries the implication of mutual participation in the wide varied range of activities essential to the maintenance and improvement of the conditions of human existence.

In the labor movement all men are equal in one respect-they all work, and this common property is given pregnant and consequential significance in that it is made the basis of participation in the activities of organized labor. To organized labor the great distinction is between those who earn and 
those who own. The importance of this basis of distinction between man and man can hardly be over-estimated. It conditions all the contributions of labor to a change in our political and social ideals. It is this fact that makes the organization of the working class the carrier of a new civilization-a civilization wherein citizenship is determined by work, by participation in the varied creative and productive efforts of man that make possible social life under modern conditions.

This fact, that to be a member of a union one must be a worker, that to be allowed to take part in the life of this new social force one must be a contributor, a carrier, of our task of building and beautifying the world, makes all the difference between it and any other organized movement for democracy. It must be clearly and finally realized that labor in this sense means any useful work essential to the social life of the community. The actor, the teacher, the university professor, has a place next to the hod-carrier, the street cleaner and the mechanic. There they all meet on the same basis of equality-they are all participants in the community's essential functions.

This differentiation of the organized labor movement gives the "Dictatorship of the Proletariat" a peculiar significance. It must be examined and evaluated in terms of this basis of labor organization. The phrase "Dictatorship of the Proletariat" is a revolutionary slogan-battle-cry, an emotional summary of an ideal. It is in this sense to be comlpared with such other political slogans as have been 
born of the vortex of revolution. The French "Liberty, Fraternity and Equality," is a good example of a similar condensation in statement of political ends and ideals.

But the Dictatorship has another basis of significance than that which it might be accorded as the summary of a political ideal and revolutionary battle-cry. Its peculiar value does not lie in the sense that it implies a dictatorship. There have been dictatorships before. It does not lie in the fact even that it is the dictatorship of a majority over a minority. There have been such dictatorships in the world before. Its real contribution to political practice and ideals lies in the fact that it has drawn the simplest distinction between man and man and made that distinction the basis of citizenship.

Governments have at all times determined the conditions upon which they admitted the individual to citizenship. This fact has been as constant as group organization. The Bantu Negroes, the Chinese, and the people of the United States have this one fact in common-that to be a member in good standing one has to conform to certain specified regulations, to certain provisions in the process of initiation into membership. Amongst some of the Negro tribes the initiation includes blindfolding and the forcible knocking out of a tooth, all of which is performed in accord with ancient rule, with proper pomp and with all of the solemnity required by traditional procedure.

In the United States, initiation to the rights of citizenship is conditioned by certain specified reg- 
ulations of time and includes a formal declaration of loyalty and the taking of an oath, all of which, as with the Negroes, carries with it a solemnity and a definiteness without which the granting of the right to citizenship would be considered a violation of the law. In short, all governments have generally been characterized by this process-they have all decided for themselves who could and who could not be a citizen. This fact was constant, but the conditions varied with time and circumstances. To be a citizen has at different times meant to be a member of a certain class. These conditions, these formal demarcations, have included at times class, property, education, sex, and color qualifications. It is in this sense that governments have always been dictatorships-dictatorships in which the dictators themselves determined the conditions of admission into the privileged group.

It must be obvious, however, that these conditions are highly exclusive. It is difficult to escape from one's class, to acquire property, to secure an education, and it is impossible to change one's color, sex or race. There is no way to become a citizen under these conditions; exclusion is permanent. It is a distinction that cannot be bridged. It sets off man from man in terms and qualifications which cannot be acquired. It makes democracy impossible and makes invidious distinctions inevitable. This has been and still is to a large extent the basis of government.

In the United States, for instance, citizenship is circumscribed by time, by birth, by residence, 
and, in addition, some of the States include qualifications of property and sex; ${ }^{1}$ in the South, color is a practical if not a legal bar to citizenship. Put in another form, governments have been based on slavery-on the subject of a monarchy, or on the citizen of a democracy. Men have been slaves, have admitted loyalty to a king, and are to-day equals before the law; but men have never been classed as coworkers and that classification made the basis of citizenship.

The significance of the "Dictatorship of the Proletariat" is that it is a new construction of citizenship in which the formula that divides the citizens from the non-citizens is the simplest and most inclusive that has ever been made the practical basis of government. The requirement for citizenship is labor. This distinction excludes from active citizenship only the imbecile and the child. The distinctions of race, class, color, sex, religion, property, and education have no significance for admission to the right and privilege of the group.

From the point of view of labor, all men are equal in the sense that all men are workers. The old cry of fraternity and equality has at last received its conditions of fulfillment-the reducing of men to some one standard of human significance in which they all can be participants. This division between worker and non-worker eliminates the claims for special privileges and for special powers on account of any "vested interest." All men must live by their work, and in work all men have the

${ }^{3}$ Sex has now been eliminated as a qualification for voting. 
same share-a share that differs only in kind but not in fact. The old barriers between man and man, the barriers of race, of class, of religion, of sex, lose their meaning in practical application under a system that reduces the basis of group privilege and citizenship to the one thing that all men may do-work.

It is important to understand fully this demand of the revolutionary movement that all men must work, and the light it throws upon all of the new values which are being developed in the current economic struggle. The revolutionary labor government of Russia and the conservative labor movement in the United States have this thing in common as a conscious basis of participation in their group activities. No one may enter a labor union who is not a worker. No one may be a citizen in Russia who will not work.

What a flood of light is thrown upon the very character of all labor activities by this simple comparison, by this placing of the revolutionary labor government of Russia side by side with conservative labor organizations in other countries. In the one fundamental thing upon which all else is determined they are both agreed-that none may enter the group who is not a worker. The difference is that in Russia this condition is universal, while with us it is gradually assuming forms of universality. In Russia this condition came into universal existence by revolution, while here it is achieving community representation by gradual if not entirely peaceful means. 
The growth of the labor movement leaves an ever more narrow gap between the industrial citizen and the non-citizen. How narrow the gap will grow before all personal privileges will be evaluated in terms of labor rather than in terms of possession is at present not to be determined. It may well be, however, that with the present rapid growth of organization of labor the greater part of the working community will be included in the industrial organization in a short time, and that would make the thing which is called a "Dictatorship of the Proletariat" the natural consequence of the activities of the labor movement. It would simply mean that all men would participate in the functioning of the community on the basis of their personal contribution and not on the grounds of legal sanction or "vested interest." Such seems the logical result of the growth of labor organization.

The spiritual and social consequences of such a change are revolutionary. It tends to make men and women value their labor and not their possessions. Respect and honor tend to flow in the direction of service rather than in the direction of legal control. ${ }^{1}$ It tends to upset all of the current values, all of our current methods of control and direction. It tends to give power where power actually is, in its factual rather than its legal possession. Socially it reduces all men to a greater personal equality, to a greater conscious personal interdependence and to greater harmony, for it tends to make the interest of each the interest of all. The

${ }^{1}$ Think of Robert Smillie and Lloyd George. 
interesting point is that the conservative and the revolutionary labor movement, the Russian revolutionary government and the American Federation of Labor, have in their practical applications basically the same grounds of evaluation-work. 


\section{CHAPTER IX}

\section{CONSERVATIVE AND RADICAL LABOR}

$A^{\mathrm{LL} \text { organized labor is revolutionary in fact if }}$ tion of the labor movement. It is not revolutionary because it wills to be; it is revolutionary because its activities are such without regard to the immediate object in hand. Organized labor is revolutionary because it is the organized embodiment of what must be described as a comprehensive social transformation. The unsettled, turbulent strife characterized by struggle between employers and workers-a struggle which assumes larger proportions as the workers become better organized-is often popularly called the movement for industrial democracy.

Organized labor gives this movement its most poignant form and content. The labor movement is in fact, from this point of view, not to be described in terms of a "problem." There is no labor problem, broadly speaking - there is only a process of rapid transformation from one type of social organization to another. It is a process of rapid growth, of realignment of forces from one type of 
economic grouping to another. The machine has changed the face of the world and the labor movement is the method of readjustment to this fact. It is the visible means of what might broadly be described as social digestion-of including the machine and its implications in the re-grouping which it has forced upon the world.

The labor movement seems destined to be to capitalism what the capitalist system was to the feudal organization of society. It would be incongruous to speak of the decay of feudalism and the growth of capitalism as a "problem," except in the sense of the historian who might describe the process. For the people concerned with the change at the time of its actual occurrence it was revolution. So, too, is the labor movement. It is revolutionand the revolution is not to come. It is here. Every strike, every working class committee, every contract between worker and employer, every working class council, be it Whiteley or Shop Steward, is an element in the process. They all have the same tendency to increase the power of the worker, even if their immediate motives, outlook, ideals and purpose are different.

The development of capitalism was no problem which, from the feudal point of view, could be solved. There was no solution for the rising capitalist system which feudalism could provide and yet remain intact. It had to be shed. There is no solution, and there is no labor problem for which a solution can be found by present-day social organization. The growth of the power of labor and 
capitalism are seemingly as antithetical as were feudalism and the system of free labor, international commerce and the growth of the bourgoisie. They could not both exist in the same social organization. From this point of view organized labor is not something which "experts" can deal with, nor is it like a problem in algebra for which a formula may be discovered. This change is worldwide. Present-day society the world over is obviously bound up in this great and intense process of reorganization-from Russia to Japan and from Argentine to Alaska. There is not a place upon the globe where men meet to work in factory and mine that this growth of labor organizations, this struggle for power, for control, for self-determination by the workers, is not manifested. This is no "problem." It is a social metamorphosis of universal extent.

When described in these terms the labor movement becomes significant primarily on account of its inclusiveness. It is broader than any program, than any party, than any social labor organization. All of these, from that of the craft unions to the demand for minimum wage, social insurance, industrial unionism, revolutionary strikes and peaceful collective bargaining-all are but parts of the labor movement. It includes them all. They all contribute towards the organization and education of labor in the process and problems of technique and control over their own destinies. That may not be the aim and end of the movements involved, but it is their chief consequence. Every step in 
the process, every little struggle, every passion, every bitterness, every bit of sympathy and pity, every bit of hope and idealism which receives an organized embodiment, contributes to this remaking of the world. These groupings are chiefly significant because they serve as a stimulus to the imagination, to training in the powers of organization and cooperative discipline, and the stiffening of the will for the control of the world's destinies, which the workers are manifesting everywhere and in always greater intensity.

Nor can the labor movement be described in political terms. A labor union is as different from a political party as day is from night. And to speak of the organized workers, as we do of political organizations, describing them as reactionary, reformist, or even radical, is to apply terms to the labor movement that have little if any meaning. A political organization may be either revolutionary or conservative. That is, it may be organized for the purpose of maintaining the status quo or for the purpose of capturing power and changing the present for some differently conceived organization. This is, however, not the method by which the labor movement operates.

A labor union is revolutionary in fact. It is not the expressed desire to change the world; it is the change already embodied if not completed.

What a political party says it would like to do and what the labor union, even the most conservative in outlook, does, cannot be compared or described in terms of similarity. A labor union is 
a new realignment of social forces in the community -a revolutionary, democratic, cooperative grouping of men and women around the tools and the industry with which they are concerned, and the grouping has only one purpose and one result-the constantly greater control of the machine, the industry, the tool which happens to be their particular means of life and labor.

Revolutionary activity consists in the absorption, the wresting of power and control by one group from another-and that is what every labor union does. It gains power from the employer. The most important part of the process is the first step. Once the organization is begun the logic of their struggle and the discipline of their unity drives the workers to constantly greater effectiveness and more control, regardless of either avowed aim or political ideal. The control of the machine is the pressing problem of the present political situation. Conservative and radical, revolutionary and reformist parties are each and all concerned with the question of how the machine is to be controlled. Each political party answers this question in different ways. The labor unions have only one answer. Their answer is simple, direct and expressed in action-the workers must control. They all make this answer in so far as they have the power, and they always try to increase that. $\mathrm{He}$ who doubts this may reflect upon the fact that any attempt to take away such power as the workers already have would be met with steel-like resistance, and that any attempt to set a limit to the growth of the labor 
movement would be scorned. The workers hold what they have and they want more. They all want it without regard to ultimate purpose, reactionary or conservative.

It must always be remembered that men in labor unions have common problems, common interests, common background of experience, constant personal contact, direct knowledge and immediate power over industry. These facts are all given their importance only when the workers are organized. The individual worker is helpless. The organized worker has power. The real struggle is for organization and not for the program after organization is completed. This is the revolutionary significance of the labor movement. Its program is achieved if it has complete or anywhere nearly complete organization. Then it becomes a matter of scientific use of power for the best social ends, a problem of statesmanship. A political organization needs to conquer power after it is organized and then to use it indirectly. The labor movement once organized has already achieved all the power it is ever going to have, except such as will come from greater experience and knowledge. A labor union takes the individual competitive worker and gives him cooperative strength for direct use in his industry after organization.

Labor is thus revolutionary, not because it organizes for purposes of control and change, but because its very organization is the essence of control and change. This is the consequence of all organized labor. The rest of the chapter is con- 
cerned with the discussion of the separation of the different labor unions into conservative and radical. It is the thesis of this chapter that all labor unions are equally revolutionary and equally conservative. They are as revolutionary and as conservative as their organized power and not their words make them. A revolutionary theory may prove in action a conservative working force, while a conservative theory may be revolutionary in terms of actual change. It compels because of the power it has.

The labor movement is generally described as either radical or conservative. This description is assumed to be a statement of the basic difference that the two forms of organized labor exhibit. The grounds upon which this differentiation is made are supposed to be evident in the formal structure, method, avowed purpose and principles which are said to be characteristic of the different groups in the labor movement. The conservative labor movement is said to be safe, sane, law abiding and orderly. It is repeatedly pointed out that it accepts the present economic system, that it believes in contracts, that it is opposed to the One Big Union, that it avows itself against violence and other forms of activity which seem to be typical of the radical labor elements. All of these outstanding differences in the labor movement are so obvious and have been the basis of so much discussion and struggle that it seems generally to have been overlooked that this description tells very little of the real function of organized labor. Yet a moment's thought will 
convince anyone that any divergence, any vital distinction between the radical and conservative labor movement must be found and must be stated in terms of contradictory functions, if any, that these labor organizations perform. It makes little difference whether an apple is described as green or red. Both may be sweet.

Very little has been said about the labor movement when it has been described as radical or conservative, as industrial or trade unionism, as favoring or rejecting the present system. These distinctions seem to be important. But are they? The difference between them must be found in the things they do; not what their avowed purpose is, but in what the actual consequence of their activity is. The discrimination between conservative and radical when applied to the labor movement will hold water only when the activity of the one organization is in its results different from the other.

The statement of the proposition in this form places the problem in a new light. We shift our interest. and our attention from appearance, from belief to consequence, to factual results. We want to know, not what the labor movement is called, not what it thinks it ought to be called, not what it believes, but what it does. What does the labor movement do? What is the difference in the actual function of the conservative and radical labor movement? The simple answer to this question is that all labor organizations, regardless of their name, their ideals, their structure, their method, actually do the same thing. 
I do not mean so much that all labor participates in practically the same activities, that all organized workers strike, increase wages, shorten hours of labor-but rather that they all increase the power of Labor; that they all substitute a group control for individual control; that they all tend to increase intelligence, initiative and self-reliance on the part of the workers; and, more important than all else, that they all tend to eliminate the capitalist system by substituting the capitalist's function, by absorbing his power and wresting control from his hands and placing it in the keeping of the workers. Every labor movement performs this service, and no labor movement does more than gradually displace the capitalist system by absorbing the control and directive power of the capitalist.

Any analysis of the history of labor organizations will make this self-evident. The labor movement began as an isolated small-group affair. It had its beginnings in small shops, in single trades, in narrow localities. In the last one hundred years it has grown from single-shop organizations to organizations in great industries; from the city local it has become international; from demanding little more than better wages it has come to demand direct control and mastery of industry as among the railway workers in America, the miners in Great Britain. It has year by year become more powerful, more dominating, more intelligent and more insistent. It tends to increase its own power and to decrease that of the capitalist system. It is true that it has not yet arrived at what seems its final goal- 
the elimination of private control, but it has traveled a long way from its early and timid beginnings. ${ }^{1}$ It is important to realize the full significance of this growth of labor, for it is the substitution of the group for the individual in the dominion of industry the substitution of cooperation for competition as the motivating force in economic activity.

The labor movement fully developed, and the existence of the competitive method of production, are seemingly not compatible. There is no place in the same social organization for both of these methods of control, and the inevitable tendency of the labor movement is to grow ever more powerful, more dominating and more impatient of the individualistic profit-making element in the community. This, however, is a trait common to both the conservative and the radical labor organizations. They both tend to become more powerful and more impatient and more insistent as a consequence of their activity. There is thus little difference in the consequence of their function regardless of the concepts with which they started out.

The radical labor movement begins by assuming some final revolutionary goal and indulges in a struggle for immediate and particular objects-organization, power, better conditions and othen immediate ends, while the conservative labor move-

"Think of the social change implied in the power of labor in England to make the recent threat of a general strike and remember that a hundred years ago Trade Unions were outlawed and considered criminal associations. 
ment begins with a struggle for the immediate and develops the power that tends to eliminate the capitalist control of industry. The radical labor movement wants to destroy the capitalist system and has this objective in mind in most of its activities. The conservative labor movement tends to destroy it without knowing it. They both have this one thing in common as a result of their effortsthe destruction of the capitalist system. To the conservative it is a consequence; to the radical it is an ideal and a consequence. The radical to achieve his ideal must develop power. The conservative develops power for the mastery of industry, and this power is in itself a proof of the function of the labor movement, for every ounce of labor cohesion and strength is wrested from the capitalist system and in spite of it. There is thus no difference in the distinction generally drawn that has any significance in function and consequence. Organized labor is the mortal enemy of the present capitalist system, but is not always conscious of it.

There is, however, one difference between the radical and the conservative labor movement. That difference is not of form, of purpose, of method. These are trival by comparison. For any labor movement may and in fact does assume all of the different possible types generally classed as conservative and radical without changing one whit in its essence. The distinction that $I$ have in mind is one of consciousness, a distinction that has considerable significance. The real and vital divergence, 
in so far as a divergence does exist between the conservative and the radical labor movement, is that the first is not conscious of the significance of its own activity. The radical labor movement knows that it is its tendency, its destiny and the logic of its growth to make inevitable the elimination of the individualist control of industry. The conservative may not realize that. The operation of the conservative tends unconsciously in the same direction as that of the radical without his appreciating the full meaning of what he is about.

This explains much. It explains the fact, for instance, that the conservative leader often disparages the activity of the radical labor movement as subversive and revolutionary. He fails to realize that he is in the same boat. He fails to see that everything he does to strengthen the power and the numbers and the influence of the organized labor movement is no less revolutionary in its results than the similar activity of the radical labor movement. It explains too the apparent faith that our reactionaries have in the conservative labor organizations. It makes reasonable the absurd insistence upon the fact that the conservative labor movement is loyal, is safe, is sane, is law-abiding. They seem to take the conservative labor leaders at their word -a word that may be honest enough-that they accept the present system, that they do not intend to destroy it, that they are loyal to it. But as a matter of fact, the labor movement is loyal only to itself because its activities and its interests are prime to it. Its interests and activities are always 
contrary and in opposition to those who are in present control of industry.

This distinction between the conservative and radical labor movement, as one of consciousness, as one of understanding the full significance of its own activity, gives the radical labor movement an additional and highly important function.

It is true that all organized labor is revolutionary, but only a part of it-the radical labor elementis consciously so, and it is the chief significance of the radical wing of the labor movement that it serves as an educational influence. It makes his own activities meaningful to the conservative. It educates the labor movement into a realization of its own inevitable destiny. I say inevitable because the only way the conservative labor movement could hope to save the individualist system would be by disbanding its organization and ceasing its activities. It cannot continue to function, to grow, to become powerful as a labor movement without ultimately displacing the capitalist system, and the radical element in the labor movement serves to make this fact clear and conscious to the conservative, thus increasing the idealism and the speed as well as the intensity of its activity. 


\section{CHAPTER X}

\section{INDUSTRIAL GOVERNMENT}

THE DISTRICT COUNCIL

IN its preamble the Industrial Workers of the 1 World proclaims that in organizing along industrial lines the labor movement is "building the structure of a new society within the shell of the old." This sounds like an extravagant statement. On analysis, however, of the actual contribution to the structural changes which the labor movement is making in society, it becomes evident that the quoted opinion is more than a mere wish.

Labor is essentially constructive and that not only in its influence upon motive, purpose and cooperative function but also in its contribution to the political and economic reorganization of the community. These changes are concomitant with the growth of labor organizations, and an examination of the community in which labor has developed will make this evident.

A city like New York represents many aspects of social organization, but its predominant char- 
acteristic is the fact that it consists of millions of men occupied in a cooperative process, each contributing to the sum total of the community life. Most people in the city are specifically employed at something and dependent for support upon the rest of the community. The baker cooperates by feeding the shoemaker, the butcher, the teacher and the electrician, while they in turn contribute their services to satisfying his needs. This process goes on without end. Every individual in the city is in some way closely knit into the body of the rest of the people. Be he a contributor or recipient, his dependence is immediate, direct and constant. His life in the city is bound up with a thousand threads over which as an individual he has no control and the breaking of which would either disarrange or threaten his life.

This activity might almost be ciescribed as unconscious. It is an habitual mode of procedure for those individuals who have acquired some particular function and who live by its performance. Before organization of labor takes place each individual in every trade is by and large an independent and disconnected unit. He cooperates, but his cooperation is organic rather than volitional. He does his little job and others do theirs, blind to the connections which bind their individual efforts together.

Every industrial community is fairly contained in this description. Men and women carry on their economic activity as individuals within a political setting which represents them as a group. Differ- 
entiation is more marked between communities than between individuals. This is the character of the political community before the labor movement develops. As soon, however, as labor organizations come into existence there immediately grows up a realignment of the community's forces and allegiances.

The political community may be compared to a circle in which all individuals theoretically occupy similar places. Each individual is but a unit-and is like other units in the group. But wherever labor organizations are developing, this circle breaks down and is replaced by a new kind of integration. The labor movement begins by collecting a few workers and tying them together. As soon as two or more groups have been formed they unite in a kind of central federation-generally called a Central Federated Union or District Council. That is, every labor union in the locality is supposed to have representation in this central body. As soon as two are organized they try to form a third union, the three a fourth, and the four a fifth. If we represent the first union as a kind of little circle which is developed within the larger political unit, every time a new union is organized this new labor group grows larger and more representative of the community.

What labor organization implies must be fully understood if we are to appreciate its social consequence. The organization of a trade means the giving of a consciousness, unity, purpose, integration and power to the people working in that trade. 
If the bakers are organized it means that some thousands of men who have up to date carried on an individual function within the cooperative life of the community have suddenly been given group consciousness. Their cooperation, which was individual, has now become corporate. Group interests, group powers, group problems, group character, have suddenly been imposed upon an important industrial function. One might describe this graphically by comparing the political community to a round chocolate cake and by comparing the process of organization to that of cutting a slice from the body of the cake and giving it the power of withdrawing itself from the rest; that is, a community function has been individualized in its corporate consciousness and given the power to control its activities and determine the basis upon which it will continue to work.

Labor does not stop with the bakers. It organizes the butchers, the teachers, the electricians, the clothing workers and the many others who make the life of the community go round, from the street cleaner to the actor. What all this means is that every cooperative function hitherto carried on by individuals independently is given a group contact, a group relation. The actors who as individuals did the same kind of work they are now doing as an organized group have a unity, a consciousness, a power and a sense of control which they lacked before organization. The individual is made a part of a larger industrial unit. His functional cooperation with the community is hereafter deter- 
mined by his group interests. This may again be represented as the cutting of the cake into additional pieces, each slice representing some industrial function. As the labor movement is growing larger and more inclusive, it is tending to contain an ever more complete representation of the actual cooperative needs and functions of the community. That is, the men and women organized and given corporate consciousness by the labor movement are the men and women who keep the community's economic and social life going.

The full significance of this change becomes evident when we realize that what is taking place is not only an individualization of the industrial functions, but their incorporaiton. Every trade organized is not only made individual as a trade but given a social contact through the Central Federated Union with all the other trades and functions which have achieved similar organic unity. The Central Federated Union or the District Council unites the different unions. It is composed of delegated members from each local and each local represents some function. The activities of the city are thus mirrored and tied together in the District Council. In this Council there is a tendency to have represented all the industrial power, technique, knowledge, ideals, passions and purposes of the men and women who do the city's work. It is a new structure in social organization based upon function. These men and women represent the working activities of the city, its industrial technique and its economic problems. They, too, re- 
present the actual working power of the community. The represented workers know just where the bread is baked, just how the milk is distributed, just where the power houses for lighting the city are, just where the locomotion, sanitation and amusements of the city are controlled and operated. All this is represented in increasing totality as the labor movement enlarges its membership.

This fact is the most important contribution that the labor movement has made to local political structure. Without planning and without deliberately setting out to upset the political equilibrium of the community, the labor organization, simply in the natural process of its growth, transfers the power of the community, its actual power and knowledge, its control and discipline, from a political to an economic affiliation. The central labor union represents the outline of the new structure of community government which the labor movement is creating as a consequence of its growth.

This process is gradual. It consists of two distinct functions. First, it organizes men around their industry and gives them a corporate consciousness in terms of their contribution and place in the community, and second, it ties these corporate bodies together through representation on a common council. We thus have the development of a distinctly new power, the limits of which cannot at present be foreshadowed except as the numbers, functions, powers and knowledge represented by the increasingly inclusive industrial community indicates them. 
What is actually happening can be understood best by comparing this new industrial council with the mayor's office. The mayor has the political powers of the community vested in him, and with him are associated such functionaries as the chief of police, the heads of the departments of correction, health, water supply, and so forth. What is the comparison of the sum total of the knowledge, power, and control represented by the mayor when set off against the knowledge, contract, and immediate powers of control represented by the individualized industrial corporate bodies as united in the district council? The district council contains, in theory anyway, all the important functions of the community-light, gas, water, bread, milk, locomotion, amusement, every conceivable cooperation function. It can bring the life of the city to a standstill. It is true, of course, that the mayor controls the Board of Health, but then the nurses and hospital attendants may belong to the industrial union. It is also true that he controls the police, if the police are not members of the central federated union. ${ }^{1}$ I am not at present doing anything more than trying to describe the fact that a change is taking place and that this change is in proportion to the degree of organization of the workers in the community. In so far as the workers are organized they transfer the powers of the community from the old geographical-political to the new industrial-political grouping. This change is concomitant with the labor movement. It is a part of the change in the

${ }^{1}$ Think of Boston. 
political structure which labor organization is bringing about.

The local general strikes in Belfast, Winnipeg, and Seattle illustrated this fact. In each of these three cities, and especially in Belfast and Seattle, the political organization found itself practically impotent in trying to carry on the ordinary functions of the community.

In Belfast the streets were cleaned, mail delivered, hospitals cared for, milk delivered, garbage taken away by permission of the central organization of the workers. In Seattle the same problems arose and they were handled by the workers-the problems of sanitation, food and milk delivery. It became evident as soon as the strike was declared that the workers would have to undertake certain responsibilities-for instance, the removal of organic matter from the public streets, the maintenance of the water supply, the establishment of restaurants. These facts were presented vividly to the workers by the circumstance that if they did not do these things they would remain undone.

The strike committee was forced into making political decisions-decisions of priority, including even that of appointing a worker's police force to maintain order. They had to do these things not only from choice but from compulsion-they and only they had-not legal but actual-power to do them, under the conditions. What is this but evidence of the fact that power shifts from the political grouping to the industrial as the workers organize? We thus see that 
the growth of labor power apart from any political ambition which it may have tends to absorb this control of the community and in time of crisis finds itself in possession of it. That this is not always a conscious process is illustrated interestingly by a remark of one of the strike committee of fifteen who were in charge of the Seattle strike. When accused of being a revolutionist and carrying on revolutionary activities against the government, he said: "Why, we were not revolutionists. We were ready to give the mayor anything within reason." It never occurred to him that for the workers to be able to give anything within reason as a voluntary offering to the political state was in itself the most revolutionary of all facts about the situation.

The labor movement, however, is only in its beginnings. Before any judgment of the contributions of the labor movement to social organization is made this must be fully recognized. The labor movement is really rebuilding our social structure. It is doing it without planning, yet it is making a definitely different social organization out of our present political democracy. This is one of labor's great contributions to the future-a contribution which is only foreshadowed by this reconstruction of the community's forces. 


\section{CHAPTER XI \\ INDUSTRIAL GOVERNMENT \\ II \\ THE INDUSTRIAL UNION}

THE labor movement is developing new political 1 institutions. These institutions are industrial in character. They are industrial in character because the worker's chief problems arise from his function in industry and his contact with the machine. This is an age of large-scale industry and the labor unions are compelled to adjust themselves to that fact. Their adjustment takes the form of gradual transition from trade unionism to industrial unionism. In fact, this transition has not kept pace with the rapidity of the general industrial change.

I say "industrial union" because the drift towards organization in terms of industries is the outstanding fact of the contemporary labor situation. Not only is industrial versus craft unionism one of the dominant topics of discussion and interest amongst workers but it is actually the form of organization which many industries have already forced upon 
their workers willingly or unwillingly. The workers are compelled to develop industrial unions because an industry knows little of crafts. It is an integrated whole that works as a unit, and the labor movement grows to meet that fact. This tendency is evident even from the most cursory glance over the industrial situation. We have definite industrial union movements in Australia, New Zealand, and Western Canada, and there is insistent agitation for it by the Industrial Workers of the World in this country. The triple alliance in England, the railroad brotherhoods in America who work as a unit, the departments developing in the American Federation of Labor, the Amalgamated Clothing Workers Union, the United Mine Workers of America, including all the workers around the mines, are unmistakable evidences of this trend.

What is happening is this. The workers employed about an industry, all the workers, the skilled and the unskilled, those who have crafts and the common laborers, the clerical and the professional, seem in some way or other to show a marked urge to organize. The organization begins generally in separate localities and often in individual trades. These organizations in various localities are duplicated so as to include within the boundary of organization all the places where a particular industry is found, and these crafts tend to spread around an industry so as to absorb all of its functions. The craft unions are organized to control individual and isolated trades, but as in the case of the Railroad Brotherhoods they seem 
ultimately to be driven to cooperate for purposes of greater security and more effectiveness and to become industrial in fact if not in form. ${ }^{1}$ We thus have, in every locality where an industry is found, a grouping of men and women whose lives are spent about that particular industry. That grouping tends to become more inclusive, more unified, more conscious, more deliberate and more powerful, as the years of agitation, organization and education continue.

Every industry of any size has more than one locality in which it operates. Following the line of these, the workers are drawn together into a constantly more effective organization. A good illustration of such general tendencies is represented by the Railroad Brotherhoods. After years of persistent effort the railroad workers have succeeded in building an organization that follows the railroads of the country from coast to coast, and into every nook and corner where the rails find their way. There is not a car nor a switch nor an electrical wire which in some way does not depend directly upon the workers who are organized in the industry.

It might be said that the workers who are banded together have torn the rails from the ground and taken possession of them so that they are now held fast in their arms. Without the consent of the organized group, the rails and the implements connected with them would, one might say, disintegrate

1 "The Sixteen Standard Recognized Railway Labor Unions," now have a working agreement which makes them into a single fighting unit. 
and fall to the ground. This is a startling phenomenon. The function of a community, a function imperative and essential, one upon which its very life depends, has been absorbed by this organized group. It belongs to them in much more than a metaphorical sense. They own the industry in the sense that they control it, and they fit the industry as a well-worn coat fits a human form. It is almost impossible to separate the railroad from the railroad workers as an organized group. Each standing alone would be a monstrous instrument of imbecility, because it would be useless.

What has happened is, therefore, that one of the interdependent elements of the larger community has been crystallized, given consciousness, form, and made the object of increasing control by an organized section of the community. It means that a new instrument of political government in terms of industrial control has come into existence.

This fact is even now being recognized. Such an innocent performance as that of giving the organized worker three representatives upon the Railway Labor Board is the legal recognition of the fact that a new type of control has developed in the community. It means that the community has become differentiated within itself functionally and that it has recognized this differentiation. It is not as yet ready, apparently, to make this recognition apply to all industries, but there is evidence of an increasing consciousness that we have outgrown the day when the chief function of government was to deal with the individual, and that government is 
now increasingly concerned with the group. This differentiation, which has now been recognized in the railroad workers and made so evident by the refusal of the Railroad Labor Board to deal with any workers in the railroad industry unless they were represented by certain recognized unions in the industry, ${ }^{1}$ is only an indication that a new social alignment is taking place and that it has already taken place in the railroad industry.

Our political democracy, our conception of the individual as the unit of government, is thus unconsciously slipping from us into a recognition of the group as the basic element of society. The community is adjusting itself to the fact that its larger dealings are now with the industrial group to a greater degree than ever before. What we described in the last chapter as happening to the locality is evidently taking place also in the larger industrial unit.

This new structure foreshadows, apparently, the development of a new type of industrial control and industrial government. For the time being, anyway, the railway unions are here to stay. The railroad industry is increasingly theirs in the sense that their power grows as their education, experience, unity, and conscousness grow. It is also evident that as these things develop, in that degree does the community become more and more dependent upon the group which is organized around the railroads. This group has sapped one of the

${ }^{1}$ Think of the fact that to the government there are "legal" and "outlaw" strikes as defined by the unions. 
functions of the community to its roots and is acquiring an undeniable priority of control. What is true of the railroads tends to be true of the mines, factories, shipyards, bakers and butchers in the country. Each group is slowly, unconsciously, but persistently and unavoidably increasing the same strangle hold upon its particular industry. Differentiation between the groups in terms of their industries is at hand. A new political community is coming into being and the labor movement is but the visible expression of that fact.

It must be remembered that this growth of differentiation away from the community goes hand in hand with a greater integration of the group around the industry. There seems to be no denial of the fact that as unions have developed around an industry, either in craft or industrial form, they have become more completely unified and more completely conscious of the problems of that industry. A kind of functional citizenship, a kind of industrial patriotism, a kind of pride and interest, a sense of power and with it a sense of responsibility has made its appearance. ${ }^{.}$

It is interesting to analyze the particular structure of these unions. They are organized in locals, because every industry has a locality and the locals are concerned largely with the particular problems which the industry there represents. There is a considerable degree of differentiation in size, in structure, in technique, even outlook, as the industry

${ }^{1}$ The charge of inefficiency against the railroads by the railway worker is an interesting illustration of this tendency. 
differs in locality. Yet all these locals, like signposts on the road, follow the rails or the mine around the country. Each local, in its strategic corner, is absorbing the technique of the particular problem relevant to its industry, and yet all are tied together by the steel bond of the rail. They are tied together because the industry is a unit. All industries are units in the larger sense. The shoemaking industry is a unit. The flour industry is a unit. The cotton industry is a unit; and this unit is represented by the national or international organization, not fully, but certainly in an increasingly complete form.

What has now become evident is that regardless of politicians or political theories, regardless of what statesmen think and soldiers say, in spite of all condemnation, and with little regard to favorable comment, a new social structure has been born and is growing to maturity. Politicians may come and go. Administrative politics may change; acquiescences or opposition may characterize the present political state as it faces this new departure in the structure of society. As long as the rails require physical cooperation, just so long will men be driven irresistibly to give the physical cooperation its spiritual content; and in this case spiritual content means control.

What changes the structure of the future political organization will embody may be hard to predict. One thing, however, stands out clearly, and that is that no government can in the future function without recognizing the industrial group. The rail- 
roads cannot be run without the railway workers; coal cannot be dug without the miners; and electricity cannot be had without electricians. In some way, in some form, in terms of some compromise greater or smaller, the political government must recognize its new competitor in the field. The character of government is changing as a result of the labor movement. From being an aggregation of individuals expressed in political unity it is becoming increasingly an aggregation of industrial groups expressed in industrial political unity. We are therefore face to face with one of the long distant results of the innocent act which the individual worker performs when he joins a little union in his locality to make a better bargain with his employer, to stem the tide of insecurity-the growth of a new industrial and social order. This is one of the consequences of the labor movement. It does not represent its purpose except in so far as it becomes that purpose when the labor movement achieves consciousness of the significance of its own activity. 


\section{CHAPTER XII \\ INDUSTRIAL GOVERNMENT}

III

THE NATIONAL UNIT

THE political state is a geographic unit. It is a separation of one ethnic group from another. Political organization seems to thrive on isolation and by attempting to achieve self-sufficiency. This is, however, precisely opposite to the trend of all industrial organizations. Industry is international.

The rails that cross the boundary lines of the country are not conscious of any political demarcation. The railroads of Europe are a unit in spite of the extreme nationalism by which that continent is characterized. The farmer works his land with very much the same tools and under similar conditions on both sides of the national line. The chemist, the engineer, the miner-all people who work exchange methods, participate in each other's problems and benefit by each other's achievements.

This is one of the reasons why the labor movement has been consistently international. It is also one of the reasons why industrial enterprise, investment, has been international in spite of the 
obscurantism of national politics. This fact has an important bearing upon the development of the industrial structure which the labor movement is contributing to the community. International industry is compelled at present to adjust itself to national political boundaries. This contradiction between political nationalism and industrial internationalism is a definite hindrance to the natural adjustment of the labor movement, to the needs and technique of international industry. This conflict raises problems which are purely political and unrelated to the industrial aspects of modern, largescale industry. It makes the railway problem for the railroad workers in this country a problem limited by politics to the United States, when as a matter of fact the railway industry is a unit stretching over the whole North American continent. What is true of the railway industry is true of the others, and it determines for the time being the limitation within which the adjustment must take place.

This situation is compelling the growth of national labor movements, although the character of industry is international. The growth of large industrial unions which are gradually absorbing power from the state is limited for immediate purposes within national boundaries. Thus it happens that while both industry and the labor movement are international in character, the line of geographic demarcation compels and confines the struggle within the national boundaries. It is not at all unlikely that the future may see international combinations. 
of workers operating their industries as units. For the present, however, until the workers are free to follow the needs of the industry as circumstances and not as politics determine, it will be necessary to adjust an international technique to a national scheme. It is apparent, therefore, that the struggle of the labor movement is under existing conditions, a national struggle in form if not in fact, and we must examine the structure which the labor movement is developing to achieve national self-determination. This structure is clearly indicated by the present form of the labor movement.

It has been pointed out already that the District Council gradually absorbs the power in a locality as the community becomes differentiated in terms of its industrial groups. In the last chapter it was also indicated that what takes place locally repeats itself nationally in the industry. The railway workers, the miners, the electricians, develop a technique, a form of control which embodies within itself all the important aspects of particular industries regardless of their distribution and locality. The labor organizations which embody this control tend to unite these industries in a national congress.

The British Trade Union Congress contains within itself the representation, the control, the affiliation and the loyalty of all the British workers who are organized. In this congress nearly every industry and profession in the country which has achieved some kind of organization is represented; such as the railway workers, the miners, the seamen, the teachers, the street cleaners, the civil service em- 
ployees, the building trades, the needle trades, and many others. This congress is the industrial government of organized labor. With the growth of the labor movement this congress becomes more representative of the English people.

The convention of the American Federation of Labor in this country approximates this industrial congress. The next convention of the American Federation of Labor will represent some six million people. Many of the important functions of the community will be reflected in the delegates at that convention. It is true that these delegates will represent trade unions rather than industries. It is also true that the representation as chosen at present is not entirely democratic. Moreover, a large number of organized industries will not be fully represented. This convention is, however, to be considered only as an indication of the structural growth of the labor movement.

The trade unions are gradually making place for industrial organization. It is a fact that one of the largest unions in the American Federation of Labor is industrial - the United Mine Workers of America. However, the American Federation of Labor, while incomplete as a full representation of even the organized workers, is yet a body that has already an extraordinary amount of power vested in it. It could in a time of crisis become a determining factor in the community. It could bring to a standstill some of the most important industrial functions of the United States. This workers' organization, however, is only a harbinger, a fore- 
shadowing, a general outline of the greater possible growth of the workers' movement. A tendency towards fuller industrial unity is indicated by the prospective alignment of the Railroad Brotherhoods with the American Federation of Labor.

If we assume that within years this industrial convention will include not only the present representatives of the trades already organized but also the many workers who will probably have joined the ranks of organized labor by that time, then it will be a formidable body indeed.

We are fairly safe in assuming the steady growth of the labor movement. At least there seems to be no immediate reason to suppose, if we are to judge by the recent history of labor and the current tendencies in other countries in the direction of organization, that the labor movement will not continue to gain members. ${ }^{1}$ In fact, growth for the time being seems inevitable. People join the labor movement to secure protection and one might say to acquire dignity, but as more people join it the more powerful it becomes, the greater the protection and the more social standing do its members acquire.

We may also safely assume that to this growth

${ }^{1}$ Trade Union membership in 20 of the more industrial countries according to International Labor office at Geneva has increased from $10,836,000$ in 1910 to $32,680,000$ in 1919. In England from 2,400,000 in 1910 to $8,024,000$ in 1919. For the same period the increase in the United States has been from $2,100,000$ to $5,607,000$; Germany from $2,960,000$ to $9,000,000$; France 977,000 to $2,500,000$, etc. 
will have been added the present Railroad Brotherhoods, the independent unions in the clothing trades, and many other industrial organizations. It is not even impossible that the Industrial Workers of the World will have found themselves drawn into a single organization of all the workers. It must never be forgotten that the labor movement is undergoing structural change, and that the change is in the direction of one big unit. This basis, which seems to be fairly possible as a background for industrial unity, would give the convention of the organized workers of America an exceedingly important place in American political life.

What it would mean is not difficult to visualize. In this yearly gathering of men would be found an ever increasing representation of the American people. Each delegate would represent directly a body of integrated, conscious, unified and differentiated men and women centered around some organic function of the community. A baker would represent the bakers. A miner, the miners; a railway man, the railway men. This is of course actually the case at present in so far as the industrial activity of the community is represented. It has men of its own industry as spokesmen. In a more comprehensive organization ail the important industrial functions of the community would be included. What a power would be concentrated with this group, which would be legislative, judicial and executive! It would concentrate within itself the knowledge, the idealism, the basic needs and 
all the important contacts of the working community-and the machine is rapidly making most of our people into a typically wage-working community.

This convention to-day represents a new type of loyalty as well as a new type of control. It has become evident that labor unions have a dominion over the imagination and affection of the workers which is not rivaled even by our political state. We saw recently that the coal miners considered their industrial affiliation of greater importance than their political one and refused to go back to work when ordered to do so by the political state. This is but one instance of the general fact. The convention, therefore, would enjoy actual representation of the industrial functions of the community and with it the apparent industrial and political backing of those represented.

There are other elements in this working-class convention which are worthy of notice. The first is that if we assume a slight change in the choice of delegates, these men and women would actually represent a group on a democratic basis. They would be chosen directly by a differentiated industrial union possessing fairly common interests, common knowledge, common problems, and a common purpose. The miners would represent the mines and the mine workers as no Congressman represents his constituency, because few Congressmen indeed can ever achieve that common experience and outlook which is characteristic of a delegate for an industrial group organized around 
an industrial function for a length of time sufficient to give it a sense of its own importance. These men would be political-industrial representatives, but even more than that, they would represent their groups psychologically because they would be carved from the same stone, moulded in the same crucible, and strengthened with the same purpose as the group which elected them. This is ideal. The ideal is unattainable, but how much nearer the ideal we should be as far as representation is concerned than can possibly be the case when we are represented by politicians who succeed only in reflecting the needs of the political machine which elected them. The politician succeeds in representing the political machine because that has a common purpose, but where is the common purpose of the political community which he can represent? The industrial community exists as a definitely integrated whole composed of differentiated groups each conscious of its needs and purposes.

Another fact in this working-class congress is connected with the individual representative. Every delegate will be a man who has risen from the ranks. $\mathrm{He}$ will have entered his industry as an apprentice in some form. He will have worked at his particular task, acquiring knowedge and developing that sense of group responsibility and group interest which will have made it possible for him to rise to a position of importance.

These delegates will be the pick of the industrial group. They will be the men and women who will have shown themselves to have served their group 
loyally, consistently and honorably. The labor group is inclined to be hard-headed, suspicious and severe in its judgments of the people who strive for leadership in it. Men must be tested and found to be true and capable before positions of responsibility are entrusted to them. This means that every representative at the labor congress would be a man who had shown not only social-mindedness, the power to hold the confidence of other men on the basis of service to them, but also knowledge of the actual problems upon which they are to act. The miners will know the mines; the cotton industry will be represented by men who have had many years of contact with it; the teachers will have educators trained in the service and saturated with its difficulties. These men will not only actually represent groups but they will also reflect the information, the technique, the needs and the possibilities of their separate services. In comparison with this kind of representative group what can be said in favor of the average congressman or legislator in our present political structure? The delegates would approximate a consciousness of the community's problems which cannot be achieved by political representation.

This is, of course, only a description of a group larger than the one which already represents the workers in their yearly conventions. It is not a hypothesis. It is a statement of a fact in a somewhat larger setting than it has at present. From the point of view of political government, the grouping of the important functions of the community 
within a concentrated form represented by a convention means that a new governmental structure is growing up. It is obvious that no political government could carry on industry without some compromise with this group. It must be remembered that the group represents railways, mines, water supply, bread-all the basic needs of the community; that its power cannot be taken away by a political coup d'etat. It is organic. Its function and its power are one and the same thing, and cannot be separated. Whatever the structure of future political organization may be, this industrial grouping is bound to achieve an ever more important place within the controlling powers of the community. It may be possible that all political power will be transferred to it. It is a certainty that no political power could continue without its consent.

This striking fact was made evident very recently in Europe. The German revolution was saved by the refusal of the labor unions to cooperate with the reactionary government brought in by Kapp. It became vividly manifest that the labor unions, if they acted in concert, were the pivot of the socialpolitical structure. The other manifestaton of this power showed itself in Denmark when a general strike of the workers compelled the King to reverse his action on an important matter of state and form a government which was acceptable to the workers. It must be remembered that neither in Germany nor in Denmark have the workers as yet achieved that fullness of organization, that completeness of 
control, that concentrated unity which the present growth seems to indicate will probably be theirs in the no distant future. ${ }^{1}$

We have thus the development of a new power of government, a government controlled in terms of industrial groups in which industrial representation is being substituted for political representation; while the future no doubt embodies many changes, this is one that for the time being seems inevitable.

Industrial organization is becoming a pivot around which political control can be centered. Political theorists may speculate upon the place of geographic representation in the future governmental structure, but the very fact that the question is being raised indicates some doubt about that place. There is little question as to whether industrial representation shall remain. That is taken for granted. Political representation in terms of the geographical unit is on the defensive, and there is considerable doubt whether it will be able to maintain any foothold at all in the light of the growing importance of industrial representation as indicated in the

${ }^{1}$ New York Times, Copenhagen, April 6, 1920. "A definite agreement to call off the general strike which resulted in forcing King Christian to dismiss the Liebe Cabinet has been reached by employers and workmen here.

"The result of this strike is the second remarkable illustration within a few wecks of the entirely novel use of the strike weapon, which has hitherto been employed almost exclusively in industrial disputes. It has been employed with surprising effect in two important constitutional crises. The first was in Germany, where the reactionary Government set up by Dr. Wolfgang Kapp was forced to relinquish power at the end of five days. The second was in this country, where it was employed with almost as quick success." 
growth of the labor movement. This is one of the great consequences of the original act of the isolated worker who joins a union because he wants a little more security in the world. Without knowing it and without planning it, he is the great revolutionist of the age. 


\section{CHAPTER XIII}

WORK AND WAGES

IF the general point of view of this book, that the labor movement represents the most vital contribution that is being made to social change and reconstruction, is correct, then all of the more important practices of the labor movement are of significance as a possible indication of future method in social relations. The arrangements of the future are likely to be vitally influenced by the contributions to social procedure which will be carried over with the transition from competitive to cooperative industry implied in the labor movement.

While it would be too much to suggest that all of the practices of the labor movement are important as possible contributions to future method, still it is desirable to see clearly that the transition is bound to carry over with it a great deal that is permanent and basic in labor structure. From this point of view the apparent tendency of the labor movement to equalize income is highly significant, for there are few things so deeply ingrained as its policy of remuneration and its ethics of income.

This may seem a startling statement. There is, 
however, an unmistakable tendency in the labor movement to narrow the distinction between incomes and the bases upon which incomes are computed. There are certain very definite things which the labor movement has done, and certain definite principles which it has avowed, in this important direction.

The first of these is the insistence upon a minimum living wage. This is a revolutionary demand from the point of view of the older economics and politics. It is revolutionary because it violates the first principle of competitive economics upon which the present system is based. The present. system is assumed to take competition between man and man as the basis of its political and economic policy. The idea of the survival of the fittest becomes increasingly difficult and the survival of the "unfit" increasingly easier when a minimum standard of living for all men is assumed. What is of equal importance, however, is that the minimum wage is the first step in the direction of establishing the equality of men in an economic sense. From this point of view, all men have an equal right to survive economically, for the minimum wage is really only the statement in another form that all men have an equal right to common standards of livelihood. Here we have the first rung in the ladder leading in the direction of equality of income. The first step establishes the level below which income cannot fall, and so limits the difference between man and man that much. All men have an equal minimum, an equal right to exist. 
The second great step is the general acceptance of a maximum income. This maximum, like the minimum, varies with time and place, condition and group, but generally speaking, all organized labor, even the most conservative, has accepted in principle and advocated in fact the limitation of income for all classes in the community. This limitation may vary from a million to fifty thousand dollars or even less, but there is a general acceptance of the principle. In so far as labor has the power, it has insisted upon this demand. The advocacy of income taxes, inheritance taxes, profits taxes, are all of the same thread. The attempt is to set a practicable limit to maximum income. We thus have the two outlines of the tendency to reduce the economic difference between men.

While the minimum and maximum policy has been accepted in principle and applied in fact, in so far as the labor movement has been able to influence the political practices of the community it has attempted with more success this general practice in its own organization. The enforcement of a minimum wage for all organized workers is an insistent purpose of the labor union. This minimum, which is described as a fair day's wage, is but an attempt to raise the standard of living - a standard which as yet has not been expressed in terms of finality but which may not fall below its present position. The future is indefinite beyond the expressed hope that the margin of increase will rise rapidly. To this basic effort in organized labor is to 
be added a number of other activities, each tending in the same direction.

As far as possible the labor movement has enforced an equal length for the day's labor. The eight hour day is a practical fact in the lives of the greater portion of well-organized trades. This standardization of the day's work in point of time is approximated and tends to become a fact of ever widening influence in the lives of thousands of others who are not organized. We thus have a practical equalization of one of the bases upon which the day's pay and the weekly income are computed. The hours of labor of all men are thus equalized, or tend to be, and with that goes a tendency to limit the wage, as the wage may be and in many cases is computed by the hour. When men work an equal number of hours they cannot, generally speaking, vary in income as much as if they worked different hours. At least one element in the variation of income tends to disappear. In addition to the limitation of the hours of the day, there is a limitation of the hours of the week which may be employed in gainful labor. The general aim is 48 hours per week, and in some industries it has shifted to 44 and even to 40 hours as the maximum; this tendency to approximate a common level is apparently irresistible.

The point of interest next to that of the hours of labor that a man may work is the amount of work a man may do during those hours. Limitation has become a general policy for the worker. In piece work, as well as in day work, there is a generally 
accepted understanding among the workers as to what constitutes a fair day's work, and few organized workers go outside of the general rule in their working hours or in their output. I am speaking of well organized trades, the others always tend to approximate them. I am not at present concerned with the morals of this fact, nor am I here concerned with explaining that attempt to control and regulate the work in hand which is so important a part of the labor movement. This was developed in the third chapter. What is important to note is that the amount a man may do is limited by his union organization, and that this limitation tends to equalize income as between man and man, for it limits and controls one of the causes for difference in pay-productivity.

The whole question of union responsibility was recently given new and significant implication by the adoption of working class production standards by the Amalgamated Clothing Workers at their convention in Boston. They adopted, after a great deal of discussion, the principle that their union must work out standards of production and enforce them. It must, however, be noted that these standards are not competitive but cooperative. They are the determination of the group as to what the individual can and ought to be expected to do.

In the discussion the President sait: "We cannot evade this question of production. The Amalgamated cannot accept the ordinary rule of commerce, the principle of the business man, which is to give as little as possible and to take as much as 
possible. We must take a different attitude and accept responsibility for production. We cannot have sabotage by withholding production; we cannot have loafing; we must have production and we must recognize our responsibility."

This change in attitude represents one of the most remarkable evidences of the constructive and creative character of the labor movement which we have at hand. It must be fully understood, however, that the change in attitude toward work represented here does not discount the cooperative character of the labor movement, nor deny its defensive and protective nature. The simple fact is that this remarkable union has achieved such a degree of control and solidarity that it can best maintain and increase its powers of defense and protection, of service and cooperative effort, by a new emphasis towards the question of work. The work is still subject to rules and regulations which meet the needs and interests of the workers. It has simply ceased to be negative, has assumed the character of positive contribution, of deliberate service to the community.

In addition to the tendencies already enumerated there is the important fact that all organized workers, regardless of their particular trade, approximate each other in wages. ${ }^{1}$ There are, of course,

${ }^{1}$ An interesting illustration is to be found in the Railway Shop crafts. The Coremen, Boilermakers, Electricians, Sheet Metal Workers, Blacksmiths, Signalmen, all of whom used to get different wages, now all get the same basic wageif they are classed as craftsmen. With this there is an equalized period of apprenticeship. 
differences dating from traditional wage adjustments, differences in standards of living, differences in personnel. These differences tend constantly to be narrowed. In almost every wage dispute the raise demanded for the lower paid worker is greater in proportion than that demanded for the skilled and higher paid worker. Any union where a number of trades meet on a common level, will, when a wage dispute is on, make a demand for a higher percentage of increase for the lowest paid trade. This fact and the fact that the lowest paid workers are constantly demanding higher wages, organizing and increasing their power, as well as limiting both the hours of labor and the output, tend to bring their earnings nearer to those of the skilled workers. ${ }^{2}$

${ }^{1}$ That standardization of wages is characteristic of the labor movement is interestingly illustrated by two disputes now going on in different parts of the world. In the United States the struggle over the National agreement on the Railways is to a large extent a struggle about the standardization of wages. In England the same issue is in the forefront of the dispute about the miner's wages. This is made clear by the following quotation from the manifesto issued by the Tripple Alliance.

"For generations the trade union movement has set the establislment of national wage agreements in the forefront of its program. The miners, railway men and transport workers, after a prolonged effort have secured them. Now the mine owners have flung that principle to one side. The condition which it is sought to-day to impose on the miners will, unless resisted, be imposed to-morrow on other classes of workers, the standardization of wages among all grades of railway labor is in danger. The dockers minimum of 16 shillings whether in Hull or Liverpool or any other port and the uniform rates of seamen will be insecure if the miners are defeated." 
The demand by the labor movement for equal pay for equal work is another illustration of this tendency. It is a tendency to standardize the income and the basis of remuneration for all participants in the productive effort of the community. This is of practical importance when applied to the labor of women, for the woman worker has generally been the lowest paid and least protected of all other workers. She has generally been the last to organize and up to date she has, as a general rule, lacked the skill which makes organization for the male worker so much easier. With the equalization of the wage for women, we have (where this has become a fact as with the women teachers in the New York public schools the raising of the income of a very large part of the community to that of the rest of it-a striking illustration of the tendency toward an equal wage.

One of the consequences of this tendency is illustrated in the striking equalization of the income of the workers with that of professionals. Teachers in public schools, professors in colleges, writers on newspapers, civil service employees, engineers, draftsmen and innumerable other skilled and professional workers who until recently were considered as outside the working-class group now find themselves within it in terms of income. Many skilled workers earn more than professional people. The privilege and influence that come from organization are enjoyed more to-day by organized labor than by the professional group, with the result that the professional group is finding itself compelled to join the 
organized labor movement. ${ }^{1}$ This is a striking illustration of the tendency towards equality of income in the community.

The other positive contribution in the direction of equality between the professional and the worker is the approximation of the hours of labor in both groups. The day when the professional could enjoy his half-day off on Saturday while the manual worker continued at his task, is practically gone. The manual worker and skilled tradesman, the professional, teacher or chemist, are to-day more than ever on a common level on the basis of income, hours of labor, standard of living and social standing in the community.

To those already enumerated must be added other influences. The lower income of the laborer and the great insecurity of his position have, up to date, made him a prey to accidents which reduced his existence below the level of a decent standard of living, and in so doing have increased the distance between the well-paid, comparatively secure members of the community and the insecure members by forcing the manual worker to a lower level of existence.

Sickness, accidents, lack of employment and other evils centering about the life of workers made constant inroads both on the vitality and the income of the manual laborer and left him constantly on a lower level of income and security. The labor

${ }^{1}$ The significance of the organization of such professional function as Teachers, Actors, Engineers, Yard Masters, Train Dispatchers, Railroad-Traveling Auditors cannot be over estimated. 
movement, however, both through its internal organization and through its influence upon the state, has established many bulwarks against complete exhaustion and wrecking of workers' lives. Thus many trade unions have sickness insurance, out-of-work payments, and other benefits. While their influence has been very largely contributory to the adoption of state out-of-work insurance, accident insurance, old age pensions, and in some cases of maternity insurance as well, the importance of these bulwarks, in the worker's own world can hardly be overestimated. What I am concerned with at present is their limitations upon the reduction of the minimum of subsistence. They tend to limit the difference between man and man economically, and by doing so tend to keep people on a greater equality of income, of social position and of standard of living. We thus have the following tendencies, well marked in the labor movement, all leading in the direction of equality of income:

1. Minimum wage for all workers.

2. Maximum income-taxation of wealth in various ways.

3. Limitation of the hours of labor-reducing . thus the variant for computing wages.

4. Standardization of output-another reduction of the variant for computing wages.

5. Approximation of equal wages for all organized groups by generally raising the proportion of the lowest paid workers in a wage dispute. 
6. Equal pay for equal work for women.

7. Approximation of the manual to the professional worker in income and in hours of labor as well as in power and social position and standard of life.

8. Sickness insurance.

9. Unemployment insurance.

10. Accident insurance.

11. Old age pensions.

12. Maternity and widow compensation.

13. The giving of a labor status to professionals through organization.

14. Standardization of wages for large groups -miners, dockers, etc.

To all of these tendencies, which are subject to enumeration and description, there must be added others more subtle, more organically bound up with the whole process of the world in which we live. The tendency towards greater equality of income which the labor movement is evidencing is stimulated by a remarkable development in the comparatively equal educational background of the whole community. Public schools, high schools, colleges, lecture platforms, moving pictures, newspapers, magazines, are constantly supplying to the mass of men and women in the community a greater imaginative equality than they ever had before. The differentiation of the community into groups, the development of industrial power by small groups and their ability to inconvenience the community also tend to develop a sense of importance and equality which 
they did not possess in their isolated individual setting.

The greater opportunity to travel, the street car, the Ford automobile, the commutation ticket, are also important influences in the breaking up of the isolated provincialism of the individual which tended to make income a divinely arranged affair. The political democracy, with its appeal to the individual voter and its insistence that the people are the root of political power, make the demand for a greater equality of income inevitable since it is only a demand that the spiritual approximation of the community be substantiated by an economic one. The significance of the labor movement lies in the fact that it provides the machinery for the fulfillment of the growing demand by the working class of the community for equality. 


\section{CHAPTER XIV}

THE CONSERVATIVE FUNCTION OF THE LABOR MOVEMENT

I $\mathrm{T}$ is the ideal aim of the labor movement to 1 abolish revolutions. It aims to eliminate the cost of human sacrifice due to social change by making change a pragmatic and deliberate thing.

The current as well as the age-long method of political and economic change is violence and human sacrifice. Every important change in our political status, in economic relationships, has largely been achieved by the crude method of physical struggle and suffering. Not only is this true of such all inclusive upheavals as the French Revolution and the present Russian Revolution, but it is true of other less startling changes such as the struggle for the eight-hour day. How many strikes, battles with the police, evictions, jailings, hangings, how much misery and death have been exacted by the eighthour movement! The fact that we have paid in human life and suffering for almost every change towards smoother and more pleasant relations gives the labor movement a role of extraordinary significance and force if it really has elements which may ultimately eliminate this crude process of social adjustment. 
The heavy cost that we have paid for social change is due not to the essence of change as such. The cost of life and the demand for human sacrifice are bound up intimately with the situation within which change takes place. If the proposed readjustment of the suggested new methods and procedure is one that arouses class interests, we have the conditions that make for struggles, revolutions and the payment in human life for change. This is a very characteristic fact. No revolutions are needed to stem a pestilence which endangers the whole community. Everyone will admit that the river or the wells or the swamp ought to be subjected to whatever scientific treatment is required. This is done with the consent of the whole community and it is left to the experts to determine methods and means. But a suggestion that will shorten hours of labor, that will readjust property relations, that will change the standards of life of one part of the community is generally resisted by another part.

The difference between the two changes does not lie in the fact that one is more essential than the other. Changes in working regulations and remuneration may involve conditions of sanitation and nutrition that are of the greatest importance to the health and life of the community. The difference lies in the fact that in the case of malaria the interest of the whole community is involved, while changes in working conditions are opposed by one class in the community - the employers-and demanded by another class-the workers. In the case of malaria the interests of one are the interests of all. 
Every one is subject to the danger and will benefit by the improvement. In the second case the interest of the employers and of the workers are diametrically opposed. The friction arises where one group stands to lose by the definite gains of another group. The resistance is caused by class interests and has nothing to do with the merit of the suggested changes.

Revolutions, and the cost of human sacrifice which they imply, are caused by resistance to change and not by the desire for change as such. The satisfied and entrenched part of the community forces the dissatisfied and discontented to revolution because peaceful progress is opposed and repressed. Revolution is a class affair. I am speaking of social revolutions and such have always been the work of the masses of people against an entrenched class. This revolutionary method is made inevitable by conflicting interests and by the difference in point of view and ideology that goes with it. The pway out of this situation is the reduction of human progress to a deliberate and group-determined thing, a thing that is to benefit the whole community. But such a proposal is only feasible in general application when the interests of the whole community are one, when the benefit of one is the benefit of all. Without such a common interest, social progress must involve the friction with which we are familiar in revolutions and in strikes. The labor movement has as its ideal function to achieve this unity of purpose and interest for society. It is a conscious aim on the part of radical labor and is at the same time the less articu- 
late but generally accepted end of even the most conservative labor groups. This general acceptance of the elimination of strife in social adjustment as one of the ends of the labor movement is highly important because it is so vital a part of our current life activities. This idealism receives fuller significance when one realizes that this is not only the ideal but the method of the labor movement.

The labor movement functions by reducing friction within a given group. It functions by eliminating competition, difference of pecuniary advantage and personal economic worth within any given labor element, to its minimum. This is the source of labor power. It is strong and vital because it can act on group consent based on community of interest. This community of consent is attained by reducing the economic and social interest of the group to a common denominator. When the labor movement has succeeded in organizing a hundred thousand men in any given industry into one organization, it has at the same time succeeded in eliminating economic differences and competition for economic survival within that group. The wage interests of one engineer on our railroads are the same as those of any other. The two men do not strive against each other for a living. There is no competition for economic goods, for better wages, or more favorable conditions between them. They work in unison. They have succeeded as a matter of practical application in making the economic advantage of one member of their group the economic advantage of any other member of that particular group. 
The theory of the survival of the fittest has no economic implications within an organized group of workers. They are all fit to survive economically when all are members of the union. They live by cooperation and not by competition with each other. This is one of the basic facts of the method of the labor movement when viewed as an economic entity. It is the living embodiment of the poverty of the economic theory of competition, of struggle and of belief that men live by friction rather than by cooperation. It is true, of course, that their unity is a unity for more effective competition. They are a unit for more effective competition against an entrenched class of legally protected owners. This must be fully evident when we realize the fact that the labor organization has the inevitable tendency to spread this basis of unity over an ever wider field, reaching from a hundred thousand to a million workers, of growing from the bounds of a locality to the limits of a nation, and stretching beyond the boundaries of a nation to include the world. It functions by reducing human friction, by the elimination of individual competition, by making the interests of one the interests of all on an ever larger scale. It works by cumulatively reducing economic incomes, economic ambitions and economic incentives to a common denominator.

It is this fact, along with the apparent tendency of the labor movement to grow ever larger in its inclusiveness, ever greater in its numbers and fuller in its consciousness, that makes the suggestion for reducing economic classes to a single class more 
than a mere verbal threat. Labor does so in fact wherever it succeeds in organizing. It tends inevitably to narrow the economic equation between man and man. As current social revolutions are mainly the product of class economic interests, labor tends to make revolutions needless and ultimately unnecessary by making the interests of one the interests of all. It makes for social peace by eliminating the economic class and with it all the paraphernalia in the way of social and political ideology that follows such a differentiation between man and man in the terms of income and possession. It tends to make progress pragmatic, deliberate and purposeful. Men in the labor union take action in terms of the interests of the whole group and do it by democratic procedure. This is only possible when the group feels its concerns to be vital to the whole of its membership. Community of action is determined by community of interest.

Labor, when organized, thus tends inevitably to a reduction of the economic equation between man and man. It makes competition unnecessary for economic sustenance. But this material equalization has a great influence upon the growth of competition for spiritual and social ends. It eliminates the struggle for bread and stimulates the struggle for leadership. It saves energy from the competitive economic field and provides opportunity for its expansion and development in the group activities which it stimulates.

This aspect of the labor movement is very interesting and throws a good deal of light upon the 
problem of human incentive and interest in a community where the economic motive is reduced to its minimum. As a matter of historical origin, the labor movement is primarily an economic organization, and is instituted for the purpose of monetary advantage and the security which said advantage implies. This advantage is attained by equalizing the differences in income and by reducing to a common equation the monetary interests of the individuals in the group. The struggle for social and æsthetic values is enhanced by the elimination of individual competition. The economic aspect of the worker's existence loses a good deal of its prominence. It becomes subsidiary to association, to community of feeling, and to mutual trust. The whole scheme of union activities involves a number of things other than the struggle for financial gain. Social, educational and group interests make themselves felt, although they have no immediate bearing upon the economic situation.

These activities increase in importance with the growth and stability of the organization. They become the basis for the greater part of the struggles that are current in the different unions. These, however, center in other than financial things. They are the spiritual consequence of association. By eliminating economic competition, the competitions for emulation, for leadership, for honor, for a place of trust and confidence, are enhanced. Incentive becomes centered about the privilege to serve the group, about the opportunity to exercise responsibility, to participate in the councils of the union, 
about the opportunity to exercise one's ingenuity for service rather than for gain. Life may still be said to be a struggle, but it is a struggle to serve the group. I am not at present concerned with the question of selfishness or altruism. Let it be assumed that it is still personal selfishness and the desire for power which stimulates the activities of the active element in the union. But the result is different from that which follows the competition for gain. Here one strives to be in good standing, to attain the confidence of others. These things are to be had only on the basis of merit-a merit which displays itself in the service rendered to the group.

Anyone acquainted with the functioning of the labor movement knows what energy, persistence and activity enter into its make-up. It exhibits services to the group which stretch over years of sacrifice, and the remuneration consists in the feeling of pride and joy that comes to one who knows that he has given his best to serve his group and earns in turn the respect of his fellow members. Here develop motives which are not financial. They are simply the demand on the part of the individual for conspicuous presence in the group. The motives here are group interests, place and opportunity for leadership and the possibility for creative activity. The worker here becomes a conscious and important man, a person with dignity and with individuality. He does all that through having sunk his financial and economic interests into that of group, of assuming a standard of economic equal- 


\section{THE CONSERVATIVE FUNCTION 175}

ity, of eliminating competition for gain, and of substituting the motives centered about the spiritual rather than about the material interests of life. This single fact alone gives the labor movement a mighty spiritual function. It indicates that the economic struggle within any group may be supplanted by cooperation, and that such substitution enhances the motives of service rather than those of gain in the individual. It makes working for others towards the attainment of personal good a fact in the worker's life. It gives the labor movement a highly conservative function. It conserves energy, transmutes economic interests to spiritual values and makes progress pragmatic rather than violently revolutionary. 



\section{PART III}

\section{Consequences}





\section{CHAPTER XV}

\section{REMUNERATION}

THE problem of remuneration is bound to be one 1 of the most crucial in any attempt at industrial democracy. How shall man be paid for his work? Under current conditions this is determined dogmatically and without fine distinction, on the basis of competition. Competition is often modified by various social factors; such things as the standard of living, organization and legal regulations come in and modify the pure workings of the forces of competition. While people generally are not satisfied with what they receive, and while the money wage is a fluctuating and changing thing in the face of a rising of prices or development of new needs, it is still a determination. Wages are paid and received in the commercial world in a commercial way. Each man is given what he will accept and he accepts what he must or thinks he must accept if he is to serve his best interests. I am not at present concerned in the theory of the payment of wages.

None of the theories represented seem satisfactory and all that can be said of them, even if one would give them their fullest value, is that the 
theories of wages explain what is supposed to determine the wages and income rather than whether that division is either desirable, good social policy, or even a proper distribution of the produced wealth of the community. This division of the income of the community on the basis of competition is a working method under the present system. When the whole work of man is computed primarily in terms of money profit-and-loss, when all values are market values, it seems justifiable and at least workable that wages, too, should be determined on the profit-and-loss money motive. It is assumed, however, that under any system of industrial democracy where social control and service will take the place of money income and loss, where cooperation will take the place of competition, the competitive wage will not serve. Some other form of remuneration will have to be determined. Some other basis of payment for service will have to become a fact in the group. What shall that be?

The formula of the Socialist, "The full product of one's labor," seems thoroughly unsatisfactory for practical application even if it may have attractions as a theoretic statement. The full product of the labor of the community is its full income. The work of the community includes everything-the making of baby carriages, horseshoes, bridges, checkers, violins, microscopes and scarf pinsevery object of use that has some labor attached to it. All of these individual things taken collectively represent the whole work of the community; practically not one of them represents the work of any 
individual. Goods are social products and there is no method of determining the value contributed by any one individual to the final product. In fact, it would seem that from the point of view of the consumer the contributions of all the individuals whose efforts were actually required for its fruition and for its being placed at his service were equally necessary, and the consumer's point of view is in this case the crucial one. Things are made for us. The user alone is the one who gives value to any product, for if a thing has no value to a consumer or consumers it has no value at all. I am, of course, thinking of the consumer in a very broad sense to include him who uses machinery for further production as well as him who actually enjoys the final product of the machine as it is served to him.

How vain it is to attempt to distinguish the value of any labor contributed to the making of any article, from the point of view of the consumer, is easily made vivid by a simple illustration. California pears have to be grown, picked, separated, packed, shipped and placed at the disposal of, say, the consumer in New York City. To achieve this result it is necessary to employ an innumerable host of people-those who serve indirectly by supplying boxes for packing, chemical products for spraying the trees, coal for transportation, and iron or steel for nails to nail the boxes together. But let us take the more immediate efforts of the people directly concerned with the pear. There is the grower who may be a highly skilled specialist; the picker who is a common laborer; the packer 
who may need some skill; the shipping clerk, the longshoreman who will pack the fruit on or take it off the boat.

Now who is the most important contributor to the final product in so far as the consumer in New York City is concerned? Is it the grower, the packer, the sailor, the longshoreman? If any one of these had failed to do his part of the work the consumer would have to be content without California pears. They might never have been produced if the fruit grower had failed to spray the trees; they might never have been picked if the picker had gone on a strike; they might have rotted on the way if the handlers of the boxes had refused to touch them. If the men in any one department in the pear-raising industry had refused to do their work the New York City consumer would have been deprived of the final purpose and end of raising pears. Without the cooperation of any one of the series, the work of all the others would have gone for naught. There would have been no consumption value to the pear and the labor that has no consumption value in the end has no value at all. To attempt to pay any one section for the part it contributed to the final product, "the full value of his product," as the Socialist would say, has here no meaning, unless it be that all contributed equally to the work of making the pear of consumptive value.

What is true of the pear is true of the ten thousand other products and services which make up the community's income. So far as the consumer is concerned, every product which he uses and which 
is essential to his well-being has a value which cannot discriminate between the separate contributors to its final consummation. This is true of ice cream, of medicine, of bread, as well as of clothes, houses and books. The author is essential; so is the printer, the distributor, the maker of ink, and the machinist. Each of them has contributed to make that an enjoyable or useful product, and the failure of any one of them would, under present conditions, have made useless the work of all the others.

It must be obvious also that the ordinary distinction between skilled and unskilled labor as the basis of remuneration becomes untenable when the workers are fully organized. Not only does the machine tend to destroy skill but even without that destruction, when the labor movement succeeds in grouping a sufficiently large number of unskilled men in any industry as a unit in that industry, it makes them for all practical purposes, of equal importance with the highly skilled specialist. The industry cannot continue without the single trained chemist, nor can it continue without the organized group of unskilled workers who make it possible for the chemist to direct the industry. If it is assumed that all the major industries will be organized, then skill and lack of it cannot be differentiated in determining wage payment, because the organized unskilled are as important to the industry as the skilled. This fact is strikingly illustrated by the constant approximation in wages and hours and importance which the unskilled are making as the result of organization. We thus have the unskilled hod-carrier occupying a 
place in the building industry which may be compared to that of almost any other trade therein.

The general impossibility of dividing the separate contribution of any individual from the finished product is also true when the contribution of industry, profession or trade is considered. The view here taken is the consumer's view, for it is he who gives value to production. The consumer requires coal, but the miner must have steel, electricity, chemistry and transportation as his immediate cooperators if the consumer is to enjoy his coal. The consumer wants bread, but the skilled farmer, the farmhand, the railroad worker, the mechanic who makes the tools, the miller, the baker and the baker's boy are all essential to provide the bread to the consumer, and all are equally valuable for him. Their individual services have no value except in so far as they are parts of a cooperating group of labor -having in view a certain consumer's end. The same, of course, is true of the professions. The doctor without the instrument maker, the engineer without the laborer, the sanitary engineer without the street cleaner, the chemist without the miner and the agricultural worker without the implement maker, are helpless and of little practical value to the consumer in a community as complex as ours, and unless they can serve the consumer they have no useful function to perform.

It is thus evident that under present economic conditions it is not possible to evaluate the work of any one individual. It is not even possible to evaluate the work of any given group, profession or indus- 
try. All industries are practically so bound together, so interdependent, that one cannot continue to serve without directly feeding upon many others and indirectly upon all of the cooperative functions of the community. This fact makes the separation of earnings such as takes place to-day a purely arbitrary and dogmatic thing. Evaluation is in terms of profit and money, and both of these are habitual arrangements rather than such as actually correspond either to the value of the service or to the socially desirable distributive serving of the consuming needs of the community.

In the chapter on wages it is pointed out that there is a very strong tendency within the labor movement towards an equalization of the wage income of the worker. This tendency deserves special emphasis and significance in the light of the above discussion. A cooperative industrial community would of necessity be a consumer's community-consumer's in the sense that production would be for service and not for profit. This fact, combined with the general tendency towards a greater sense of individual equality, makes the assumption of a possible change from varying to an equal income a strong possibility under any cooperative democracy. In fact, it does seem that a community which is organized for the purpose of raising the standard of living of all people in it, which is concerned with limiting the points of friction between man and man and group and group in its economic aspects, may find the equal wage a very convenient process for achieving that end, for as has already 
been pointed out there are no differences of value for the consumer in the contributors to a finished product. He values them all in terms of use, and in terms of use they are all equally valuable. A community that is not organized on the profit motive will have as its end the consumer's interests, the producer himself being the consumer.

The likelihood of the acceptance of such wage payment becomes more evident when it is seen how difficult it would be to find any system that would involve less friction, less discontent, and would by and large give greater satisfaction to the mass of men. Such a system would also have the positive value of limiting the friction between group and group for greater economic advantage and meeting in advance a criticism which is very serious indeed when urged against the syndicalist-unless he accepts the principle of the common value of all necessary labor, leaving the word "necessary" to be defined by the producer's congress on the basis of economic priority. That is what we did during the war with the difference that our priority was in reference to war for destruction while their priority would be in reference to peace for constructive and living ends. During the war we gave the first place to guns and munitions; they would probably give it to health and bread. I shall discuss the problem of priority a little later.

The question of incentive which is often raised in this connection seems to the author a somewhat unreal and exaggerated matter. Not that the incentives are unimportant, but that specific formula- 
tions of the conditions under which incentive may properly function are rather superfluous. We are concerned with an organic social transformation which is re-shaping social institutions. This process is a natural consequence of the development of the machine, the competitive ownership of industry, the commercial spirit and profit motive which dominate present-day economic organization. These and similar factors have given rise to the labor movement as a matter of defense against the indifference to the well-being of the most defenseless group in the community-the propertyless worker. When the possible outcome of this defensive process is indicated the defenders of the status quo immediately raise the question: "What will happen to incentive?" The easiest and probably the best answer that can be given is that it will take care of itself.

Incentive is not a special thing which must have money or inequality to operate. Incentive is primarily an internal matter. It is related to the drives, the instincts, which compel human nature to activity, and money or inequality are mere incidents. It is related to such prime things as hunger, sex, playfulness, the desire to shine, to dominate, to conspicious self-exhibition, to pure physical joy that follows likable activity, to the response to color, form, sound and touch. These are the factors which awaken human interest and maintain human activity. Anyone who thinks it is money, the pay envelope, or inequality that is the controlling factor in human activity is simply out of date and unac- 
quainted with the best in modern psychology. $\mathrm{He}$ belongs to the good old age of Ricardo and Bentham when rationalism and self-interest were considered the essential facts in human behavior. It is a mere fable, a theory as far removed from the facts of human nature as is the Ptolemaic conception of the universe from the present relations known to exist therein. The only question that one could raise legitimately in the postulation of industrial democracy would be something like the following: "Would industrial democracy tend to stifle, repress, and inhibit the ordinary demands of human nature upon its environment in greater degree than does the present industrial system?". An answer to this question has been given in many ways in various chapters of this book; what we can do here is suggest certain other considerations that have a bearing upon the subject.

We do know that the present system does not provide sufficiently for incentive in industrial operations. The outstanding fact about contemporary industry is the constant complaint that the workers have lost interest in their work. The manufacturers are always retailing that the men are shirking, that they do not work, that they loaf and are indifferent, that not only the quality but the quantity of labor is on the decline. Some of the reasons for this fact may be found in the chapter on labormovement psychology. It has in fact been predicated that the present system is disintegrating mainly because the workers refuse to work any longer under the present conditions. To say that 
they refuse to work is to make it a conscious matter. It is much deeper than that. It is passivity or actual disgust with the confining and repressing limits which the present system imposes. The worker's life is lived in an atmosphere of confinement. It is lived within an area of mechanical force which denies to the individual any opportunities for play, for control, for self-assertion, for artistic joy. The modern factory is the antithesis of all these needs of the individual. It is primarily repressive because it compels an unvarying and single reaction during the whole day and for long periods at a time. It saps the worker's energy and takes his time; it leaves him little of either to find a satisfactory outlet for all the other needs of human nature. This predominating fact about industry cannot be too often emphasized. It lies at the root of the greater part of the discontent of the industrial worker. If incentive is to be provided it must be in terms of the greater outlets in the industrial field where the worker spends his greater energy and strength. The possibilities of a change in industrial control's making room for that kind of outlet are more than an assumption if one remembers the significance of a group morale in its influence upon individual behavior; the industry of the future which is predicated by the labor movement makes that a seemingly unavoidable consequence.

There are in addition to the general considerations suggested above the possibilities that would naturally arise from group association. The first of these is that we should assume greater interest in the in- 
dustry because we assumed a sense of ownership and group determination. It has been observed that there is always greater interest where there is a prevailing sense of ownership. This in fact has been one of the chief arguments for the maintenance of private property. With this greater feeling of personal control and determination which would arise from democratic ownership and management of industry we may safely postulate a greater incentive, for interest and incentive are concomitants. The second fact that we may also safely postulate is that industrial democracy would provide a greater degree of scientific training and insight into industrial processes on the part of the mass of the workers than at present. We may assume this because industrial democracy would depend largely upon group decisions, and such to be satisfactory would have to depend upon a knowledge and understanding of the industry. This fact is dealt with in the chapter on Labor and Education.

We know that a human being is generally active and that he likes to be active in the things which his group approves. In a situation where position, honor and power would in all probability go to those whom the democratic group approved of, in such circumstances activity in the interest of the group would be the basis of promotion, and activity would by the very nature of the situation be concerned with the industry. The desire for approval and good will, so strong a factor in human behavior, would compel activity in terms 
of the industry through which one had a group contact.

The possibility of awakening the latent interests of the workers is another element that may be expected to play a part in awakening and maintaining incentive. The degree of decentralization is very great. Not only has an industry a corporate self and individual unity, but each factory and each shop is in a similar way a unit for administrative purposes. Where the group in question assumed responsibility for its own function, a tendency indicated by the Shop Steward movement, there would probably arise a great deal of the same esprit de corps which we find in practically all groups. We need only recall the feverish competition of different committees selling Liberty Bonds during the war to see the possibilities of that kind of situation, under favorable conditions.

It is not beyond the sphere of reasonable conjecture that each group in industry would strive for honorable mention and recognition as a group, a fact characteristically manifest in other groups engaged in a social enterprise. And we must never forget that the labor movement points to a distinctly corporate and social organization of industrial functions. Such intensity would give rise to a degree of stimulus and call forth latent powers of inventiveness and ingenuity to a degree which the present cannot claim to have achieved. Most people have a greater degree of such powers than is ordinarily assumed.

As an instance: Many more people love music than can actually play an instrument. These people 
could, most if not all, have acquired a respectable degree of technique at some instrument if the opportunity had been provided. This is true in other fields; human possibilities are greater than present achievements, and they would probably be brought out more fully under the stimulus of group activity. In fact, a whole series of ethical concepts may be postulated in terms of the group life which industrial democracy would make necessary. All of these suggestions are but adumbrations of the real problem of incentive, of the forces which the individual obeys when he displays activity. ${ }^{1}$ The author, however, is not competent to write a realistic chapter in psychology dealing with incentive, and he is not acquainted with any published material that would satisfy that problem. We are rather ignorant of the causes of human incentive-at least we are not enough acquainted with them to supply satisfactory explanation. One thing is clear. The present system of production and distribution does not provide a satisfactory monetary incentive, even if money in itself is incentive enough. Upon the deficiencies of the present system of monetary incentive John Stuart Mill deserves quotation at length.

${ }^{1}$ As a suggestive contribution to incentive, the following from Thomas A. Edison is interesting, "What motives have actuated you during your life-ambition, curiosity, altruism, or what? Has your attitude always been invention for invention's sake, or with some material reward in view, or what?"

"I have put that question tc myself many times," answered Mr. Edison, "and still I cannot answer it. I suppose it is like a man who becomes very expert in billiards: he wants to play the game all the time."-Saturday Evening Post, Feb. 11, 1921. 
"The objection ordinarily made to a system of community property and equal distribution of produce, that each person would be incessantly occupied in evading his fair share of the work, points, undoubtedly, to a real difficulty. But those who urge this objection forget to how great an extent the same difficulty exists under the system on which nine tenths of the business of society is now conducted. The objection supposes that honest and efficient labor is only to be had from those who are themselves individually to reap the benefit from their own exertions. But how small a part of all the labor performed in England, from the lowest paid to the highest, is done by persons working for their own benefit. . . . If, therefore, the choice were to be made between communism with all of its changes, and the present [1852] state of society with all of its sufferings and injustices; if the institution of private property necessarily carried with it as a consequence that the produce of labor should be apportioned as we now see it, almost in an inverse ratio to the labor-the largest portions to those who have never worked at all, the next largest to those whose work is almost nominal, and so on in a descending scale, the remuneration dwindling as the work grows harder and more disagreeable until the most fatiguing and exhausting bodily labor cannot count with certainty on being able to earn even the necessaries of life; if this or communism were the alternatives, all the difficulties great or small of communism, would be as dust in the balance." Book $I$, Chapter I, paragraph 3. 


\section{CHAPTER XVI}

THE FUNCTION OF INDUSTRIAL GOVERNMENT

THE remolding of the community which is im1 plied in the growth of the labor movement carries with it a reconstruction of all the more important institutions in present-day society. Of all the changes which the labor movement is bringing about probably none is likely to be more sweeping, more comprehensive, than its influence upon government. A discussion of the government, of the future industrial community indicated by the labor movement, is at best likely to be conjectural. It is essential, however, that the problem be discussed and if possible its limitations marked out. Before any such undertaking, it is necessary that we define the institution of government specifically.

Political theory of the last century and a half has generally been an over-simplified statement of the problem. It has assumed that government in both its administrative and directive aspects was the essential relation between man and man. In fact, one might almost say that these theories of government generally, if not always, made the state as a governmental unit and society synonymous terms. 194 
This hypothesis is essentially untrue. The governmental institutions characteristic of men of social organization cannot be described as the most important relation the human being exhibits. There are many other contacts, interests, fidelities and loyalties which play not only an equal part with that of government in the life of men but which have a far more constant and sensitive influence. The family relation, the work a man does, his intellectual and social interests, his friendships, his loves, his hates, his hobbies, the games he plays, and the things he makes, are in their influence upon the individual more evident, more insistent, more regular and generally more crucial than the organization of the community which determines the general legal contacts of the life a man lives in the company of his fellows. That is, we must see society as multi-cellular, social organization as varied, loyalties as numerous, and government at best as only one element and that not the most important in the lives of men. Any theory of society that would state the problem of human cooperation primarily in terms of political organization is such an oversimplified description as to be essentially untrue.

The first and most immediate influence upon government structure and function implied in the development of the labor movement is the change from individual to group responsibility. Our political government rests upon the individual. In theory the defense of the rights of the individual, the duties of the individual, the relation between individual and individual, constitute the chief concern 
of contemporary political government. The structure of political democracy is built on the assumption of the essential equality of man and man, and upon the assumption that the function of government is to regulate men's relationship's with one another. This description of the individual as the basic unit of community organization, however, has become and is becoming daily less true of the actual state of affairs in the community.

The labor movement has been, if not the only, certainly one of the chief factors in shaping society away from individual self-sufficiency, individual responsibility, and towards functional group solidarity. The labor movement has differentiated the community into its organic industrial elements, and the function of government, even at present, is becoming daily more and more a function of harmonizing the conflicting interests of groups rather than those of individuals. All one has to do to convince himself of this fact is to examine the activities of any legislative body. He will find associations of all kinds, as associations, as groups, demanding and receiving legislative attention. The railroads, the railroad workers, the mine owners and the miners, the inter-state commerce commission and the chambers of commerce, educational associations and organizations of civil employees, groups upon groups of all kinds are the subject of legislative activity. We must, therefore, be prepared to admit that the tendency has been and still is for government to become more constantly concerned with the development of the technique of group relation- 
ship. The organic unit rather than the individual, one might say, is to-day the actual if not the theoretic basis of governmental function.

It has already been indicated in the chapters dealing with the development of governmental institutions by the labor movement that the future government will probably be one composed of representatives of organic groups of industrial workers; that is, functional representation is likely to become the pivotal force of governmental structure. If that should prove to be true, as there is every reason to believe it will, then the problem of government will be the problem of harmonizing, coordinating, controlling and directing the relationships of these differentiated industrial units in the community. What those problems may be, how they will be met, and the technique they will call for, constitute the chief problem of future government from the point of view of industrial democracy.

It must also be recalled that this change in community organization postulates the elimination of the competitive commercial system, that it assumes the substitution of service for profit in industrial activity; it also takes for granted that production will be for the consumer's interest rather than for the producer's gain. We thus have the conditions upon which the discussion of governmental function and method may be based. We have described the labor movement as a dynamic process forging a new social organization with the interest of the community as a community the basis of activity. The problem is concerned therefore with what such 
a community would demand from its government. What functions would such a government of necessity have to undertake?

Being a producer's congress, with the consumer's interest foremost, the problem would seem primarily to be a problem of so coordinating the activities of the community as to satisfy the best interest of the consumer, who incidentally is also the producer. If we visualize such a government in action we may clearly see a grouping of some hundreds of men chosen by all the important functional groups of the community. This central congress would represent the chosen delegates of all the differentiated and self-conscious groups. All of the community services, from that of the humblest window cleaner to that of the most skilled artisan, would find place there. The teachers' organization would be represented by the teachers; the miners' by the miners; the building industry by members of the building trades; the steel workers' by steel workers; the railway men by members of the railway unions. There would be, too, a complete synthesis of the cultural, social and functional activities of the community. The artist, the actor, the musician, the scientist, the hodcarrier, the street-cleaner and the ditch-digger, the farmer and the fruit picker, the maker of hairpins, of candy, of toothpicks, would be there with the printer of books and the architect of tall buildings, and the builder of mighty bridges.

What would be the first business of such an organization? Obviously, its first business would be to determine what the community was producing 
and whether it was so organized as to meet the best interests of the whole community. One might say that the first function of such a congress would be to get information of the producing powers and activities of the community placed before it, analyzed, discussed and arranged in terms of their importance. It must always be remembered that this is a cooperative, industrial democracy with the interest of the community always and primarily the first consideration. This information would be available because it would actually be there in the experience, contact and knowledge of the individual representative of the various groups. We have assumed a complete organization of the community and a group representation of it in that congress. This body of men would be a miniature reflex of the community.

It is perfectly natural, as we have assumed, that the first order of business would be to find out the number of men employed in the different industries, their productive capacity, the kind of things they are making, and to arrange that material production in some order of social utility. What this order would be it is not necessary to predict. The only thing that we can say safely is that such a congress would be inclined to give the essential services and products first place and the others their places in the catalogue of activities in the degree of their importance. While any such arrangement is bound to be arbitrary and ideally unsatisfactory, it must yet be assumed to be a possible arrangement, possible because it would be a necessary arrangement. It is also 
safe to assume that the arrangement of the community's productivity in terms of priority would be a fairly sensible one, for, after all, these men would be hard-headed experts trained in their own industry and saturated with a degree of social-mindedness not to be found in the profit-making community. Their interests would be primarily social interests and their judgment would be largely expert judgment. So, while we cannot say that the works of these men would be perfect, we must assume that they would be workable and of course subject to change if found unsatisfactory.

Priority of production then promises to be the first important order of business of any industrial government. Priority must have a purpose, a standard of value, a thing for which production is assumed to be important. During the war we developed a system of priority. In that system the point of importance was war, successful war. It meant that the whole system of productivity was deliberately organized, is so far as possible, to meet the end of war. Munitions, cannons, rifles, ships, clothing for soldiers, sanitary implements needed for war, all the thousand demands of successful warfare were placed in the first order of essentials. Bread, health, happiness, comfort, shelter, everything was made or not made, stimulated or not stimulated, emphasized or not emphasized in the degree in which it seemed to be essential for the furtherance of successful war. We had priority for purposes of victory. We had it because we were motivated by a common end, a common purpose-successful warfare. 
If it is true that, in spite of a competitive system, of profiteering, of self-seeking, it was possible under the influence of a common purpose to organize a workable priority method of production, it cannot but be assumed that a community which has a common purpose of social well-being, organized on the basis of cooperative service, could emulate an equally workable priority system for its own ends. But in this case the priority system would be for purposes of producing basically essential goods first in what would seem to be the desirable order. I take it that food and health would probably be the first considerations; shelter, clothing, amusements and other elements would be subordinated to essential food and health, in the degree in which they would be necessary-pragmatically necessary-and subject to revision as experience determined.

The second order of business, really a continuation of the first, would probably be the consideration of so arranging the labor forces and capital in the community as to carry out the implications of priority to their fullest advantage. It might be decided that for the time being the community would dispense with certain elements of production considered less essential than others, and that the capital and labor at present employed in these industries would for the time being be turned over to those more essential uses, a process of limitation and direction of goods and activities which was in a similar way carried on under our system of priority during the war. It might be possible that after listing the, say, five thousand different types of activi- 
ties which the community at present carries on from the making of artificial flowers to the baking of bread, this congress would decide either to completely curtail or to limit the production of a certain portion of these five thousand activities and increase by that much the others.

The third order of business would probably be what might be described as the determination of the basis of industrial citizenship; that is, this congress could and probably would say that only those who were employed in the activities determined as essential under the priority system were entitled to the benefits of citizenship. The benefits of citizenship would of course be the very basis of existence in an industrial community. It might be a necessary regulation for the enforcement of the priority system. However, there are other ways of making priority effective.

The fourth function of government under an industrial democracy would be the determination, not alone of the kind of product, but also of the amount. Take as an instance the question of shoes. The shoe industry through its statistical experts might say that for next year it will be necessary or desirable to produce so many hundreds of millions of shoes of such fashion and such grade, and that for this production it will be necessary to add so much new machinery, so much more leather, so much more thread, so many more workers. The building industry, anxious to win a place for itself, as having been most thoughtful of the interest of the community, might suggest that it would have to double 
the building of last year and for that purpose would also need a very heavy increase of labor, material and machinery. This too might of course be done by the tailoring industry. It is perfectly possible to assume that all the demands of all these different industries, even under a system of priority, could not be satisfied without injury to some of the other vital activities of the community. It would therefore be necessary for this congress to pare down the amount decreed after discussion, compromise and group judgment, so as to meet the best needs of the community; that is, it would have the function of determining social policy in production, of determining the kind of production and the amount of it.

In this discussion of social policy as a function of the industrial government, the problem of agriculture is of immediate pertinence, and it is very likely that the agricultural problem would receive early attention. The point here is that for purposes of increasing food and of decreasing the amount of labor involved in raising it this congress might decide that the greater part of all the possible saving in steel and labor which an organized community could make should go into the production of farm machinery and implements of various kinds so as to increase productivity and decrease the effort per individual. That is, this congress might decide that for the next ten years all the steel and labor which went into making high class automobiles under present conditions should for that time be devoted to making farm tractors and other farm machinery, and that after ten years this subject might again be 
raised for consideration, so that, if the community then found that it had sufficiently provided itself with farm tools, it could divert that newly released labor and steel to the making of high class automobiles if it so desired.

The fifth function of such a congress would probably be the problem of international relations. International relations are, it seems, destined to become more complex as the community becomes more dependent upon mechanical organization. With the increase of communication, of travel, of machine production, the world becomes proportionately smaller, and external problems become proportionately more complicated and more important. The condition, for instance, on which coal from Pennsylvania might be shipped to South America in return for coffee is a subject that must, by the nature of the problem, be one delegated to a congress representing all of the trades and interests of the community.

The sixth function of such a congress would probably concern itself with the problem of education as a matter of social policy. It would not take upon itself to determine the kind of instruction to be given. That would naturally fall to the organized teachers of the country. As a matter of fact, that is to a large extent a problem determined by the teachers themselves even under present conditions. The question of the extent of education over years which the community could afford to give to its young and the question of use by the community of the energy and interest of its youth for purposes 
of doing the cruder, more hazardous and more disagreeable work of the community, might very well be a problem for this congress.

These are, of course, merely indications of what seem to be the likely and more immediate problems of the community which this congress would have to deal with. It must be noted that these are problems of determining social policy rather than of administration. One might almost say that the chief function of an industrial government of such a kind would be the providing of statistical information, the discussion of policies, the determination through group judgment of the most important work to be done, while in actual application the carrying out of these functions would probably fall in a very natural way to the special industries and organized groups to whom these particular tasks belong as an organic part of their place in the community.

As an illustration, let us again take the shoe industry. This industry consists of some hundreds of thousands of men, spread over various parts of the country, whose business it is to supply the community with footwear. To a very large degree they are a self-determining group. The individual business men make what shoes they think essential for the purposes of the market, with comparatively little consultation with other groups. For instance, they do not argue with the cap-maker on that subject. Under an industrial democracy this industry would be organized in full, containing within itself all the experts in the industry as well as the common laborer. It would be represented in the central con- 
gress of the community and to it would naturally be delegated the problem of carrying out its own function-the making of shoes. It-would probably come to the congress and say, after discussion and deliberation, that during next year it would have to make so many pairs of shoes. To make those shoes it would need so much coal, so much machinery, so much leather, so many needles, so much thread, so much paper, and so forth. As a matter of fact, the industry says that to-day, but not quite in the same way. This congress would then say to the machinery industry, "It will be your business to supply the shoe industry with so many machines"; to the coal industry it would say, "It will be your business to supply the shoe industry with so much coal next year"; to the makers of thread it would say, "It will be your business to supply the shoe industry with so much thread." This in a large way would represent the chief function of the central government in its relation to the shoe industry. The styles, the relation between boots and shoes, between rubbers and leather shoes, are things which the industry determines at present and might very well be allowed to determine. That is a technical problem of administrative organization and as such it belongs to the industrial union.

The shoe industry would then, at its own congress, decide in accordance with its own knowledge how the distribution of the work could be carried on. It would know what factories were best adapted to the making of boots and what to the making of shoes. It would also know where shoes were 
more essential than boots. In fact, it knows that to-day. It would simply be a matter of organizing and collaborating in the work. It might say to the shoemakers in California, if there are any, that they had better produce footwear for themselves than ship shoes from Massachusetts to California, and shoes from California to New York. This industrial shoemakers' congress will also, through its technical organization and committee arrangement in conference with the machinery industry, decide just what kind of machinery it needed and with the railway industry just where it wants those machines delivered; this, of course, being true of all the other dependent and related industries. That is, selfdetermination for the industrial groups along technical lines would probably prove to be the easiest, the most natural, as well as the most desirable kind of functional coordination in an industrial democracy. This, in general, represents the probable technique of industrial government which the labor movement is developing as the result of its differentiation of industrial functions in the community and their coordination through functional representation. 


\section{CHAPTER XVII}

\section{SOCIALIZATION}

THE tendency towards socializing the services 1 and goods of the community and placing them at the disposal of the individual is one of the outstanding characteristics of present-day society. There is undoubtedly a growing sense of social responsibility for the individual on the part of the community. This shows itself in many ways. We have socialized such things as water, public highways, education, lighted streets, bridges, medical service for the sick through public hospitals, dental services for the children in public schools, parks, museums, books through libraries, and information services of various kinds, and many other such services are at the disposal of the individual in the community. To this must be added sickness insurance, unemployment insurance, care for the old through old age pensions and for the young through maternity pensions, factory and mine inspection, and legal enforcement of protection against dangerous machinery. None of these movements has as yet reached its full development, but all show the trend of social or208 
ganization. I have enumerated these well known facts only because they receive an altogether new significance when related to certain tendencies within the labor movement.

The labor movement, as has already been pointed out, stands for a minimum wage. It has definitely committed itself to a common basis of well-being which shall belong to all working members of the community, and the various types of social insurance are only a broadening of the basis of the minimum to include all the members of the social group. What this means in its present form is that the community is inclined to hold itself responsible for a certain standard of income for the individual. These community services and goods are supplied as real goods rather than as monetary income. The community does not give a sick man money to hire a doctor. It provides him with medical service in a hospital. It does not give the father of a school-girl money to pay a dentist, but provides dental service. That is to say, there is an obvious tendency to broaden the number of services which the community feels obligated to render to the individual; and this is definitely a new note in modern social policy.

However, it is only when we compare this tendency of the general political community to socialize its services and to assume responsibility for the individual's well-being with two outstanding tendencies of the labor movement that the full significance of this policy becomes evident. The two elements referred to are the insistence upon a mini- 
mum for all workers and the tendency for equal payment which is characteristc of the labor movement. In the light of the discussion here carried on, it is apparent that the labor movement is transforming the community and carrying over into it some of the practices which labor has developed. Because of the prominence of these two factors in the present labor movement we may assume that the minimum of service and income, as well as the equal pay tendency, will be carried over into the future industrial community. We shall thus have a community composed of differentiated groups of producers with the consumer's point of view dominating and determining social policy. What under such conditions would be the probable outcome of the policy already embodied within the labor movement and provided in part by the community as well as of the tendency towards equality of remuneration implied in labor organization?

It is safe to assume that the minimum would probably be a minimum of the services sufficient to maintain a certain standard of living. In concrete form it would probably mean that in addition to socialized water, light, police protection, educational facilities and medical service, the community would add as many other elements essential to a minimum standard of livelihood as could be easily provided on the basis of a large-scale manufacture. It is reasonable to believe that such things as matches, for instance, and collar buttons, shoe laces and overalls, and such other things as can be produced on a large scale and as would be of universal use might 
very well be provided in sufficient numbers to be free to all those needing them. We are thinking of a community organized for production and in the interest of the consumer, where every individual is entitled by the nature of the organization to his minimum income and where this minimum income might very well be provided in services and goods rather than in money. Bread, as an instance, is of universal use. In a non-competitive community where a minimum of income was established, it would be a useless procedure to give money for buying bread rather than make bread available to whoever needed it. A sick man goes to the hospital and stays there until he is cured. We do not give him money on the basis of probable sickness; we give him medical service in terms of actual necessity.

The whole problem of socialization is bound up with the problem of priority which we discussed in the last chapter. In that chapter it was shown that in an industrial cooperative community there would be an inevitable development of graded productivity in terms of social need; the emphasis in productivity would be on the production of essential goods in sufficient number to maintain the well-being of the whole community. This system of priority would fluctuate in the number of things considered essential as conditions of production and social utility determined. It is easy to conceive that under such circumstances, the things considered of basic utility and as essential to the well-being of the community would be made in sufficiently large proportion to 
be capable of socialization. Bread, essential clothing, essential footwear, essential housing, essential light and other basic necessities would, as a matter of course, come under the term of the minimum, and as we already provide to-day some of them in actual service rather than in money, there is no reason to believe that the community would then provide money rather than services for its minimum income.

As an illustration, we have free libraries with all kinds of books in them which anyone is allowed to borrow. Here is an educational institution socialized in terms of service. It is perfectly possible to see that the community might consider footwear as important as books and socialize a dozen or more different kinds of footwear so as to admit of individual choice and yet render service in terms of the minimum rather than in terms of money. As the powers of the community to produce increase, the socialized minimum would probably be made to include goods which were not subject to socialization before. For instance, it might in the first years of industrial organization, prove impossible for the shoe industries to produce on a large scale more than four or five grades of shoes in sufficient numbers to be capable of socialization. But, with the improvement of machinery in the shoe industry and other subsidiary developments it might easily be possible to double the number of fashions and types of shoes subject to socialization so as to make choice easier and more pleasant.

In the case of bread, for instance, we know in a 
rough way, or at least the baking industry knows, how much bread is consumed. It might be possible to socialize bread free for all who wanted it. To be socialized, however, this bread might have to be, for the time being, of a certain kind or grade which would not satisfy a large portion of the community, who would therefore prefer to buy different bread, just as people to-day prefer to buy special bottled water rather than use the water from the sink faucet. However, with improvement in the baking industry, change of machinery and increase in productivity, it might prove possible to add to the variety of bread and ultimately to include certain kinds of cake, always leaving it to the individual who had his money income as well as his right to the minimum services of the community to buy such other things as were available in the line of bread if he was not satisfied with what had been socialized up to date. It is always assumed that the principle of the minimum standard of living has been carried over by the labor movement into the new social organization which it is obviously moulding. It is also believed that this minimum will in all probability be a minimum of services and goods rather than a money income; that is, a minimum of real wages rather than of money wages. We give all children an education rather than their parents money to pay for it. It would only require an extension of this principle to include other goods as the community developed the power to produce them in sufficiently large quantity. The system of priority worked out in such a community would determine the degree, 
the kind and the succession of socialization of goods in the community.

It is also evident that the labor movement is carrying over a tendency towards an equality of wages. In the chapter on Remuneration it was argued that the acceptance of equality of payment would probably prove a happy political expedient in any industrial democracy. Taking the human being as he is in his variable and differentiated self-assertiveness, it is not possible to assume an equalization of desires or of needs. Differences of taste, of fashion, of likes and dislikes, of hobbies, the desire for special articles and personal idiosyncracies, are things which are likely to increase rather than decrease as the individual becomes more cultured and more self-conscious. This fact must be fully recognized. No imaginary Utopia will make all people equal or make them all satisfied with the same thing. No world can be built upon that assumption. Human nature is what it is, and it is different as it expresses itself in different individuals, All of this simply means that no matter to what degree any community may find it possible to broaden the minimum of services and goods which it can render to the individual, in addition to that minimum a large and indefinite field of choice and selfdetermination in the acquisition of personal goods and the spending of time in self-expression must be left free. In fact, the ideal in such a discussion would be to make provision for a constantly increasing degree of individual differentiation as the community's powers of production and services develop. 
It is, therefore, important in any discussion of industrial democracy to remember that if it is to work at all it must make provision for this varying character of the human being. The combination of the minimum of services and goods and the increase of them is not at all inconsistent with a development in the opportunity for choice and personal self-determination in the acquisition of essential things. The labor movement not only demands a minimum but also carries with it a tendency for an equal wage payment. It is perfectly safe to assume that this equal wage payment could be maintained in any industrial democracy and made the basis upon which the self-expression of the individual might function through purchase and choice. As an instance, we furnish water for all people in New York City, and yet a great many homes have specially bottled water for drinking purposes. We have public school education, and yet many people prefer private schools or private tutoring. We provide books through the public library, and yet many people love to own their own books. We may well believe that under a system of priority and a socialized minimum the individual would in many cases find his special hobby and personal idiosyncracies unprovided for.

The wages which we assume will be paid to all people will thus make possible the satisfaction of that particular need which the individual may have. If we assume, for instance, that a community has found it possible to socialize some dozen kinds of different ties in different colors and shapes but has 
not under the conditions been able to include in the socialized product all the different ties now on sale, it would then be possible for the individual on the basis of demand and supply to purchase such special ties at cost. The neckwear industry would, if the community had any good judgment in the matter, make possible the production of that particular article. Another instance of that kind of possibility may be assumed in books. Any community interested in the cultural growth of its members would probably print on a large scale all the chief classics and make them available to anyone who desired to read them. However, it would probably be quite impossible to print all books on that scale and also quite useless, as many are of special character and have a small appeal. Under those conditions it would be perfectly feasible as well as sensible to print books which would have this special appeal and make them subject to purchase by the individual who cares for them.

Admittedly, the suggestions in this chapter are conjectural. It is an assumption which may have no validity in fact at any time in the future. However, it does seem that with the community developing as it does at present, with an increasing tendency to socialize essential services, with the labor movement insisting upon the minimum standard of living and an equal wage in practice, with an increasing sense of responsibility for the individual, with a greater interest on the part of the community for the easiest provision of basically essential needs, with increasing powers of production, with the elim- 
ination of the competitive spirit and profit motive in industry, and with the substitution of the service and consumer's utility motive, all these tendencies might well lead to some such development under an industrial democracy as is here indicated. This possibility would seem a fairly natural and easy transition under such conditions when carried over from the present into the future by the labor movement. 


\section{CHAPTER XVIII}

COOPERATION AND DISCIPLINE

$\mathbf{R}_{\text {EVOLUTIONARY labor leaders predict the }}$ $R$ control of industry by the workers. This prediction has more than usual cogency. It seems evident that every union develops a technique for a constantly greater hold upon the industry with which it is connected. This tendency has become in the minds of many people so obvious that the question has arisen whether the unions can cooperate better with each other than with their employers. It is a crucial question and one which must be answered so far as possible in terms of the present activities and tendencies of the labor movement.

There has been much friction in the growth of the labor movement. In fact, this characteristic was so predominant a part in the development of organized labor that organized labor to many has seemed to be primarily a disruptive and subversive force in the community. Struggles against the employers, differences amongst the workers themselves, hindrances of the activities of other people, the upsetting of habitual methods, demands which were 218 
declared contrary to social interests, have given the labor movement a character of apparent destructiveness. Upon this fact has been based a great deal of the opposition to the labor movement. People have said that if the workers continue to increase their power, strikes instead of becoming fewer will become more numerous, organized greed and selfishness will become more powerful, and the little peace we still have with us will disappear. It is assumed that each union will strive to benefit its members, using its powers of inconveniencing the community as a club to compel submission. We are told that jurisdictional disputes, evidences of dishonesty amongst labor leaders and practices such as are now said to exist in the New York building industry, are among the many examples which have been and could be used to argue this point. The bakers will strike to outdo the butchers in greed and irresponsibility to the community, and the butchers the bakers; the electricians will threaten to cut off light, and the railwaymen communication. This picture has been painted in varied colors, but there has been general agreement that harmony, peace and good will would pass out from among men and a new autocracy - the autocracy of labor-would replace our democratic government. With this replacement we are told will disappear all security, all freedom, and all the rights of the individual which have been gained by humanity after long and bitter struggles.

It is possible to formulate a fairly satisfactory, even if hypothetical, answer to this question upon 
the basis of the analysis which has already been made. It has been shown that the labor movement carries with itself a certain creative tendency. It implies a socialized outlook, a greater degree of personal responsibility, a profound interest and knowledge of the economic life of the community, and integration of the different individuals within their group upon the basis of a common industry and the achievement of cooperation through the district and national organizations. It has also been shown that the tendency towards equality of income is strongly pronounced, especially when we remember that a democratic industrial organization has a consumer's rather than a producer's economic outlook.

A community is assumed to have developed, in which everybody is working. All those who are working are organized around their industry. Every person is thus a member of some well-defined industrial group which has its special function and problem, its particular service. Remuneration is equal for all the members both of this and of all the other trades. The work done by this group is in harmony with the decisions of the community of which this one is a member and only an agent-a conscious, deliberate and organized agent. This particular trade is merely performing one of the many services the community requires, and for these services it is paid in kind. The problem involved is this; what method of control may we expect the community to exercise over this particular group? What is there about community organization which might insure continuity of operation? 
What defense has the community as a whole against the individual group?

In other parts of this book it has been pointed out that integration and dependence are increasing elements of industrial civilization; that while any group receives industrial self-determination it receives it only as a link in a chain-a chain of other groups. There are three outstanding facts which seem to be a concomitant of the growth of labor organization. The first is the simple fact that the industry would, under the conditions described, serve the community; that a strike which is at present directed against the employer would at that time be directed against the rest of the workers. At present the support of workers going on strike on the part of other workers is almost unanimous. The feeling is general that the battle which any particular industry may be carrying on under present conditions represents the interests of the workers as a whole. That fact would then seemingly have no existence. A strike by one group of workers would be a strike against all the other workers. It has already been pointed out that the remuneration would be approximately equal for all. In other words, a strike on the part of the workers would be for the purpose of gaining something which the rest of the community did not have. It would be for the purpose of establishing a special privilege, a special right to services and goods which were not shared by the others.

Public opinion would undoubtedly, under such conditions, be directly and immediately against the strikers. An analogue to-day is seen in scabbing. A 
worker who scabs upon his fellows does so to benefit himself at the expense of the rest of his group. The word "scab" has acquired an unsavory imputation among workers. The scab is excommunicated by the working group. His activity is considered a crime which may not be forgiven and for which no excuse will atone. The scab is the deserter from the ranks of the workers. It cannot be doubted that such would be the attitude of a working community against any group which held it up to secure benefits or special services for itself as against the rest of the community of organized workers. It must always be remembered that progress, as has already been pointed out, would under these conditions be pragmatic, deliberate and purposeful. Income and services would be increased as the powers of production on the part of the community increased, and such behavior would be doubly condemned as an interference with the possibilities of growth and production in the community and as an infringement upon the very possibility of greater income and goods which this group was demanding.

The second fact which must not be over looked is the peculiar personal integration which such an industrial organization involves. If we assume any organization representing a hundred thousand workers, we assume personal ties with all the other industries in the country. If it is the railway group that makes this special demand, it would find itself making it against its own relatives in the other industries. The railway men would represent family contacts. They would have fathers and mothers, 
brothers and sisters, cousins, friends and comrades, employed in the other industries against which they were striking.

A hundred thousand railway workers would have connections in this personal and intimate way with the occupations of all the life of the community. Some would have brothers in the mining industry, others in the civil service, while others still would have connections with the shipping industry, the chemical and engineering trades. The striking industrial group would be bound by threads of affection and personal relation with the very groups against whom they were undertaking a battle for greater privileges than were enjoyed by these same relatives and friends. These ties do not make themselves felt at present because the struggle has the character of being fought against an employer. Under those conditions the struggle would be against one's own kith and kin. There is but little doubt, when one considers the sense of solidarity which binds the workers together at present, and the greater responsibility, the broader education and the fuller knowledge which such an organization implies, that an attempt against the community would be well-nigh impossible on the grounds already suggested. There is, however, one more important consideration which must be taken into account in attempting to find the basis of cooperation and discipline which an industrial community would possess.

The industrial community would be characterized by the clear-cut differentiation between industry and industry. The bakers, weavers, miners, electricians, 
would have clearly marked responsibilities and functions. The community would depend upon them and they would in turn depend upon the community. The very facts which would make it possible for any group to withdraw its cooperative function would make it possible for the rest of the community to excommunicate the group that withdrew. Such excommunication would be fatal. There is no group which can stand alone, no matter how important its service seems to the community. The railway men and the electricians are very strongly entrenched, but the rest of the community is more powerful still. If the electrician refused to continue serving the community, it could under these conditions immediately refuse to serve the workers who withdrew from the cooperative life of the whole. If the railway workers stopped work, the bakers, the milkmen, the doctor, the druggist, the electrician, every link in the chain upon which the individual depends could under such conditions immediately refuse to serve them. The economic life of the community is so interlocked, so interdependent are men to-day, that it would be impossible to resist this kind of excommunication. Excommunication would mean death.

This fact and its possibilities of enforcement would make its use unnecessary. The social pressure of the group would make the duty of cooperation a social law. We have seen how strong social pressure can be. During the war individuals were gradually transformed into accepting the dominant opinion and its ideals as their own. They did it with- 
out themselves being conscious of the fact or even of the process. The need for cooperation, the power of excommunication, the social and personal ties, the greater sense of responsibility, the greater equality of income, the more positive interest in the affairs of the community which would result from greater responsibility, the fuller knowledge, and the fact that men would be able to change their standards of life as the powers of production of the community made such changes possible, would all combine to make the strike a needless as well as an impossible instrument.

It seems hard to conceive at present a time when the strike should be outlawed by the working class community, but it must not be forgotten that the strike is a weapon of war and an instrument of selfdefense, a means of self-assertion when no other is available. The strike is evidence of the weakness of the workers, of their being in a subordinate position. Mastery by the workers would make the strike unnecessary-a useless and purposeless instrument. If the workers achieve mastery and selfdirection-as every important tendency of the labor movement seems to indicate-then the strike will go its way like so many other instruments once useful but now discarded. Excommunication will come into its own and will carry a weight and power which it has never had even in the best day of its use as a religious weapon, and its very power will make its use unnecessary. Cooperation thus implies its own discipline. Just as the capitalist system with its competitive organization gave the strike its use 
and purpose, its values and power, so will cooperation probably give responsibility and sense of cooperative unity its place as an instrument of control. The gregarious character of the human being would transmute the whole process into an ethical concept.

This process of control will come naturally to the labor movement. It is the method at present employed. A worker who does not carry out the implications of his organization is punished by expulsion. This is also true of a local union. It has already become a matter of serious concern to a worker or a group of workers to be denied the privileges of labor union membership. The union has at present considerable value. How much more perfect would all this be under conditions where all workers were organized and where organization, like present-day citizenship, was as natural as life itself. 


\section{CHAPTER XIX}

\section{PRODUCER AND CONSUMER}

THE economic literature of the more "classical" 1 school has carried with it a distinction between the consumer and producer. This distinction rests on the supposed natural contradiction between a man's interest as a consumer and as a producer. The Guild Socialists are the more recent contributors to the discussion with their attempt to compromise the differences between the State Socialists and the Syndicalists. The guildsmen assume that the State, as it is at present organized, may be said to represent the needs of the community as consumers. The "Marxian" Socialists, in their demand for the control by the State of all the important industries on the community, based their chief argument on the ground that these industries were at present run for profit and not in the interest of the consumer. A Socialist State, they argued, would have no other interests than those of the consumer, and would, therefore, perform the service of the capitalist with the consumer's interest in view. This position of the Socialist of the older type was challenged by the 
Syndicalist, who, for various reasons, became very suspicious of the State and therefore insisted that the interests of the producer were primary and developed a demand for a particularistic control of industry by the workers. This is a very bare statement of the problem, and is very much oversimplified. It is, however, sufficient for the purpose of this chapter, which is concerned with an examination of the attempted harmonizing of differences between the State Socialists and the Syndicalists on the part of the Guild Socialist.

The Guild Socialists postulate the organization of the whole community of workers into their respective functional groups. Each industry in the community is supposed to be organized, and each worker in whatever industry is expected to belong to his special industrial organization. It is also assumed that the capitalist will be replaced by the community and that democracy in industry will replace present-day organization. The structure through which this democratic community will govern itself is assumed will be of a double character. All the workers in the community will be represented in an industrial parliament, and the community in its capacity as a consumer will be represented in a national parliament elected on the basis of geographic districts rather than industrial organizations. In the first, the individual will vote as a worker; in the second, as a citizen. In the first, he will be represented as a producer; in the second, as a consumer.

The producers' congress, it is assumed, will be 
concerned with the more technical aspects of industrial life, and the second will be busy with the interests of the consumer. "Such things as price, wages, international relations and amount of production would, according to the Guild Socialists, be the proper sphere of the the consumer's congress, while the conditions of labor, apprenticeship and technical problems of organization and cooperation would naturally fall into the hands of the producer's organization. All matters of vital policy would always be referred to the consumers for ultimate decision.

It is thus assumed, as a basis of political structure and policy, that there is a division in man between himself as producer and himself as consumer, that this division can be harmonized by a political machine in which each half will function in its separate interests. What is important to remember is that the Guild Socialists take it as a matter of course that the future will see an industrial community in which all able-bodied members of the community will participate as producers, but will not be able to harmonize their interests without dividing their functional and consumers' needs for purposes of political manipulation. They also believe that the differences can be compromised and harmony achieved by having a double representative system where each separate interest will be fully and with proper partisanship defended against the other.

The assumptions of a difference between the producer and the consumer are justifiable under certain very definite conditions and only under these. 
After all that is said, a man is a man whom you can in theory but not in fact divide against himself. What his interests are as a worker, they are as a consumer when he is free to act as a worker and as a consumer. If man produced for purposes of consumption rather than for sale, and consumption was the basis of further enjoyable production, it would be hard to distinguish between them. The Indian who hunts his bison with great pleasure and eats it with avidity cannot be said to have separate interests as a producer and as a consumer. It is only when elements have been introduced into his work which make it a non-personal, non-creative thing, that the distinction arises. It is when work has become forced drudgery and when that work is remunerated by a wage in a competitive world that his interest as a producer and consumer may be said to be different. These differences of interest become prominent only when:

1. The worker is a hired person who does not take an interest in his work, when all creative and artistic interest is lacking.

2. When all consumers are not producers; when in fact, the most extravagant consumers do not participate in the labor of production, thus increasing the burden of the worker and diverting his product to non-useful channels.

3. When the incomes of the producer and the non-producing consumer are different, making him who toils a lower power in the market than he who idles.

4. When the producer and consumer are sepa- 
rated by a profit-making middleman; when between the work a man does and the purchase he makes there stands a profiteering middleman who is interested in paying as little as possible for the first and exacting as much as possible for the second.

5. When the producer has no consumer's interests in the product he works at; when he is ignorant both of its purpose or use and is conscious of the fact that what he makes is an alien thing for him, something the disposal of which lies outside of his powers of determination.

It is assumed that under Guild Socialism those conditions will not obtain. This is true under present conditions when labor is for hire and business is for profit. Under Guild Socialism industrial democracy would be a fact. That would mean a reversal of all the more important conditions suggested above as being the basic cause for the difference between the worker and the consumer as a single person.

When capitalism is replaced by industrial democracy, then :

1. There will be no profit-making middleman between the producer and the consumer. Production will be for use and not for profit. The producer as such will have a consumer's interest in the product of his labor because he will have a voice in determining the process and character of the production-something that is lacking at present.

2. All consumers, within certain natural limitations, will be producers. There will thus cease to be the distinction between the parasitic consumer 
who lives by the labor of others and the man who toils.

3. All producers, under democratic organization, will more than is possible under present conditions have a creative and artistic interest in their work. Education in industry, democratic management, group control and activity will develop a creative interest in the productive activity of men employed in industry.

4. When the incomes of producer and consumer are assumed to be on a common level, they will not divide themselves into wasters and spenders on one hand and meager bread earning laborers on the other.

5. When sense of ownership and community of interest follow the present restriction of propertycontrol in the community, a greater sense of freedom and interest in the work in hand will be possible.

6. When education in industry has given the worker a scientific interest in his work, he will be capable of the ordinary scientific interest and curiosity which is so powerful a motive with the scientist. The possible spread of this feeling and interest through education, cooperation, and its consequences in industry can hardly be overestimated.

These changes make the current distinction between the producer and the consumer invalid for a democratic industrial organization. They, at least, make a problem so different that it would be desirable to await the development of the industrial democracy postulated by the Guild Socialist before we take it for granted that it is essential to build a 
structure to meet this hypothetical difference of interest in political expression. Certainly the most obvious differences at present prominent would tend to disappear with the suggested changes in industrial structure. However, even if we agree that a division such as the Guild Socialists insist upon exists between a man's interests as a producer and a consumer, and that these interests are so persistent and ingrained that they cannot be obliterated by time or change in conditions and that they must always be reckoned with as a constant and troublesome factor, it is suggested that their proposed political structure does not meet the difficulty they postulate. Separate houses for consumer and producer would be unnecessary encumbrances, and only duplicate effort. Every worker would be organized under the Guild Socialist scheme. Every voter would be a worker. In the actual voting, each man would vote in each case both as consumer and as producer. He would be both, and it is just as useless to try to separate him as it is to divide water into its separate elements and use it as water at the same time.

The two houses would each be elected to represent a separate interest-one the consumer's and the other the producers. All the producers, however, would live in the same place; they would in fact represent the territorial unit of which the community was made up. The representative in the consumer's congress would be a worker and would naturally represent, even if unconsciously, his interests as producer (if he had separate interests as 
such), and would thus defeat the original purpose of his choice. Nor can it be assumed that the consumer's congress will represent only one group in the community, say the electrician. In all probability it would include among its representatives all of the important industries. Bakers, miners and teachers by profession as well as others would find themselves elected to this congress. The consumer's congress then would also in a very large measure be a representation of the industries and the producers, unless of course it were assumed that a separate group of special consumers or representatives can be maintained who will not have the producer's interests. This is a patent absurdity in a community for which it is postulated that the basic equality of the whole group will lie in the fact that each and every one will be a participant in some one of the many creative enterprises required to keep society going.

There is, however, another and equally damaging criticism that one must raise in discussing the proposal for a separate representation of consumer and producer; that as a matter of fact the socalled producers' congress is really a grouping of men and women around their territorial as well as around their consumptive interests. It is obvious that a congress representing all of the productive efforts and undertakings of the community would, as a matter of course, tend to represent that community territorially. All men have to live somewhere, and they cannot live in one place. The congress would be made up of bakers, shoemakers, rail- 
road workers, miners, teachers and other participants in the manifold interests of the community. The baker might, when addressing the assembly, speak as a producer having narrow producer's interests, but he would address himself to an assembly of consumers, of users of bread. He would not be speaking to producers of bread but to men and women who use his product, and the consuming interests of the community would thus find full and adequate representation in the congress of so-called producers. In fact, a congress of industrial representatives who are individually producers is a congress of men who are collectively consumers of the product of this and that individual. The consumer's interests would thus have a preponderant representation-equal in fact to any consumer's congress that could be organized under the conditions. What holds true of the baker is true of the butcher, the teacher, the doctor, the miner, and of any other representatives of the guild. The butcher would address himself to a community of consumers of meat, and so on with all the others.

The problem of a possible conspiracy on the part of one or more powerful producing groups to hold up the rest of the community if they were organized as producers is no real argument for a consumer's congress, for the consumer's congress could not be any more effective than the producer's congress against a really powerful and solid functional organization, and it could do nothing that the producer's congress could not do under the same conditions. In 
fact, it would probably be able to do less rather than more. This, however, is a question of discipline and cooperation which we discuss in another chapter. ${ }^{1}$

In fact, it seems that the attempt to carry a double representative system into an industrial community is really an unconscious translation of current methods into a situation where they have little or no significance. It is carrying over a traditional method because it is traditional rather than because it has proved either effective or useful. G. D. H. Cole's use of the United States as an analogy of the value of such a system of checks and balances is not convincing. It has, in fact, been the opposite of useful. There is another objection to the system of consumer's representation, and that is that it lends itself to greater abuse and manipulation than seems likely to occur under functional organization.

The producer's interests are single; they are constant; they are immediate and personal. A man working on a job and doing something definite acquires a knowledge of its problems, needs, capacities, interests and other peculiarities and specialities which the consumer seems hopeless to achieve in anything like so effective a degree. The consumers' interests vary; they are numerous; they do not involve a personal and a constant association, and they are not personal in the sense in which productive and creative effort is. The other point that might be raised about the consumer and the trades which are directly subservient to immediate con-

${ }^{1}$ See Chapter 16. 
sumption-such things as education, medicine, hospitals, music, acting, and all directly consumptive activities on the part of specialized groups-is whether they could be classed as functionally productive and as possible of representation in a producer's congress. Just as teachers are now members of the trade union movement, so would they best be represented in a producer's congress of the future. This but adds another argument for a single congress. Such a congress would be a complete synthesis of the community. It would include its territorial representation, its consumers' interests, its productive interests, and also those which are directly concerned with the production of what are called immediate consumer's goods. 


\section{CHAPTER XX}

\section{LABOR AND EDUCATION}

THE education of labor for mastery and control 1 of the economic forces of the community-for conscious control-is, next to organization, the most important problem that labor has to face. As has already been pointed out, the very process of organization is education, but this education, this discipline, this growth of the powers of cooperation which organization implies is chiefly an education in morals, in responsibility, in character and in initiative. While it is hard to overestimate the importance of this aspect of the education of labor, it is obviously not all that is needed. Without this training industrial democracy would be impossible, but along with it we must still have a conscious and deliberate preparation for the handling of the complex and interwoven mechanism of our industrial system. This phase of the education of labor, the deliberate preparation for manipulation of industry by the workers, has strangely been overlooked by most of those who have been the chief exponents of the democratic control of industry, and yet without it any real industrial democracy must remain an irridescent dream. 
When the history of the last hundred years is written in terms of its great psychical and intellectual changes-a history that must still wait for a better perspective than is afforded by the present moment-it will give a prime place to the story of the socialist movement, for, truly speaking, the socialist movement has been an educational one, at least more of an educational phenomenon than anything else. Its real fruits up to date have been garnered in the crystallized discontent, the general spread of common ideals of social reconstruction, in the international consciousness of its organized bodies, and in the fact that the same thoughts, the same motives, the same general perspective and outlook are characteristic of millions of men the world over. It is a remarkable achievement. It has made more rapid progress among men than have the ideals of political democracy and constitutional government. It contains to-day more throbbing vitalized force than any movement has probably contained at any time before this, for it is universal in its appeal and universal in its touch. All of this growth is concentrated in a period of some seventy years of conscious organization and propaganda, an organization and propaganda carried on against innumerable obstacles-obstacles of ignorance, of prejudice, of persecution and falsification. This tremendous growth of a common ideal embracing so many varied races, religions, nations, and over so wide a spread of earth has scarcely been exceeded by any movement in so short a period of time.

The reasons for this growth are numerous, but 
there are two outstanding psychological features of it which contributed to its appeal. The first is its negative character. The socialist movement as an educational force has had positive consequences in organization and in emotion, but its education as such was negative. It was primarily against something. It was against capitalism. This simplified the problem of its educational work. The capitalist system, or older systems still general in some parts of the globe, were by and large things not pleasant to the heart of the common men of the community -the poor, the overburdened. It was just because it emphasized the evils of the world that it appealed so generally to the men whose lives were dominated and circumscribed by a tangible evil of immediate concern. It is in this phase of its education that the socialist movement secured the greatest support, the greatest unanimity and most of its loyalty as a movement of protest.

The educational work of the socialist and radical movement was primarily but not exclusively negative. Included in the criticism of capitalism was the demand for a change and a prediction of a better and happier world to follow upon its destruction. This positive, creative side of the socialist educational movement, this demand for the revolution and the cooperative commonwealth, has largely been of a vague and hazy kind. What capitalism was seemed easy and obvious enough. What the cooperative commonwealth would be, how it was to be achieved, the kind of social organization it would imply, and the particular responsibilities 
it would impose, was harder to describe. This very difficulty of particularization served a useful purpose in the propaganda. The future being beyond immediate control and specification lent itself to facile artistry and coloring. It became easy, and as a means of propaganda, effective and useful to paint the future in rosy colors. To imagine a heaven upon earth and to forecast its appearance immediately upon the destruction of capitalism was probably inevitable.

This description is not meant as a disparagement of the fact; it is simply a statement of it. The very conditions under which the propaganda-work was carried on made this inevitable, and the hardworked and under-educated masses seized upon the prospect of a future that would be harmonious, utopian and ideal as a compensating reaction to the world in which they found themselves, a world where the antithesis of all their ideals was the actual fact. I have used the word utopian because the nature of the preparation and responsibility implied in the control of modern industrial activity did not enter into their calculations.

In general, this type of education is still with us. The labor movement, conservative or radical, as well as the socialist movement, is occupied chiefly with critical propaganda. The educational activity still mainly consists of a description of the evils of capitalism, of the inadequacies of the present régime, the callousness of the politician, and the heartlessness of large business. All of this is true and more than true, but it is not sufficient. It does 
serve the great purpose of crystallizing discontent, of making it an effective medium of social protest. The purpose, however, of protest is only the lesser half of the obligation imposed upon the labor movement in its demand for social change. No worker is necessarily better equipped to handle the problems of his particular industry just because he holds radical views. No amount of lecturing on radical literature, on price, value and profit, nor any amount of criticism of the policies of the government, makes a worker better equipped actually to participate in efficient democratic functioning in an industry so technical, so many-sided, as, for instance, the steel industry. He may have learned to dislike the present scheme of things bitterly, but he has not acquired the process of control, direction and coopertion essential to the continuance and smooth workings of such an industry.

Modern industrial organization is not the simple craft system of the days before the industrial revolution, when a single worker possessed all of the required skill essential for the production of any one article. Production is, under present conditions, divided and subdivided into innumerable processes, involving the cooperation of many scores or hundreds of workers. Included in this method of production are many different degrees of skill and knowledge, going up the scale from the simplest type of manual labor to the most skilled and trained professional expert.

Every industry of even minor character includes this gradation and complexity. The use of the 
engineer, the chemist or the draftsman goes hand in hand with the dependence upon the simple function of the common laborer. The worker as such stands outside of the scheme of production spiritually. He knows little or nothing about the industry as a whole. He is a tool directed and controlled rather than a participant controlling and directing. $\mathrm{He}$ is often ignorant of the significance of his function. He knows little or nothing about the scientific problems or character of his work; he knows little of its social value, nor is he better equipped regarding the nature of the industry when viewed as a human organization. He generally does not know the number of trades in the industry, their relation, their dependence. He knows little about the internal organization, the nature of the market, the dependence upon the arts which his particular industry may display. This is also true in regard to its external relations and dependencies, the industries upon which it feeds and upon which it depends. All of these matters pertaining to control, manipulation and direction of the industry are foreign to him. He evaluates his work in terms of the pay envelope. His relation to it is impersonal. His pleasures, his play, his creative interest and instinct find their outlet chiefly in things remote from the actual work which generally makes him significant as a member of the working community. When it is remembered that he gives the best hours of the day and the best years of his life to his work, the lack of joy or interest, of creative participation in it, make the spiritual cost of modern industrial activity appalling. 
From the viewpoint of industrial democracy, this fact is of the greatest importance, for it is these industries which make such a heavy demand upon the time and strength of the worker, yet give so little creative outlet. Democracy in industry means deliberate, conscious, intelligent and efficient control and direction by those who are actually concerned with it as working members thereof. And this control-control efficiently and successfully carried out on the basis of the present working class knowledge - might prove a very inefficient and precarious undertaking. In such an industrial community as the United States it might even prove tragic. The lesson of the Russian revolution in this matter must not be overlooked. It was the lack of working-class technical appreciation, of working-class industrial knowledge, of working-class cooperation in industry, that proved its greatest handicap in the early days. I do not want to press this point of comparison too far, for conditions here are very different, but it is doubtful whether the difference is in our favor. Industrial democracy requires organization. Next to organization, it must have education about industry by those who are to manipulate it on a democratic basis.

This is the problem of working-class education that radicals and socialists who have talked about industrial democracy have generally neglected, and yet this is the problem of working-class education. The union is the logical center of this education. Each union (the industrial union, the synthesis, the unity of an industry) ought to provide for the edu- 
cation of its workers in the problems, character, relationships and functions of the industry. Large international unions are beginning the organization of departments concerned with problems of the general industry in all of its phases and equipped to spread this knowledge among the workers. Each local union ought to do that for its locality, and each shop for the particular problems, activities and functions of its own shop. This education should include all of the problems of the industry. Where required, this work could, on account of its complexity, be divided up among different committees.

The primary aim of this education should be to make each worker in the industry conscious of the more general character and relationships of the industry, and the part he plays in it. Without some such preparation, industrial democracy in practice will come very difficult indeed. It is not suggested that the worker be taught different or better-paying trades, but that he can be prepared to participate in the direction of the industry as an intelligent cooperating unit who understands what he is about and who can visualize the industry as a whole; the aim being, let me repeat, to make it possible for the workers in any given plant to meet together and discuss the problems-mechanical, technical, economic and social-with intelligence and mutual understanding. The word "workers" is used of course in its widest sense to include both the expert and the common laborer-all who are actually required in the proper and efficient manipulation of that industry. Such education would lend itself to cultural 
and scientific interests, so that the worker would not have to go outside of his industry for the purpose of attaining a "smattering" of culture; and it would certainly equal in intrinsic value most of the socalled "cultural courses" generally offered to workers in socialist schools.

This cultural aspect of education in industry is very important. An industry, from the point of view of industrial democracy, is not only a mechanical unit but a spiritual one as well. It is not only an organization of machinery for the purpose of turning out a given amount of material goods but is an assemblage of machinery about which are collected a large group of human beings who have spiritual, intellectual and social capacities. This machinery does not manipulate itself. It has to be directed, controlled and looked after by human beings. And it is desirable, from the standpoint of social well-being, that the men and women concerned with this industry should find it a means of satisfying as many of their human needs as possible. The industry must provide room for interest, for inventiveness, for self-expression, for all those things that make work a parcel of enjoyable life rather than a mechanical drudgery. To achieve this involves first, an industrial democratic organization, and second, educational facilities within the sphere of the industry-an educational setting that will tend to make the industry self-sufficient from the inventive and technical and artistic point of view. The industry thus becomes in reality a mechanical arrangement which serves an industrial purpose, but 
which at the same time and with equal importance provides means and setting for development in ingenuity and art.

In industrial democracy the industry is assumed as the unit. The individual enters an industry when of age and becomes an industrial citizen. He does not enter to learn a specific trade. He enters as an apprentice in the industry. The organized industrial unit of which he becomes a cooperating element makes provision for his training-a training that tends to give him an appreciation of the whole industry of which he is now a member. The actual work that he finally does, the definite reponsibility that he will finally be privileged to exercise, will depend upon his aptitude, his specific interest, his ability, his age and service, and his standing with the rest of his fellow workers. Industrial democracy means spiritual growth in terms of industrial citizenship. It means opportunity for service flexibly adjusted to needs, possibilities and abilities. It means making work a creative experience and participation in industry a spiritual adventure. At least that is what industrial democracy must mean if it is to satisfy the requirements of human growth, interest and sociability, and it is clear that it can mean that not only as a consequence of freedom in, but also of education in, industry.

This education in full cannot be developed until the greater part of the capitalist mastery of industry has been relinquished and the worker has acquired greater powers of direction and regulation. A start in education, however, must be made im- 
mediately if this working-class control over industry is to be hastened, if it is to avoid the friction that must come from ignorance, and if it is to prepare the workers for that seemingly inevitable day of mastery.

The educational program described here is in fact being formulated and developed by a number of agencies in the field of labor. The English labor unions are currently facing the problem, and the labor college in London is being reorganized to meet these ends. More important than this, however, is the development of the shop-steward movement, the Whitley Council, and the worker's representatives organizations. Whatever the purpose of these organizations, their main consequence is to give the workers a sense of confidence as well as a sense of the difficulties involved in industry. They may for the time being serve the purposes of greater harmony in any individual shop between the workers and the employer, but they certainly give the workers that mental bent which makes the industry increasingly their industry in the sense that they become more fully appreciative of the technique and control involved. The employers are thus in an important way contributing to the education which seems ultimately bound to serve the purposes of industrial democracy. It is from this point of view that the labor movement's adventures in decentralized councils are contributory to the apparent goal of the labor movement-industrial democracy. 


\section{CHAPTER XXI}

\section{EDUCATIONAL REORGANIZATION}

$F$ DUCATIONAL reorganization is a constant process, it is one aspect of social phenomena which is always in a fluid state. This is as it should be, for beyond all other activities of the community the educational process is a reflex of the community's ideology and technique. The history of education mirrors the growth of the human mind, its outlook upon life, its concepts of duty and responsibility, probably in a more definite way than do all other social phenomena. Every age has carried with itself an educational process peculiarly molded to meet its own problems. This education in its conscious, deliberate and purposeful method as well as in its more subtle, unconscious and persuasive pressure has generally adjusted itself to the peculiar needs of the community in which it developed. In periods of rapid social change, educational theories and method reflect the unsettled state of the community by being in a highly transitional and varied state.

The present educational situation reflects the unsettled character of society. Probably at no other 
time have there been so many theories of education and so many attempts at putting these various theories into practice. This situation in the educational world indicates the fact that with the reorganization of society implied by the labor movement there will naturally develop a new and different educational system. What this educational system will be may be determined best by an analysis of some of the implications of the labor movement, for it is the labor movement which lies at the root of the social changes now taking place.

The labor movement carries with itself two basic factors which characterize all its important contributions. These are work and cooperation. One might summarize all or nearly all of the contributions of the labor movement in these two words. Work is the basis of citizenship in the labor community. It is the condition of privilege, of power, and the source of its peculiar significance in the world. Cooperation is the method, the technique through which these new values and the newer social organization are being achieved. Not only are these two elements the groundwork of the structure of the labor movement but they must obviously remain the bases upon which any social democracy can be built by the labor movement. It is not only the present method of procedure, but it is apparently destined to remain the source of future community organization if the future is to be a non-competitive grouping of men and women for purposes of social well-being. Education, therefore, in its reconstruction will undoubtedly have to embody these 
new values. It will have to make work and cooperation an important part not only of its ideological attitude but also of its technique. It will have to make work and cooperation not only something to be implanted in the minds of the young as a goal to be striven for but as part and parcel of the actual everyday process of education.

The essentials of community organization as it affects education will in a democratic community demand certain specific changes which may be easily forecast. Education would have to be universal. It would have to be compulsory, and it would certainly be more comprehensive in point of time for the mass of the people than it is at present. It is fairly safe to assume that all of the youth would be required to attend school until the age of eighteen at least. In fact, we are already witnessing a very pronounceed trend in the direction of lengthening the years of education for a constantly greater portion of our youth. I am referring not only to high school education and increasing college attendance but also to the numerous extension schools which draw upon a considerable portion of the community and contribute to the greater growth of better educated people. Such a social organization would insist that its youth be given the best possible preparation for the manifold problems implied in an industrial democracy in which responsibility would be highly decentralized. While it is easy to predict the extent of the educational demands in such a community, it is not quite sufficient. We must do more than say that the future will see more extensive 
training of the youth. That is commonplace and would not require repetition here. We must suggest the kind of education that would probably be called forth under the conditions suggested, even if the prediction is a hazardous undertaking. The rest of the chapter is therefore an attempt, in the main, to develop the technique and suggest the spirit which would probably govern the educational process.

In a general way the basic relationships of the human being may be separated into four elements, the physical, the mechanical, the civic and the cultural. The human being has a body which requires care. This is the first and basic fact about him. Unfortunately, education has been chiefly concerned with things of the spirit. The body has by philosophical implication and religious teaching been relegated to the background as a thing of little significance. In fact, the body has been considered a kind of hindrance to the spirit-a necessary evil-something to which wise men gave little attention. In so far as education as a historical matter has concerned itself with the body at all, it has been as a subject for the moralist rather than for the scientist to deal with. The problem at hand has been described as one of control, of self-mastery, of suppression and denial of the needs of the bodily organs. While all of this has a place in education, it is not its prime or first consideration. Control, direction and mastery must be based upon other things than moral pre-conception. It must have knowledge, the detailed and definite information of bodily structure and conditions of health as its basis. There has 
recently developed a definite tendency in the direction of giving hygienic and physiological information. But this tendency has too often the character of being an addition to the program rather than its first consideration. We must simply come to understand that physical health and well-being are the first considerations in any educational system and mold our curriculum accordingly. The recent attempt to turn physical education to military ends is a complete denial of all the purposes of early training in health and hygiene. This training should not be for the purpose of making good soldiers but of making clean, healthy, self-knowing men and women-people who will be good soldiers if they have to but who will first be healthy, vigorous and energetic citizens of a democratic community.

The second consideration with which education must be concerned is the simple fact that the human being lives in a material world. Education too often seems to forget that simple fact. It proceeds as if man lived in a vacuum. In fact, the hard physical basis-the dirt and the work, the stones and the tools of the world-things which condition everything the student does and is, is overlooked to an extraordinary degree. The suggestion for any early acquaintance with the material world does not lie in the demand for the early development of technicians and specialists, but rather in the conviction that all men and women should acquire some acquaintance with the material and physical world about them. The handling of tools, the manipulation of physical things, the participation in the up- 
keep of the material world or in the molding of the natural forces upon which life depends develops a sense of contact with the world and its problems which nothing else can provide.

It is not the learning of a trade or the acquaintance with the peculiar qualities of some of the materials and tools used, but rather influence of this upon the mind which gives such early training its significance. It contributes a nervous stimulus, a qualitative tone, a sense of relativity, a feeling of dependence upon the world's resources, and a sense of the incompleteness of things which no other experience can provide in the same degree. The milking of a cow, the following of a plow, the planting of potatoes, the roofing of a house, the felling of a tree in the woods, the painting of a barn or the digging of a ditch for a water pipe, will give the young person who does it a sense of self-assurance, of readiness to face hardship, of willingness to do the work of the world, that constitutes a basic contribution to the growth of character and responsibility. The ideal of youthful training in a fluctuating and changing world is not early standardization and specialization but rather the development of a rounded and complete individual capable of adaptation to any specific function with the least amount of friction and effort. The early industrial education should have for its aim the development of aptitude, the teaching of method and the inculcation of general principles. The educational process should, as far as possible, consist in the doing of the actual and the performance of those things that are 
obviously useful. The aim should not be to specialize but to give a rounded appreciation of the material world and a sense of the background of all personal and social existence.

The civic education which we have in mind is something different from what the ordinary course in civics attempts to achieve. It is not a training in the forms and formulæ of political government but an attempt to make vivid through personal contact and association the fact that a human being is primarily a social animal whose very existence depends upon group activity and cooperation. In a democratic community, cooperation for social good would be the basis as well as the end of the greater part of community activity; it is the technique, the habit, the sense of give and take, of subordination of self to majority rule and opinion, of harmonizing individual idiosyncracies, of achieving a sense of civic responsibility, that we have in mind when we speak of civic education. This cannot be achieved through ordinary textbook instruction or classroom method. It must come through cooperation in the educational process, in the carrying out of some common purpose and in work involving group responsibility. Those boys who get this from present-day schools acquire it not as a result of taking courses in civics but from extra-collegiate activity such as running a college newspaper, playing upon a college foot-ball team, and other activities requiring group function. It is along the extension of these activities, both in making them more general so as to include the whole student body, as well as 
in making the group activity center in some work that will have a useful purpose, that civic training would find its best results.

The cultural and the personal development of the individual which is the highest fruit of education need not be changed much in outline, although it would naturally undergo a change in spirit in a world of education that was democratic.

We have divided the function and the problem of education into four separate parts. As a matter of fact, however, they can only be divided metaphysically. Life is a unit. The cultural, the physical, the mechanical and the civic are all interwoven, and only function and operate as a unit. What is more, they operate unconsciously in their divisions. Man brings all of his nature to bear upon any specific function, and education ought to be a unit. Education should be a part of living and should be an unconscious assimilation rather than a conscious study and cramming.

There is only one way of achieving this ideal in method, and that is by reducing education in procedure to the democratic approach and in school organization to the community group. Every school is a little community with problems of cooperation, amusement, physical upkeep, hygenic needs and social responsibility. The school ought to be organized so as to make possible the handling of all of these problems by the school community as a unit. The greater part of both the physical and mechanical, the civic and the cultural parts should come as a result of dealing with the problems of the com- 
munity, the determination of which should be the responsibility of all the members, the students as well as the teachers. Obviously an organization of the school which would concern itself with the handling of these problems through discussion, suggestions and group activity would contribute to the development of initiative, self-reliance and sense of responsibility. If the teachers and students would meet as equals in the physical upkeep and in the social functioning of the school; if children would learn electricity by fixing the lights, chemistry by mixing paint, and physics by operating engines; if the teachers and the students were working as equals, we should have the conditions for the development of the democratic technique, leadership going to those who had the skill, the ability and the confidence of the group. In such an atmosphere schooling and its consequences would be something different from what it is.

There are certain elements in education, like history, chemistry and physiology, which would strain the democratic method. Just because of that it ought to be of the greatest benefit to both the student and the teacher to meet on a basis of equality in other activities. Just because their training, ideals, age, point of view and ends in life were different, this close association ought to prove of immense value spiritually and make both teaching and learning a much more exhilarating and joyous experience than the present dogmatic school methods make possible.

It would turn out men and women who had a 
sense of cooperation and of community responsibility. It would produce men and women who had learned how to work together, who knew something of comradeship, something of the difficulties of cooperation, who would have learned to sink personal differences, who would have exercised leadership and initiative and shown personal interest in community problems. In addition to all of these it would have broken down the snobbishness that comes from avoidance of physical labor and is demoralizing both the teachers and the students. All of the professors would be better for having done some physical work and for having accepted group control in some of their activities, while all of the students would be more interested pupils, better men and women for having had intimate and equal relationships and responsibility with their teachers.

This universal educational system would demand a heavy outlay. However, it would become the basis of such a widespread and intelligent interest in the problems of the community that the cost would be but a small investment for the profound socializing consequence of such an educational system. One might suggest here with William James that the youth educated by the community might well be given the exhilarating experience of doing some of the essential tasks of the community while still under school influence. It would be possible and probably highly desirable to take this youth and put him to work upon some of the large-scale needs confronting society. These young men, under democratic organization, might very well be put to the 


\section{EDUCATIONAL REORGANIZATION 259}

work of building our roads, tunneling our mountains and reforesting our hills. Two years service under those conditions with the group democratically organized, carrying out the community's purposes as far as possible under its own leadership, would but be a continuation of the schooling which they had received. And why not? Why should all the hard, laborious work go to older men, rather than to the vigorous, strong and enterprising youth who could find joy in contributing towards beautifying and improving the world they live in? After such training men, could and would enter an industry of their choosing with a spirit and an energy that would transform the present world as if with the hand of a magician. 



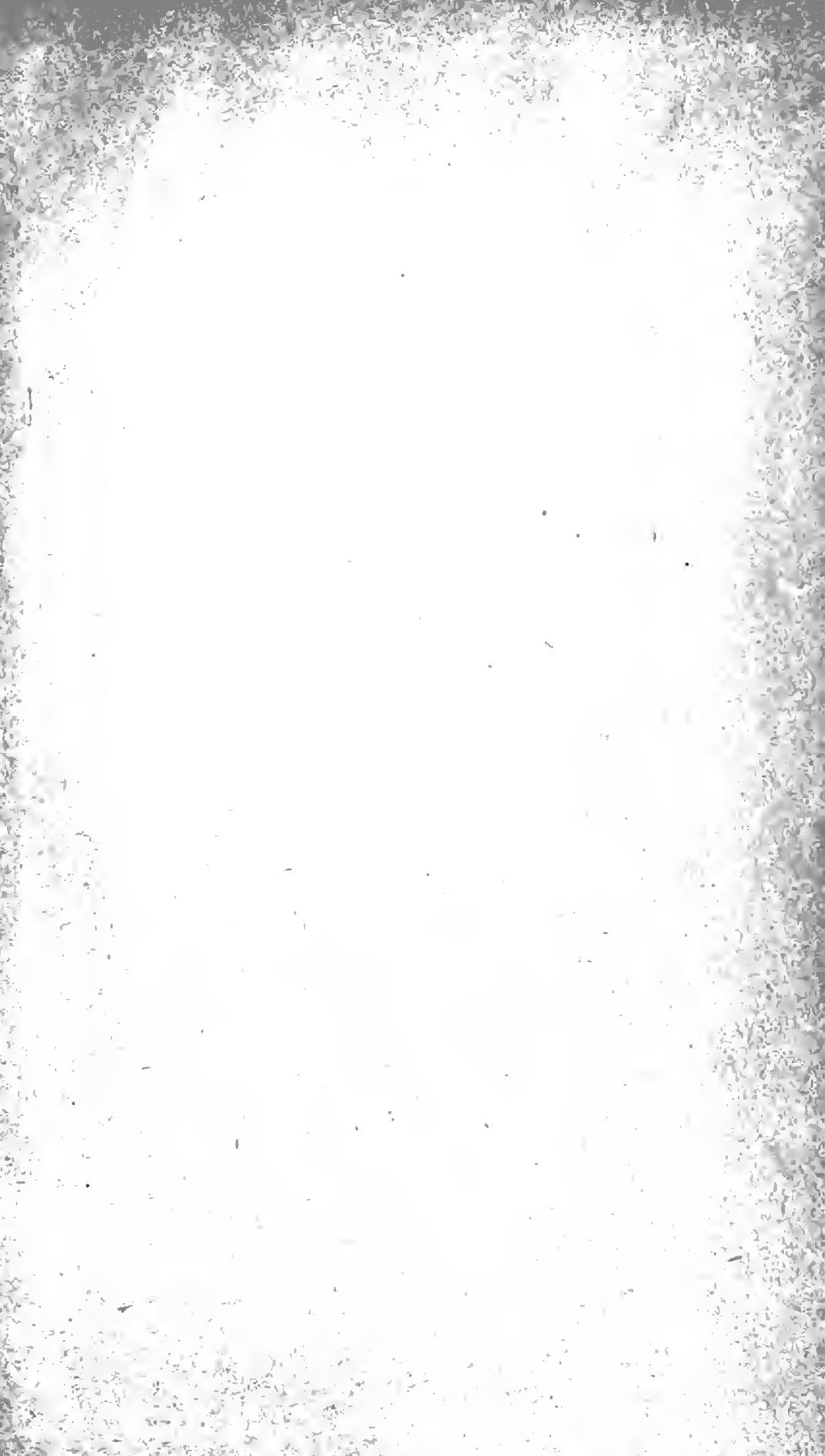




\section{DATE DUE}

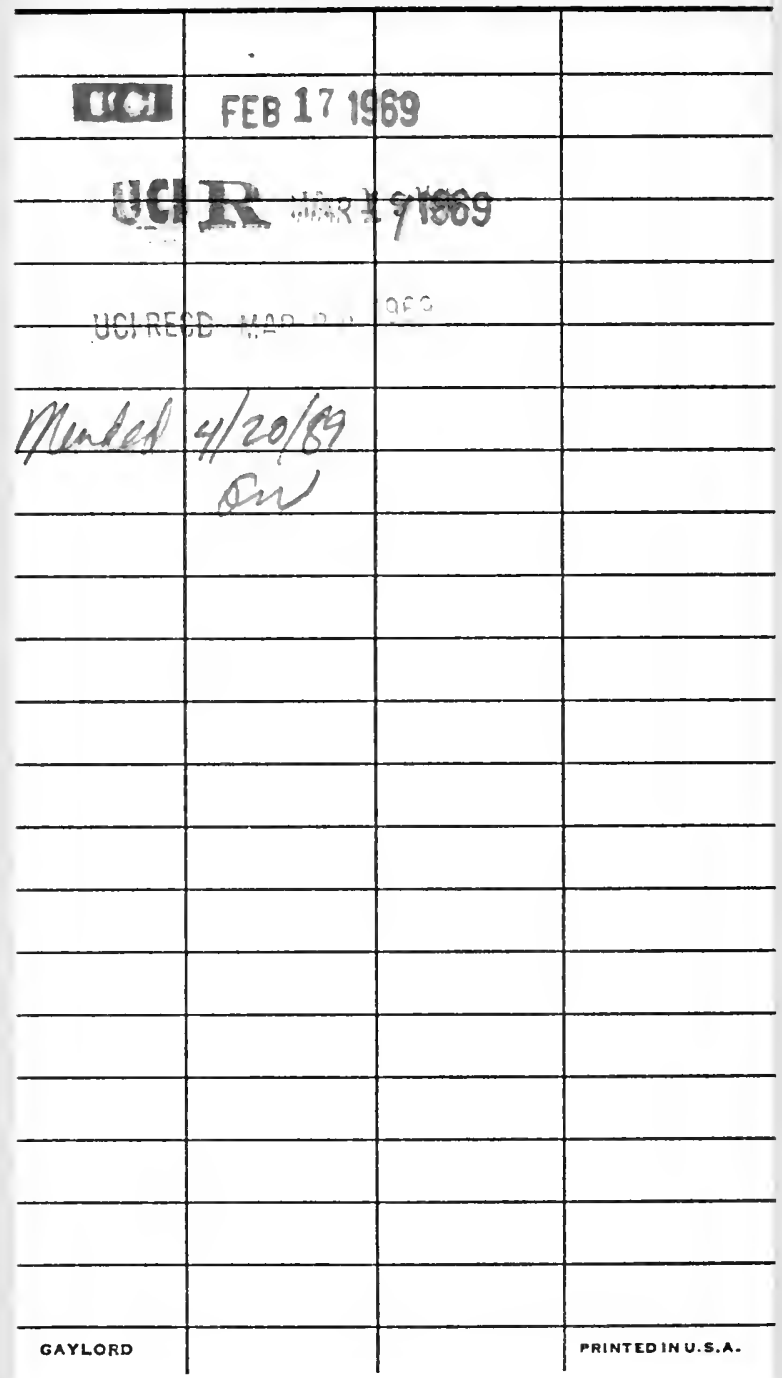


UC SOUTHERN REGIONAL LIBRARY FACILITY

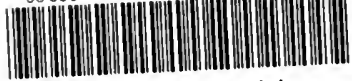

A 0005613112 
